\title{
Extração de características de imagens médicas utilizando wavelets para mineração de imagens e auxílio ao diagnóstico
}

Carolina Yukari Veludo Watanabe da Silva

\author{
Orientadora: Profa. Dra. Agma Juci Machado Traina
}

Dissertação apresentada ao Instituto de Ciências Matemáticas e de Computação - ICMC-USP, como parte dos requisitos para obtenção do título de Mestre em Ciências - Ciências de Computação e Matemática Computacional.

\section{"VERSÃO REVISADA APÓS A DEFESA"}

Data da Defesa:

$05 / 12 / 2007$

Visto do Orientador:

USP - São Carlos

Dezembro/ 2007 
Extração de características de imagens médicas utilizando wavelets para mineração de imagens e auxílio ao diagnóstico 


\section{Agradecimentos}

A Deus, acima de tudo;

À minha orientadora $\operatorname{Prof}^{a}$. $\operatorname{Dr}^{a}$. Agma J. M. Traina pela orientação, incentivo, amizade e por permitir trabalhar ao seu lado e no Grupo de Banco de Dados e Imagens (GBDI), com a qual iniciei os primeiros passos na pesquisa científica e pude aprender muito;

À minha mãe e meus tios Stela e João, por me apoiarem em todos os momentos e me incentivarem nos estudos;

Ao meu marido, pela compreensão e apoio;

À minha família amiga Nina, Ana Paula, Iracema, Frederico, Lucas e Luiz Carlos por ajudarem cuidando da minha pequena Luiza enquanto finalizava este trabalho;

Aos professores Hildebrando Munhoz Rodrigues e Luis Gustavo Nonato que me ajudaram no estudo das wavelets;

Ao Prof. Dr. Caetano Traina Junior por estar sempre disposto a ajudar;

Aos amigos do GBDI, especialmente à Marcela, Mônica e Ana Paula, e ao André, Enzo, Humberto e Pedro por participaram comigo neste trabalho;

A todos os amigos e funcionários do ICMC-USP pelo companheirismo;

À FAPESP e à CAPES pelo apoio financeiro. 


\section{Resumo}

Sistemas PACS (Picture Archieving and Communication Systems) têm sido desenvolvidos para armazenar de maneira integrada tanto os dados textuais e temporais dos pacientes quanto as imagens dos exames médicos a que eles se submetem para ampliar o uso das imagens no auxílio ao diagnóstico. Outra ferramenta valiosa para o auxílio ao diagnóstico médico são os sistemas CAD (Computer-Aided Diagnosis), para os quais pesquisas recentes mostram que o seu uso melhora significativamente a performance dos radiologistas em detectar corretamente anomalias. Dentro deste contexto, muitos trabalhos têm buscado métodos que possam reduzir o problema do "gap semântico", que refere-se ao que é perdido pela descrição sucinta da imagem e o que o usuário espera recuperar/reconhecer utilizando tal descrição. A grande maioria dos sistemas CBIR (do inglês Content-based image retrieval) utiliza características primárias (baixo nível) para descrever elementos relevantes da imagem e proporcionar recuperação baseada em conteúdo. É necessário "fundir" múltiplos vetores com uma característica em um vetor composto de características que possui baixa dimensionalidade e que ainda preserve, dentro do possível, as informações necessárias para a recuperação de imagens.

O objetivo deste trabalho é propor novos extratores de características, baseados nos subespaços de imagens médicas gerados por transformadas wavelets. Estas características são armazenadas em vetores de características, os quais representam numericamente as imagens e permitindo assim sua busca por semelhança utilizando o conteúdo das próprias imagens. Esses vetores serão usados em um sistema de mineração de imagens em desenvolvimento no GBdI-ICMC-USP, o StARMiner, permitindo encontrar padrões pertencentes às imagens que as levem a ser classificadas em categorias. 


\section{Abstract}

Picture Archiving and Communication Systems (PACS) aim at storing all the patients data, including their images, time series and textual description, allowing fast and effective transfer of information among devices and workstations. Therefore, PACS can be a powerful tool on improving the decision making during a diagnosing process. The CAD (Computer-Aided Diagnosis) systems have been recently employed to improve the diagnosis confidence, and recent research shows that they can effectively raise the radiologists performance on detecting anomalies on images. Content-based image retrieval (CBIR) techniques are essential to support CAD systems, and can significantly improve the PACS applicability. CBIR works on raw level features extracted from the images to describe the most meaningful characteristics of the images following a specific criterium. Usually, it is necessary to put together several features to compose a feature vector to describe an image more precisely. Therefore, the dimensionality of the feature vector is frequently large and many features can be correlated to each other.

The objective of this Master Dissertation is to build new image features, based on wavelet-generated subspaces. The features form the feature vector, which succinctly represent the images and are used to process similarity queries. The feature vectors are analyzed by the StARMiner system, under development in the GbdI-ICMC-USP, in order to find the most meaningful features to represent the images as well as to find patterns in the images that allow them to be classified into categories. The project developed was evaluated with three different image sets and the results are promising. 
Lista de Figuras $\quad$ xi

Lista de Tabelas $\quad$ XV

1 Introdução 1

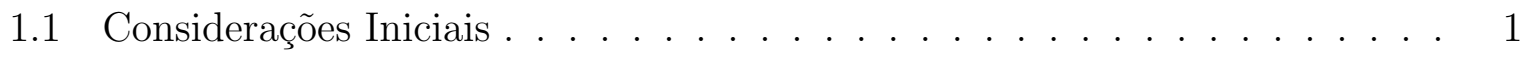

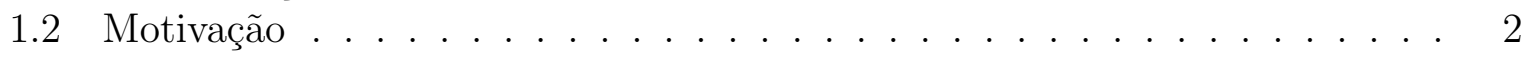

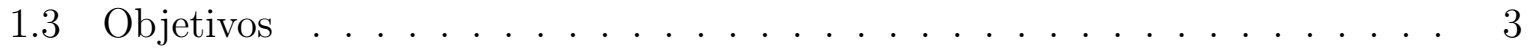

1.4 Organização do trabalho . . . . . . . . . . . . . . . . . . . 4

2 Extração de Características de Imagens $\quad 5$

2.1 Considerações Iniciais . . . . . . . . . . . . . . . . . . . . . . . . . . . . . . . . . . .

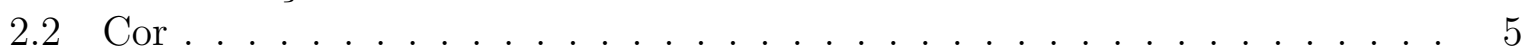

2.3 Textura . . . . . . . . . . . . . . . . . 7

2.4 Forma . . . . . . . . . . . . . . . . . . . 8

2.5 Considerações Finais . . . . . . . . . . . . . . . . . . . . 10

3 Introdução à Teoria Wavelet $\quad 11$

3.1 Considerações Iniciais . . . . . . . . . . . . . . . . . . . . . . . 11

3.2 Perspectiva Histórica . . . . . . . . . . . . . . . . . . . . . . 11

3.3 Análise de Fourier . . . . . . . . . . . . . . . . . . . . . . . 14

3.3.1 Transformada discreta de Fourier . . . . . . . . . . . . . . . . 14

3.3.2 Transformada por janelas de Fourier . . . . . . . . . . . . . . . . . 14

3.3.3 Transformada rápida de Fourier . . . . . . . . . . . . . . . . . . 15

3.4 Wavelet vs. Transformada de Fourier . . . . . . . . . . . . . . . 15

3.4.1 Semelhanças entre as Transformadas de Fourier e Wavelet . . . . . 15

3.4.2 Diferenças entre as Transformadas de Fourier e Wavelet . . . . . . 15

3.5 Análise de Wavelet . . . . . . . . . . . . . . . . . 16

3.5.1 Wavelets contínuas .................... 18

3.5.2 Transformadas Wavelets . . . . . . . . . . . . . . . . . . 18

3.5.3 Wavelets discretas ... . . . . . . . . . . . . . . . 19

3.5.4 Tipos de Wavelets . . . . . . . . . . . . . . . 20

3.6 Métodos Multi-resolução . . . . . . . . . . . . . . . . . . . . 24 
3.6.1 Algoritmo de Decomposição e Reconstrução Wavelet . . . . . . . . 26

3.7 Wavelets em Processamento de Sinais e Imagens . . . . . . . . . . . . . . 28

3.8 Wavelet de Gabor . . . . . . . . . . . . . . . . . . . . . . . . . . 29

3.8.1 Funções Gabor e Wavelets . . . . . . . . . . . . . . . . . . . 30

3.8.2 O vetor de Características . . . . . . . . . . . . . . 33

3.9 Considerações finais . . . . . . . . . . . . . . . . . . . . . . 34

4 Busca e Recuperação de Imagens por Conteúdo 35

4.1 Considerações iniciais . . . . . . . . . . . . . . . . . . . . 35

4.2 Atributos para consultas de imagens . . . . . . . . . . . . . . 36

4.3 Extração de Características . . . . . . . . . . . . . . . . 36

4.4 Consultas por Similaridade em Imagens . . . . . . . . . . . . . . . . . 37

4.4.1 Consulta por Abrangência . . . . . . . . . . . . . . . 38

4.4.2 Consulta aos $k$ vizinhos mais próximos $(k N N$ query $)$. . . . . . . 38

4.5 Funções de distância . . . . . . . . . . . . . . . . . . . . . . . . . . . . 39

4.6 Avaliação de eficiência . . . . . . . . . . . . . . . . . . . . . 40

4.7 Considerações finais . . . . . . . . . . . . . . . . . . . . . . . 42

5 Extração de Conhecimento e Mineração de Imagens 43

5.1 Considerações Iniciais . . . . . . . . . . . . . . . . . . . . . . . . . . . 43

5.2 Etapas da Mineração de Imagens . . . . . . . . . . . . . . . . . . . . 44

5.3 Pesquisas envolvidas . . . . . . . . . . . . . . . . . . . 45

5.4 StARMiner - Técnica Proposta para a Mineração de Regras de Associação Estatísticas e Seleção de Características . . . . . . . . . . . . . . . . . . . 46

5.5 Considerações finais . . . . . . . . . . . . . . . . . . . . . . . . . 49

6 Extração de Características de Imagens Médicas 2D através de wavelets 51

6.1 Considerações Iniciais . . . . . . . . . . . . . . . . . . . . . . . . 51

6.2 Abordagens para a extração de características . . . . . . . . . . . . 52

6.3 Conjunto de Imagens . . . . . . . . . . . . . . . . . . . . . . . . . 53

6.4 Experimentos - considerações gerais . . . . . . . . . . . . . . . 55

6.5 Método 1 - Extraindo a energia dos subespaços gerados por wavelets . . . . 57 6.5.1 Experimentos e resultados . . . . . . . . . . . . . . 57

6.6 Método 2 - Representação da imagem através do subespaço de baixa freqüência 60 6.6 .1 Experimento $1 \ldots \ldots \ldots$. . . . . . . . . . . 61

6.6 .2 Experimento $2 \ldots \ldots \ldots \ldots$. . . . . . . . . . . . 62

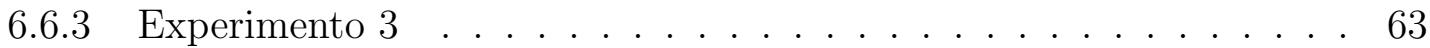

6.7 Método 3 - Otimizando o método de Balan . . . . . . . . . . . . . . 68

6.7 .1 Proposta de Balan . . . . . . . . . . . . . . . . . . 68

6.7.2 Otimizando o método de Balan . . . . . . . . . . . . . . 70

6.7.3 Experimentos e resultados . . . . . . . . . . . . . . . 70

6.8 Método 4 - Extraindo características usando wavelets de Gabor . . . . . . 71 6.8.1 Experimento 1 - Base de 704 imgens de ressonância magnética e angiograma . . . . . . . . . . . . . . . . 72

6.8.2 Experimento 2 - Base de 103 imagens de mamografia . . . . . . . . 81

6.9 Considerações finais . . . . . . . . . . . . . . . . . . . . . . . . . 84 
7 Conclusões $\quad 85$

7.1 Principais Contribuições . . . . . . . . . . . . . . . . . . . . 86

7.2 Trabalhos futuros . . . . . . . . . . . . . . . . . . 87

$\begin{array}{lr}\text { Referências Bibliográficas } & 89\end{array}$

$\begin{array}{lr}\text { A Filtros de wavelets } & 101\end{array}$

A.1 Filtros de Coifman ou "Coiflets" . . . . . . . . . . . . . . . . . . . 101

A.2 Filtros de Daubechies . . . . . . . . . . . . . . . . . . . . 102

A.3 Filtro Symlets . . . . . . . . . . . . . . . . . . . . . 103 


\section{Lista de Figuras}

2.1 Exemplo de quatro imagens que possuem o mesmo histograma de cores. . . 7

2.2 Exemplo de textura (Wang et al., 2001) . . . . . . . . . . . . 7

2.3 (a) Exemplo de uma imagem original em tons de cinza (b) e sua forma segmentada mostrando 4 objetos identificados. . . . . . . . . . . . . . . . 10

3.1 Funções base de Fourier, cobertura do plano de tempo-freqüência. . . . . . 16

3.2 Funções base de wavelet de Daubechies e cobertura do plano tempo-freqüência. 17

3.3 Wavelet de Morlet ( não normalizada). À esquerda, a wavelet mãe, no centro a wavelet escalada e à direita a wavelet escalada e deslocada. . . . . 17

3.4 Wavelet de Haar . . . . . . . . . . . . . . . . . . . . . . . . . 22

3.5 Família Daubechies. . . . . . . . . . . . . . . . . . . . . 23

3.6 Uma função contínua $f(x)$ (linhas pontilhadas) e a função de aproximação caixa (linhas sólidas) em duas resoluções. À esquerda a aproximação grosseira $A_{0} f(x)$ e à direita a aproximação de maior resolução. $A_{1} f(x)$. . . . 25

3.7 Geração do espaço superior em função de $\phi(x)$ e $\psi(x)$. . . . . . . . . . . 25

3.8 Esquema de decomposição e reconstrução wavelet. . . . . . . . . . . . . 27

3.9 Decomposição wavelet 2D. (a) Imagem original. (b) Primeiro e (c) segundo nível de decomposição (Castañón, 2002; Wang et al., 2001). . . . . . . . . . 28

3.10 Componentes (a) real e (b) imaginário de $\psi(x, y)$ gerados com os parâmetros $S=4$ e $K=6 \ldots \ldots \ldots \ldots \ldots \ldots \ldots$

3.11 (a) Conjunto de wavelets Gabor (comprimento de banda octal de 1.5) (b) sua cobertura no plano de freqüência espacial (Lee, 1996).

3.12 Os contornos indicam a magnitude do pico médio do filtro de resposta no dicionário dos filtros de Gabor. Os parâmetros usados são $U_{h}=0.4$, $U_{l}=0.05, K=6$ e $S=4$.

4.1 Exemplo de uma consulta por abrangência onde o conjunto resposta contém 7 elementos sem contar o elemento de busca $O$. . . . . . . . . . . . 39

4.2 Exemplo de uma consulta do tipo $k N N$ onde o conjunto resposta contém 5 elementos, sem contar o elemento de busca $O$. . . . . . . . . . . . 39

4.3 Conjuntos referentes às medidas precision e recall para uma determinada operação de busca. . . . . . . . . . . . . . . . . . . . . . . . . 41 
4.4 Exemplo de um gráfico de medidas precision $\times$ recall para uma operação de busca. . . . . . . . . . . . . . . . . . . . . . 42

5.1 Fases da Mineração de Imagens . . . . . . . . . . . . . . . . . . . . . 45

5.2 Regiões de rejeição. . . . . . . . . . . . . . . . . . . . . . . 48

6.1 Exemplo de decomposição wavelet. (a) Imagem original; (b) Imagem decomposta em dois níveis de transformação com filtros Haar; (c) Configuração das regiões após a decomposição. . . . . . . . . . . . . . . . . .

6.2 Imagens de exames de ressonância magnética e angiograma. (a) Angiograma, (b) Abdômen Axial, (c) Cabeça Axial, (d) Pélvis Axial, (e) Abdômen Coronal, (f) Cabeça Coronal, (g) Cabeça Sagital e (h) Espinha Sagital. .

6.3 Exemplo de imagens das categorias 2, 3, 4 e 5 de acordo com o sistema BI-RADS.

6.4 Geração do vetor de características de uma imagem baseada nos subespaços wavelets considerando três níveis de decomposição e a função $E\left(S_{n}\right)$ corresponde ao extrator aplicado sobre o subespaço $S_{n} \ldots \ldots$. . . . . .

6.5 Curvas médias de precision vs. recall ilustrando o comportamento na recuperação de imagens do vetor de características composto pela energia dos subepaços de alta freqüência gerados pela wavelet mãe (abordagem de Castañón) e da nossa abordagem, que além desses subespaços, também considera o subespaço de baixa freqüência.

6.6 Curvas médias de precision vs. recall para cada categoria de imagens da base experimental da Tabela 6.1. . . . . . . . . . . . . . . . . . . 59

6.7 Imagens retornadas à consulta das 10 imagens mais próximas. . . . . . . . 60

6.8 Processo de criação de um padrão $x$ a partir de uma imagem (adaptada de Romdhani (1996)). . . . . . . . . . . . . . . . .

6.9 Exemplo de imagens da base de angiograma e ressonância magenética de 210 imagens. (a) Angiograma, (b) Axial RM Bacia, (c) Axial RM Cabeça, (d) Coronal RM Abdômen, (e) Coronal RM Cabeça, (f) Sagital RM Cabeça e (g) Sagital RM Espinha. . . . . . . . . . . . . . . . . . .

6.10 Curvas médias de precision vs. recall das consultas realizadas na base de dados com 210 imagens de ressonância magnética e angiograma, representando a imagem pelo subespaço de baixa freqüência gerado pela decomposição em 4 níveis. Cada vetor possui 256 características. . . . . . . .

6.11 Gráfico de precision vs. recall das consultas realizadas na base de dados com 210 imagens de ressonância magnética e angiograma, representando a imagem através do subespaço de baixa freqüência gerado pela decomposição em 5 níveis. . . . . . . . . . . . . . . . . . . . . . . .

6.12 Curvas médias de precision vs. recall usando: wavelet de Coifman 6 e $D_{4}$ em 4 níveis de decomposição, $D_{4}$ em 5 níveis e Histograma. . . . . . . . . . 64

6.13 Curvas médias de precision vs. recall geradas pela aplicação de wavelets de Daubechies em vários níveis de decomposição. . . . . . . . . . . . . 65

6.14 Curvas médias de precision vs. recall das consultas realizadas usando wavelet db1 em 4, 5 e 6 níveis de decomposição e Histograma. . . . . . . . 66

6.15 Exemplo de consulta k-NN $(\mathrm{K}=10) \ldots \ldots . \ldots . \ldots . \ldots 6$

6.16 Consulta k-NN (K=10) usando histograma. . . . . . . . . . . . 67

6.17 Curvas médias de precision vs. recall de cada classe de imagem do método db1-4n. . . . . . . . . . . . . . . . . . 
6.18 Exemplo de segmentação realizada pelo método de Balan (2007). (a) Imagem original; (b) imagem segmentada em 5 classes ( $\mathrm{L}=5$ ); (c) região de classe 1 (fluido cérebro-espinhal); (d) região de classe 2 (massa cinzenta); (e) região de classe 3 (massa branca); (f) região de classe 4 (dura, medula óssea, gordura). . . . . . . . . . . . . . . . . . . . . 69

6.19 Vetor de características das imagens: $5(L-1)$ valores reais . . . . . . . . 69

6.20 Gráfico de precision vs. recall gerado usando o método de Balan. . . . . . 70

6.21 Gráfico 1: Curvas médias de precision vs. recall dos testes 1, 2, 8, 9, 10, 12, 14 e 16, descritos na Tabela 6.5 . . . . . . . . . . . . . . . 74

6.22 Gráfico 2: Curvas médias de precision vs. recall dos testes 3, 4, 5 e 18 descritos na tabela 6.5 . . . . . . . . . . . . . . . . . . 75

6.23 Gráfico 3: Curvas médias de precision vs. recall dos testes $6,7,11,13,15$ e 17 descritos na Tabela 6.5 . . . . . . . . . . . . . . . . . 76

6.24 Várias curvas de precision vs. recall. . . . . . . . . . . . . . . . . 77

6.25 Gráfico 4: Curvas médias de precision vs. recall dos testes 19, 20, 21, 22 e 23 descritos na Tabela 6.5. . . . . . . . . . . . . . . . . . 78

6.26 Gráfico 5: Curvas médias de precision vs. recall dos testes 24 e 25 descritos na Tabela 6.5. . . . . . . . . . . . . . . . . . . . . 79

6.27 Curvas médias de precision vs. recall dos testes 16, 14, 18, 5, 17, 15, 19, 10, 1 e vetor de Castañón descritos na Tabela 6.5 . . . . . . . . . . . . 80

6.28 Curvas médias de precision vs. recall dos testes 16, 14, 19, 10, 1 e vetor de Castañón descritos na Tabela 6.5. . . . . . . . . . . . . . . . . . 81

6.29 Exemplo de consulta k-NN $(\mathrm{K}=10) \ldots \ldots \ldots$. . . . . . . . . . 82

6.30 Curvas médias de precision vs. recall de cada categoria de imagem. . . . . 82

6.31 Curvas médias de precision vs. recall obtidas usando o vetor original do teste 19 com 72 atributos e o vetor de 56 características selecionadas pelo algoritmo StARMiner. . . . . . . . . . . . . . . . . 83

6.32 Gráfico 6: Curvas médias de precision vs. recall dos testes 26 e 27. . . . 83 


\section{Lista de Tabelas}

5.1 Descrição das fases da mineração de imagens. . . . . . . . . . . . . . . . 44

5.2 Valores críticos de $Z$. . . . . . . . . . . . . . . . . . . . . 48

6.1 Base de imagens de ressonância magnética e angiograma. . . . . . . . . . . 54

6.2 Base de imagens mamográficas. Número de imagens por categoria de acordo com a classificação BI-RADS. . . . . . . . . . . . . . . . 55

6.3 Quadro resumo da análise dos gráficos de precision vs. recall do método que aplica transformada wavelet e o método proposto por Balan (2007). . . 71

6.4 Quadro de comparação do tempo médio de processamento. . . . . . . . . . 71

6.5 Testes realizados. . . . . . . . . . . . . . . . . . 73

6.6 Testes em ordem decrescente de precisão. . . . . . . . . . . . . . . . . . 74

6.7 Testes em ordem decrescente de precisão. . . . . . . . . . . . . . . . 76

6.8 Testes realizados. . . . . . . . . . . . . . . . . . . . . . 81 


\section{Capítulo \\ 1 \\ Introdução}

\subsection{Considerações Iniciais}

O aperfeiçoamento dos equipamentos eletrônicos e dos sistemas computacionais têm beneficiado o desenvolvimento de muitas áreas de pesquisa, sendo a medicina uma delas. Uma característica dessa área é que o volume de dados médicos armazenados digitalmente, que inclui exames, diagnósticos e procedimentos de tratamento, cresce exponencialmente. Conforme as leis vigentes em nosso país, esses dados devem ser guardados por no mínimo 20 anos. Esse grande volume de dados históricos é uma valiosa fonte de conhecimento, que pode ser usada para auxílio ao diagnóstico médico, para o ensino da medicina e como base para pesquisas. No entanto, em virtude da complexidade da análise e tratamento dos dados que incluem imagens, os profissionais da área de saúde ainda não se beneficiam de grande parte dessa fonte de conhecimento. Por exemplo, as técnicas existentes para a recuperação de imagens dificilmente permitem que sejam encontradas imagens de exames anteriores com o mesmo tipo de anomalia mostrado numa imagem recém-obtida. Esse fato ocorre em virtude de haver um grande número de características, extraídas das imagens, que podem ser usadas para sua busca, mas são desconhecidas quais delas são as mais relevantes para identificar o que se pretende recuperar em cada operação de busca na coleção de imagens. Além disso, dependendo das características escolhidas, a busca torna-se extremamente demorada, devido ao grande número de parâmetros envolvidos. Devido a tais fatores, as técnicas de recuperação de imagens por conteúdo (do inglês Content-based Image Retrieval - CBIR) têm sido bastante pesquisadas nos últimos anos (Müller et al., 2004). 
O potencial das informações armazenadas nos sistemas médicos poderá ser melhor aproveitado quando existirem técnicas para recuperar e explorar os dados com maior exatidão e que auxiliem médicos a efetuarem diagnósticos mais precisos. O desenvolvimento dessas técnicas visa estabelecer mecanismos de mineração que associem atributos das imagens com diagnósticos, permitindo gerar automaticamente a sugestão de um diagnóstico preliminar para a imagem analisada (segunda opinião). A sugestão pode identificar problemas que poderiam passar despercebidos a um analista humano, ou reforçar uma suspeita, o que pode aumentar a precisão dos diagnósticos corretos e, conseqüentemente, aumentar a chance do tratamento prescrito surtir efeitos positivos.

\subsection{Motivação}

Os sistemas PACS (Picture Archieving and Communication Systems) (Cao e Huang, 2000; Furuie et al., 1999; Pare et al., 2005) recebem as imagens dos diversos dispositivos e as enviam para os servidores de imagens, para posterior processamento e utilização. Os PACS permitem ampliar o uso das imagens para auxílio ao diagnóstico, e ampliar mecanismos de ensino de como analisá-las para os estudantes de medicina. Nos PACS, tanto os dados textuais e temporais dos pacientes quanto as imagens dos exames médicos a que ele se submeteu estão armazenados de maneira integrada.

Outra ferramenta valiosa para o auxílio ao diagnóstico médico são os sistemas CAD (Computer-Aided Diagnosis), para os quais pesquisas recentes mostram que o seu uso melhora significativamente a performance dos radiologistas em detectar corretamente anomalias (Doi, 2005). Em Quek et al. (2003) foi apresentado um estudo que revelou um aumento estatisticamente significativo (13\%) no desempenho de estudantes na detecção de anomalias em mamografias. Em uma série de estudos realizados pelo Departamento de Radiologia da Universidade de Chicago (Kobayashi e Doi, 1999; MacMahon et al., 1999; Shiraishi et al., 2002) onde foram traçadas curvas de ROC (verdadeiro positivo versus falso positivo), permitiram a comparação da precisão de diagnósticos realizados por radiologistas sem auxílio de CAD e por radiologistas auxiliados por CAD. Os resultados desses estudos mostraram que o uso de sistemas CAD melhora estatisticamente a precisão nos seguintes tipos de diagnósticos: detecção de nódulos e distinção entre nódulos benignos e malignos em mamografias; análise de tamanho do coração; detecção de micro-calcificações em mamografias; detecção de câncer de mama; detecção de anomalias por assimetria; e mudanças temporais em radiografias da mama. Esses estudos mostram a importância do desenvolvimento de ferramentas e técnicas computacionais para auxílio ao diagnóstico médico, aumentando a confiabilidade e evitando erros devido à perda de informação.

Um sistema CAD que possa efetuar consultas diretamente sobre as imagens provenientes de exames efetuados sobre os pacientes, traria certamente um auxílio ainda 
maior ao diagnóstico médico. Por exemplo, efetuar consultas como "recuperar todas as imagens obtidas em exames de tomografia computadorizada de coração, similares a uma imagem dada". Nesse caso, o cruzamento das informações é independente das chaves de busca tradicionais, baseadas em dados numéricos e textuais, as quais associam exames e pacientes em um Sistema de Informação Hospitalar tradicional. A facilidade de recuperação de dados baseada em seu conteúdo é um dos recursos atualmente mais almejados para incorporação aos sistemas PACS e CAD (Lima et al., 1998; Müller et al., 2004). Por meio dessa facilidade, podem ser encontrados registros de pacientes cujas imagens associadas apresentam aspectos de similaridade (utilizando padrões gráficos), além de se obterem correlações utilizando sintomas previamente registrados, tratamentos efetuados, etc.

Um sistema de apoio ao diagnóstico deve então ser capaz de responder a consultas por similaridade, isto é, a questões do tipo "quais são as 10 imagens mais semelhantes (mais próximas) de uma dada imagem" ou "quais são as imagens que diferem em até 5 unidades de uma imagem padrão". Vale notar que tanto as imagens quanto a função de distância (dissimilaridade) definida são usualmente dependentes do domínio dos dados e do interesse do que se considera "semelhante".

A similaridade entre imagens pode ser medida de várias formas. Características como formato, cor e textura podem ser extraídas de imagens em uma base de dados e são informações que podem ser utilizadas em cálculos de distância (Aslandogan e Yu, 1999; Müller et al., 2004).

Pesquisas devem ser realizadas para a elaboração de técnicas eficientes e eficazes para auxiliar os diagnósticos centrados em imagens de exames médicos. Neste sentido, o Grupo de Base de Dados e Imagens (GBdI) do Instituto de Ciências Matemáticas e de Computação (ICMC) - USP tem desenvolvido, desde 1997 (Traina et al., 1997), trabalhos relativos a representação de imagens por meio de vetores de características, armazenamento, indexação de imagens e busca por conteúdo de imagens em SGBDs (Sistemas Gerenciadores de Banco de Dados). Os trabalhos desenvolvidos vêm sendo incorporados ao cbPACS (content-based PACS) (Rosa, 2007) que é um protótipo que fornece os recursos de um sistema PACS e as funcionalidades de CBIR. O cbPACS está sendo desenvolvido no Hospital das Clínicas de Ribeirão Preto da Faculdade de Medicina de Ribeirão Preto - USP (HCFMRP), em pesquisa conjunta entre o GBdI e o Centro de Ciências de Imagens e Física Médica (CCIFM) do hospital.

\subsection{Objetivos}

O objetivo desta dissertação de mestrado foi definir e implementar um conjunto de extratores de características de imagens médicas adequado para utilização em sistemas PACS e CAD que possuam mecanismos de busca por conteúdo (CBIR). Nossa proposta 
foi utilizar os subespaços gerados por Wavelets que, por sua própria natureza, separam as informações de sumarização das imagens (sub-espaços de baixa freqüência) de seus detalhes (sub-espaços de alta freqüência). Os extratores de características propostos visam à obtenção de vetores de características (feature vectors) que serão utilizados em um sistema de mineração de imagens em desenvolvimento no GBdI-ICMC-USP, permitindo encontrar padrões pertencentes às imagens que as levem a ser classificadas em categorias.

\subsection{Organização do trabalho}

Este trabalho está organizado da seguinte forma:

No Capítulo 2 são discutidas as abordagens para se extrair informações sobre cor, textura e forma de uma imagem, sendo que no presente trabalho, características de textura serão extraídas dos subespaços da imagem gerados por uma transformada wavelet e armazenadas em um vetor de características.

No Capítulo 3 são introduzidos conceitos relacionados às wavelets e suas aplicações envolvidas. A abordagem da transformada de wavelets é feita do ponto de vista da análise de multi-resolução desenvolvida por Mallat e Meyer.

No Capítulo 4 são apresentados os conceitos referentes às consultas por similaridade, os principais tipos de consultas e técnicas de avaliação de eficiência.

No Capítulo 5 são abordados tópicos relativos à mineração específica de imagens, inclusive a descrição do algoritmo de mineração de imagens StARMiner.

O Capítulo 6 apresenta a proposta e desenvolvimento de novos extratores de características de imagens médicas de ressonância magnética, angiograma e mamografias, por meio de wavelets e medidas estatísticas.

O Capítulo 7 apresenta as considerações finais, as principais contribuições deste trabalho e propostas de trabalhos futuros.

No Apêndice A estão descritos os filtros das wavelets usados neste trabalho. 


\section{Capítulo \\ 2 \\ Extração de Características de Imagens}

\subsection{Considerações Iniciais}

Sistemas de apoio a diagnósticos (CAD) permitem que o médico use o resultado de análises quantitativas sobre imagens e textos de laudos para decidir qual é o diagnóstico de um exame (Jiang et al., 2001). A primeira etapa na análise de uma imagem médica é a extração de suas características e segmentação.

As características mais usadas para descrever uma imagem de modo sucinto são baseadas principalmente em distribuições de intensidades (cores), textura e forma e a recuperação de imagens está baseada na similaridade das características derivadas delas. Embora a cor seja um atributo confiável na recuperação de imagens, situações onde a informação de cor não as discrimina bem, requerem o uso de atributos de textura e/ou forma para auxiliar e refinar o processo de recuperação de imagens. Além disso, os sistemas baseados em um único atributo da imagem podem não alcançar níveis de recuperação adequados, motivo pelo qual os sistemas procuram utilizar múltiplos atributos das imagens para a sua indexação e recuperação (Zhang e Lu, 2001).

Nas seções seguintes serão detalhados os atributos das imagens.

\subsection{Cor}

As cores presentes em uma imagem possuem um papel significativo na indexação e recuperação da mesma. Existem diferentes representações de cores que incluem desde o tradicional RGB (red, green, blue), o mais simples modelo que mapeia diretamente as 
características físicas do dispositivo de exibição, até o HSI (hue, saturation, intensity) que reflete mais precisamente o modelo de cores para a percepção humana.

Muitos trabalhos recentes de extração de características baseadas em distribuição de cores estão concentrados nos histogramas de cor. Alguns dos trabalhos prévios incluíram a indexação da cor usando interseção de histogramas (Kim e Chung, 2003). Os histogramas de cor são invariantes à translação e rotação das imagens, sendo que, com a normalização dos histogramas, obtém-se também a invariância à escala. De qualquer forma, os histogramas de cor não indicam a localização espacial dos pixels na imagem.

Alguns métodos propostos apresentam melhorias para esta técnica. Dentre eles encontram-se: o uso de histograma de cores acumulativo (Stricker e Orengo, 1995), o uso de análise por cor baseada em região (Carson et al., 1997), o uso de histogramas métricos (Felipe et al., 2006), o uso de histogramas em multi-escala (Chen et al., 2005).

Alguns trabalhos, que utilizam a distribuição de cores na imagem para montar o vetor de características baseado nos coeficientes wavelets, são apresentados por Albuz et al. (2001), conseguindo diminuir o tempo de busca das imagens similares, mas a eficiência da busca não é tão boa (máximo de 35\% de eficiência) (Castañón e Traina, 2003). Ainda em Kumar et al. (2006), um sinal pode ser modelado por dois histogramas: um pelo sinal com ruído e o outro pelo sinal sem ruído, ambos representados por coeficientes wavelet. Em Zhang et al. (2007), é feita uma combinação de interseção de histogramas de regiões geradas pela aplicação de wavelets de Gabor sobre faces.

A popularidade da utilização de histogramas de cores em sistemas de recuperação de imagens baseada em conteúdo deve-se principalmente a três fatores (Pass et al., 1996): a) ser computacionalmente simples e barato de calcular; b) pequenas alterações de movimentação na imagem pouco afetam os histogramas; c) objetos distintos freqüentemente possuem histogramas diferentes. No entanto, não é possível separar ou reconhecer imagens utilizando apenas o histograma das mesmas, pois duas ou mais imagens bastante diferentes podem ter histogramas semelhantes. A Figura 2.1 apresenta 4 exemplos de imagens (a,b,c,d) que possuem o mesmo histograma (e).

Além do problema da ambigüidade, o histograma também apresenta o problema de ter alta dimensionalidade. Como o número de cores (níveis de cinza em imagens médicas) é geralmente grande (usualmente mais de 100 níveis), indexar vetores com essa dimensão é algo problemático. Isso porque um histograma para 100 cores distintas (ou 100 níveis de cinza distintos) pode ser visto como um ponto 100-dimensional e, para valores dessa ordem, a maior parte das estruturas de índices espaciais sofre com a "maldição da alta dimensionalidade" (Ferhatosmanoglu et al., 2006), onde o melhor método de acesso passa a ser a busca seqüencial. 


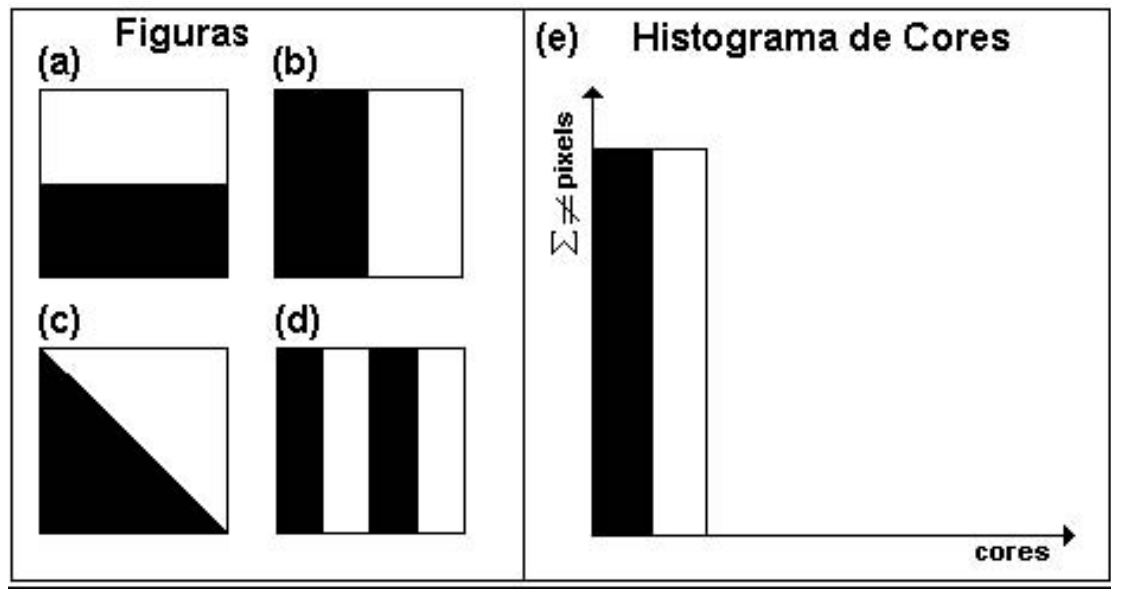

Figura 2.1: Exemplo de quatro imagens que possuem o mesmo histograma de cores.

\subsection{Textura}

A textura pode ser reconhecida e diferenciada pelo olhar humano através de características de suavidade, rugosidade e regularidade (Gonzalez e Wintz, 1987). Apesar de não existir uma definição clara para este conceito, os autores concordam em defini-la como as mudanças na intensidade da imagem que formam determinados padrões repetitivos (Jain e Tuceryan, 1993). Esses padrões podem ser o resultado de propriedades físicas da superfície do objeto (rugosidade), ou ser o resultado de diferenças de reflexão tal como a cor na superfície. A Figura 2.2 mostra exemplos de diferentes texturas.
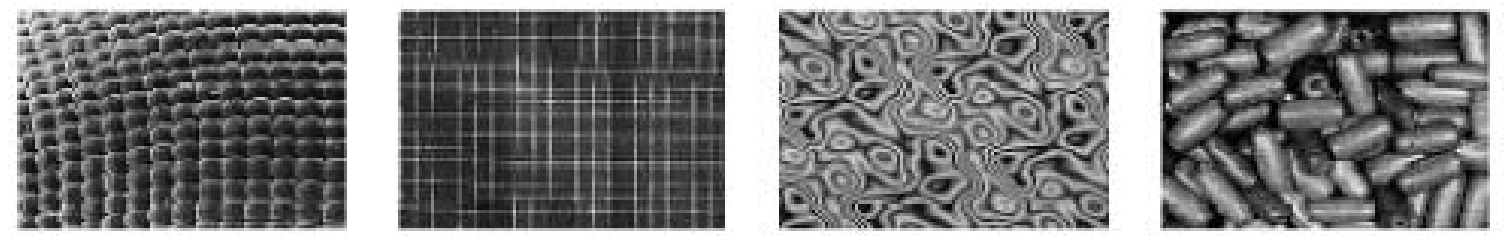

Figura 2.2: Exemplo de textura (Wang et al., 2001)

Em Gonzalez e Wintz (1987), as três principais abordagens usadas no processamento de imagens para descrever a textura de uma região são classificadas como:

\section{Abordagem Estatística}

Considera a distribuição dos tons de cinza e a variação de intensidade dos mesmos em uma janela de textura. Esta abordagem caracteriza a textura como suave, áspera e granular, entre outras.

Os descritores de textura, obtidos por meio dos métodos estatísticos, podem ser classificados em duas categorias de acordo com o método estatístico utilizado: Características de Primeira Ordem (um pixel), Segunda Ordem (dois pixels) ou Ordem superior (três ou mais pixels). A diferença básica é que a estatística de primeira ordem estima propriedades 
(por exemplo, média e variância) dos valores individuais dos pixels, ignorando a interação espacial entre os pixels da imagem, visto que os outros dois métodos estatísticos estimam propriedades de dois ou mais valores de pixels que ocorrem em locais específicos com relação a outro. Um dos métodos mais usados é a Matriz de co-ocorrência (Bortolotti, 2004; Haralick et al., 1973; Tesar et al., 2007).

Outros exemplos de medidas usadas nessa abordagem são: contraste (polarização na distribuição de intensidade de pixels); granularidade (tamanho dos elementos do padrão) e direcionalidade (forma e localização do padrão);

\section{Abordagem Estrutural}

Esta abordagem obtém os elementos de textura presentes na imagem, determinando seus formatos e estimando as regras de posicionamento. As regras de posicionamento descrevem como os elementos de textura são colocados com relação aos demais. Esta abordagem também estabelece o relacionamento de vizinhança (conectividade), o número de elementos por unidade espacial (densidade) e a regularidade da textura (homogeneidade) (Bortolotti, 2004; Gonzalez e Woods, 1993).

Esta abordagem é pouco utilizada, visto que poucas texturas apresentam um caráter tão regular.

\section{Abordagem Espectral}

Baseia-se em propriedades de espectros de freqüência obtidos por meio de transformadas tais como a transformada de Fourier e a transformada de Wavelets.

Geralmente utiliza-se a análise estrutural sempre que os elementos da textura podem ser claramente identificados. Por outro lado, aplica-se a análise estatística para texturas pequenas e não muito regulares (Tomita e Saburo, 1990). A abordagem estatística é a que apresenta melhores resultados na análise da textura de uma imagem, e é mais adequada no uso com imagens médicas, devido à natureza destas (Bortolotti, 2004). Estudos têm demonstrado que sistemas de textura utilizando Gabor e multi-resolução simultaneamente apresentam-se como uma boa técnica em sistemas de recuperação e indexação baseadas no conteúdo (Castañón e Traina, 2003; Ma e Manjunath, 1996; Shen et al., 2007).

O uso de características de textura para representar a imagem, da mesma maneira que o histograma de cores, também apresenta o problema de ambigüidade. Além disso, características de textura também costumam ter alta dimensionalidade.

\subsection{Forma}

O formato, ou forma, de um determinado objeto da imagem pode ser considerado o atributo de maior relevância para a abordagem de recuperação de imagens por conteúdo 
baseada em características primitivas. As diversas evidências de que objetos reais são identificados pelo sistema de visão humana primordialmente pela forma podem ser a justificativa para isto (Balan, 2004; Biederman, 1987).

A recuperação de imagens baseada em forma é um dos problemas mais difíceis de serem tratados pelos sistemas de recuperação de imagens baseada em conteúdo. Isto se deve principalmente à dificuldade de segmentar automaticamente os objetos de interesse presentes na imagem, levando a recuperação por formas ser tipicamente limitada aos poucos objetos mais bem discriminados que estão presentes na mesma. Por exemplo, em aplicações médicas, a forma e o tamanho dos tumores é de muita importância na hora de classificá-los como malignos ou benignos. Tumores com bordas irregulares têm uma alta probabilidade de serem malignos e aqueles que mostram bordas regulares geralmente são benignos (Alto et al., 2005).

Para obtenção de características de forma, as imagens são segmentadas e o vetor de características que descreve a imagem passa a ser composto por diversos atributos numéricos, sendo usual utilizar: a posição absoluta do objeto na imagem, a posição relativa do objeto em relação a outros, a excentricidade, a curvatura e o formato do contorno. Em virtude do grande número de parâmetros envolvidos e também da dificuldade de segmentar a imagem em regiões de interesse, o reconhecimento de formas é um processo bastante complexo (Costa e Cesar Jr, 2001).

A imagem a ser indexada deve ser pré-processada para possibilitar a busca e a determinação das bordas que estão nela presentes. Os filtros ou algoritmos de pré-processamento dependem do domínio da aplicação das imagens em questão (formas pré-definidas baseadas em geometria ou não). O tratamento de imagens mais complexas demanda muitas vezes também o tratamento e remoção de ruídos em uma etapa de pré-processamento. A Figura 2.3 exemplifica a detecção de formas, onde são esperados a detecção do fígado, da espinha dorsal e do corpo. Qualquer objeto detectado dentro do contorno do fígado é considerado um tumor (Petrakis e Faloutsos, 1997).

Após o objeto ser encontrado, sua borda precisa ser detectada utilizando-se algoritmos de detecção de contorno. O processo de detecção de bordas e formas fica mais difícil e comprometido em cenas complexas onde há, além do ruído, oclusão parcial de objetos ou sombras sobre regiões das imagens.

Uma propriedade desejável do conjunto de características utilizados é que ele se comporte da mesma maneira para objetos de mesma natureza que estejam em posição, rotação e escala diferentes (invariância a transformações geométricas), e, além disso, possa descrever adequadamente a forma do objeto mesmo quando a imagem contém ruídos. Quanto à classificação dos métodos de extração de características de forma, a mais comum e geral delas leva em consideração se o método analisa apenas os contornos dos objetos ou analisa o objeto como um todo, levando em consideração também os pontos 

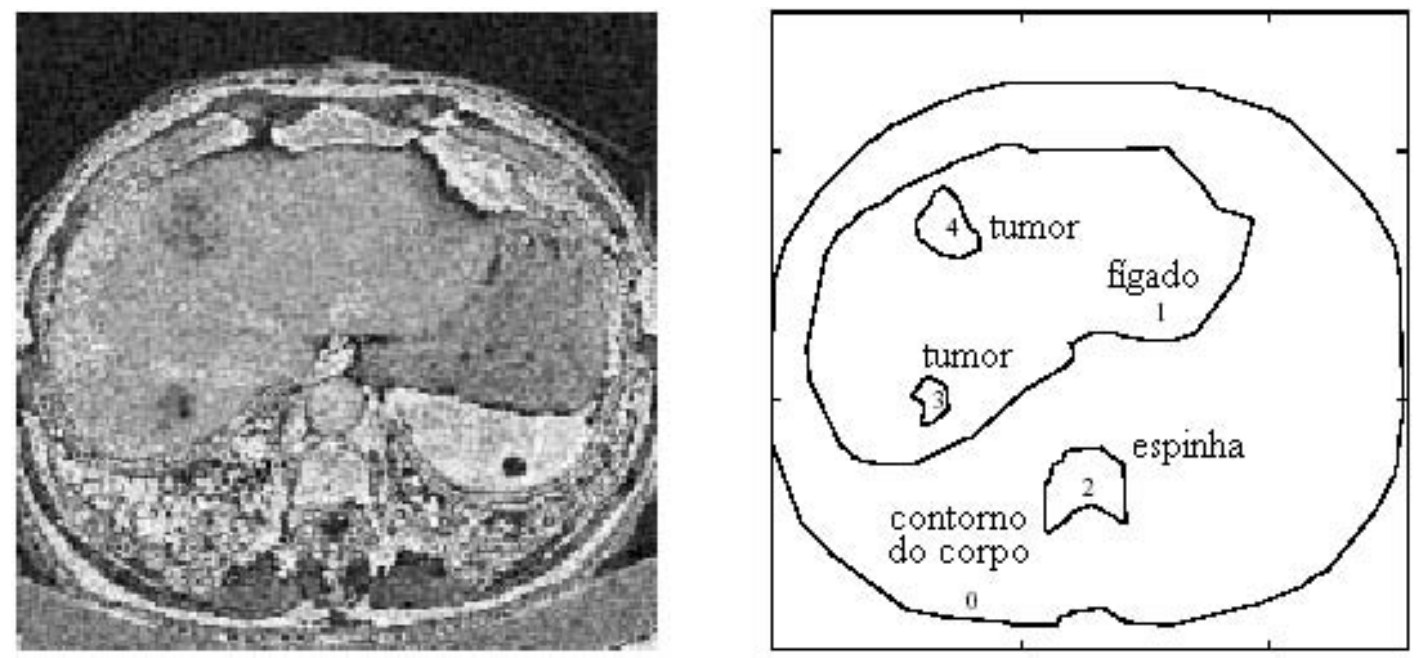

Figura 2.3: (a) Exemplo de uma imagem original em tons de cinza (b) e sua forma segmentada mostrando 4 objetos identificados.

de seu interior. Sendo assim, desta classificação são derivadas duas classes de métodos: os métodos baseados em contornos e os baseados em região, respectivamente.

Ainda segundo Zahn e Roskies (1972), pode-se descrever a forma e as características de contorno de objetos basicamente de três maneiras: por aproximação polinomial, por momentos invariantes e por descritores de Fourier. Outros trabalhos também descrevem a forma e as características de contorno de objetos por meio de descritores wavelet-Fourier (Yadav et al., 2007), da combinação de descritores genéricos de Fourier para a forma do contorno e da região (Sajjanhar et al., 2007) e por descritores de Fourier em multi-escala (Kunttu et al., 2006).

\subsection{Considerações Finais}

A extração e seleção das características das imagens são os passos mais críticos para a identificação de objetos na imagem. Um dos principais problemas é como identificar um conjunto reduzido de características que descrevam a imagem com precisão suficiente para sua identificação e para a extração de padrões em coleções de imagens. Deve-se ressaltar que a percepção humana é bastante subjetiva, e portanto, o uso de uma única característica para representação de imagens não é, em geral, suficiente (Zhang e Lu, 2001). Esse é um assunto em aberto onde muita pesquisa tem sido feita nos últimos anos (Balan, 2007; Grigorova et al., 2007; Jain e Vailaya, 1998; Marques, 2001; Müller et al., 2004; Ribeiro et al., 2006; Vogel e Schiele, 2006; Wang et al., 2006).

Visando sobrepujar esse problema, este trabalho propõe métodos de extração de características de imagens médicas utilizando wavelets. 


\section{Capítulo \\ 3 \\ Introdução à Teoria Wavelet}

\subsection{Considerações Iniciais}

As wavelets são funções matemáticas que separam o dado em diferentes componentes de freqüência, e então estudam cada componente com uma resolução combinada a sua escala. Elas têm vantagens sobre os métodos tradicionais de Fourier na análise de situações físicas onde o sinal contém descontinuidades e picos. Wavelets foram desenvolvidas independentemente nos campos da matemática, física quântica, engenharia elétrica e geologia sísmica. Mudanças entre estes campos durante os últimos anos conduziram a muitas novas aplicações das wavelets, como na compressão de imagens, turbulência, visão humana, radar e predição de abalos sísmicos. Neste capítulo apresenta-se uma breve introdução à teoria de wavelets sob a ótica da análise de processamento de sinais.

\subsection{Perspectiva Histórica}

Na história da matemática, a análise de wavelets mostra muitas origens diferentes (Meyer, 1993). Muitos trabalhos foram desenvolvidos por volta de 1930 por vários grupos trabalhando independentemente. Antes de 1930, Joseph Fourier (1807) iniciou o estudo de wavelet com suas teorias de análise de freqüência, agora conhecidas como síntese de Fourier. Ele afirmava que qualquer função $f(x) 2 \pi$-periódica é a soma

$$
a_{0}+\sum_{k=1}^{\infty}\left(a_{k} \cos k x+b_{k} \sin k x\right)
$$


de sua série de Fourier. Os coeficientes $a_{0}, a_{k}$ e $b_{k}$ são calculados por

$$
a_{0}=\frac{1}{2 \pi} \int_{0}^{2 \pi} f(x) d x, a_{k}=\frac{1}{\pi} \int_{0}^{2 \pi} f(x) \cos (k x) d x, b_{k}=\frac{1}{\pi} \int_{0}^{2 \pi} f(x) \sin (k x) d x
$$

A afirmação de Fourier teve um papel essencial na evolução das idéias que os matemáticos tiveram sobre funções. Ele abriu portas para um novo universo.

Depois de 1807, explorando o significado das funções, convergência de séries de Fourier, e sistemas ortogonais, os matemáticos foram gradualmente se direcionando da noção prévia de análise de freqüência à noção de análise de escala.

A primeira menção a wavelets apareceu no apêndice de A. Haar (1909). Uma propriedade das wavelets de Haar é que elas têm suporte compacto, isto é, seu valor é zero para valores fora de um intervalo finito; contudo, elas não são continuamente diferenciáveis, o que de certa forma limita as suas aplicações. Haar construiu a primeira família wavelet ortonormal de suporte compacto de que se tem notícia, e que leva o seu nome.

Na década de 30, diversos grupos trabalharam independentemente pesquisando a representação de funções usando uma base de função variando com a escala. Naquela ocasião, Paul Levy investigou o movimento Browniano usando a base de wavelets de Haar, mostrando que as funções da base de Haar eram melhores do que as da base de Fourier para estudar os pequenos e complicados detalhes do movimento Browniano (Meyer, 1993). Outros pesquisadores desta época (Littlewood, Paley e Stein) computaram a energia de uma função $f(x)$ :

$$
\text { energia }=\frac{1}{2} \int_{0}^{2 \pi}|f(x)|^{2} d x
$$

Diferentes resultados eram produzidos se a energia estava concentrada ao redor de poucos pontos ou distribuída ao longo do intervalo. Este resultado preocupou cientistas, pois isto indicava que a energia podia não ser conservada. Pesquisadores descobriram uma função que pode "varrer" em escala e conservar energia quando computar a energia funcional.

Em 1980, Grossman e Morlet, um físico e um engenheiro, definiram wavelets no contexto da física quântica. Em 1985, Stephane Mallat deu às wavelets um grande impulso através de seu trabalho em processamento digital de imagens. Ele descobriu algumas relações entre filtros de espelho quadrático, algoritmos piramidais, e bases ortonormais wavelets. Inspirado em parte por esses resultados, Y. Meyer construiu a primeira wavelet não trivial. Ao contrário das wavelets de Haar, as wavelets eram continuamente diferenciáveis; mas não tinham suporte compacto. Anos mais tarde Ingrid Daubechies usou o trabalho de Mallat para construir um conjunto de bases ortonormais de wavelets que são talvez as mais elegantes, e são os alicerces das aplicações atuais de wavelets. 
A partir de 1994 verifica-se uma tendência de vários segmentos da comunidade científica em explorar o potencial das wavelets principalmente em aplicações de codificação, representação e compressão de sinais. Observa-se a partir de então um interesse em torno de aplicações gráficas, especialmente compressão de imagens e processamento gráfico em multiresolução (Faria, 1997; Fournier et al., 1995).

Paralelamente aos trabalhos em aplicações específicas, diversas contribuições endereçando novos algoritmos e estratégias de implementação alternativas foram introduzidas para a transformada wavelet contínua e discreta. Implementações computacionais propuseram versões para a transformada rápida discreta (utilizando-se bancos de filtros), algoritmos melhorados para resolver efeitos espúrios de bordas e esquemas para obter maior particionamento do espectro, de forma a aumentar a resolução nas faixas de freqüências mais altas, utilizando-se técnicas como os "pacotes de wavelets" (wavelet-packets), e multiwavelets.

A pesquisa por novas bases wavelets e a formalização de técnicas para construção de bases adquirem também importância na medida em que várias aplicações apresentam melhores desempenhos. Bases wavelets são desenvolvidas tais que satisfaçam diversos critérios desejáveis, como rapidez de processamento, boa localização espacial/temporal, regularidade e suavidade, boa localização em freqüência, independência, e melhor descrição de classes específicas de sinais.

Entre 1989 e 1994 o método da melhor base é introduzido e vários algoritmos baseados neste método são desenvolvidos. Wickerhauser (1994) aborda o algoritmo da melhor base (best basis algorithm) em livro de sua autoria. Várias bases wavelets têm sido concebidas e publicadas na literatura - bases biortogonais, bases adaptativas, as bases de Malvar, Vaidyanathan, Beylkin, entre outras.

Surgem por volta de 1995 novas técnicas de implementação e síntese de wavelets que não recorrem aos métodos de Fourier para sua construção, introduzindo novos paradigmas de implementação e geração de bases wavelets, que alguns autores consideram uma segunda onda das wavelets: as wavelets de segunda geração. Sweldens (1995) introduz assim o esquema ou algoritmo de lifting, uma nova filosofia para construção de wavelets biortogonais independente da transformada de Fourier, até então importante instrumental na construção de wavelets.

É importante ressaltar que implementações em hardware são desenvolvidas a partir da década de 1990. Por exemplo, a Analog Devices lança o dispositivo ADV601, um chip para aplicações em compressão com wavelet (Faria, 1997).

A atividade em torno das wavelets é febril. Numerosos congressos, seminários, workshops, publicações especiais e conferências internacionais endereçando aspectos teóricos e aplicativos das wavelets são realizados e propostos em vários países. Diversos sítios na Internet são dedicados à teoria wavelet, à disseminação de informação, artigos, trabalhos científicos, pesquisas em aplicações específicas, à divulgação de eventos, grupos 
de pesquisa, e suporte a "usuários" das wavelets. O sítio www.wavelet.org - o Wavelet Digest - é um dos pioneiros, contando com mais de 20.000 assinantes no fim de 2001, na sua maioria pesquisadores e usuários de wavelets.

\subsection{Análise de Fourier}

A representação de funções de Fourier como uma superposição de senos e cossenos tem se tornado onipresente para ambas soluções, analítica e numérica, de equações diferenciais e para a análise e tratamento da comunicação de sinais. Análises de Fourier e wavelet têm algumas fortes ligações.

A transformada de Fourier analisa um sinal no domínio do tempo para sua freqüência. A transformada primeiramente translada uma função no domínio do tempo para uma função no domínio de freqüência. O sinal pode então ser analisado pela freqüência, pois os coeficientes de Fourier da função transformada representam a contribuição de cada função seno e cosseno em cada freqüência. Uma transformada inversa de Fourier transforma um dado a partir da freqüência para o domínio do tempo. Nas subseções seguintes são discutidos três tipos de transformada de Fourier: transformada discreta, transformada por janelas e transformada rápida.

\subsubsection{Transformada discreta de Fourier}

A transformada discreta de Fourier (DFT) estima a transformada de Fourier de uma função a partir de uma amostra do seu conjunto de pontos. Supõe-se que s pontos caracterizarem o sinal da mesma maneira em qualquer tempo. A DFT tem propriedades simétricas semelhantes à transformada de Fourier, como a continuidade. Além disso, a fórmula para a transformada discreta inversa de Fourier é facilmente calculada usando a mesma para a transformada discreta, pois as duas fórmulas são quase idênticas (Graps, $1995)$.

\subsubsection{Transformada por janelas de Fourier}

Se $f(t)$ é um sinal não-periódico, a somatória das funções periódicas, senos e cossenos, não representam bem o sinal. A transformada por janelas de Fourier (WFT) é uma solução para o problema de representar melhor o sinal não-periódico. A WFT pode ser usada para dar informação sobre sinais simultaneamente no domínio de tempo e de freqüência.

Com a WFT, o sinal de entrada $f(t)$ é separado em seções, e cada seção é analisada por seu conteúdo de freqüência separadamente. Se o sinal tem transições abruptas, "janela-se" o dado para que as seções convirjam para zero nas extremidades (Graps, 1995; Kaiser, 1994). Este janelamento é acompanhado de uma função peso que dá menos ênfase próxima 
às extremidades do intervalo do que no meio. O efeito da janela é localizar o sinal no tempo.

\subsubsection{Transformada rápida de Fourier}

Para aproximar uma função por amostras, e para aproximar a integral de Fourier pela transformada discreta de Fourier, requer aplicar uma matriz cuja ordem é o número da amostra de pontos $n$. Desde que se multiplique uma matriz $n \times n$ por um vetor de custo sobre ordem de $n^{2}$ de operações aritméticas, o problema rapidamente piora quando o número da amostra de pontos aumenta. Entretanto, se as amostras são uniformemente espaçadas, então matriz de Fourier pode ser fatorada em um produto de poucas matrizes esparsas, e os fatores resultantes podem ser aplicados a um vetor de ordem total $n \log n$ de operações aritméticas. Esta é a tão chamada transformada rápida de Fourier (FFT) (Graps, 1995; Press e al, 1992).

\subsection{Wavelet vs. Transformada de Fourier}

\subsubsection{Semelhanças entre as Transformadas de Fourier e Wavelet}

A FFT e a transformada discreta wavelet (DWT) são ambas operações lineares que geram uma estrutura de dado que contém $\log 2 n$ segmentos de vários tamanhos, geralmente preenchendo e transformando-os em um vetor de dados diferente de tamanho $2 n$.

As propriedades matemáticas das matrizes envolvidas nas transformadas também são similares. A matriz da transformada inversa para ambas FFT e DWT é a transposta da transformada original. Como resultado, ambas transformadas podem ser vistas como uma rotação do espaço de funções para um domínio diferente. Para a FFT, este novo domínio contém funções bases que são senos e cossenos. Para a transformada wavelet, o novo domínio contém funções bases mais complexas que os senos e cossenos da FFT, chamadas wavelets ou wavelets mãe.

Ambas transformadas têm outra semelhança. As funções bases estão localizadas na freqüência, tendo as ferramentas matemáticas como uma energia espectral (quantidade de energia que está contida no intervalo de freqüência) e escala útil para escolher freqüências e calcular distribuições de energia.

\subsubsection{Diferenças entre as Transformadas de Fourier e Wavelet}

A diferença mais interessante é que as funções individuais wavelet estão localizadas no espaço enquanto que as funções seno e cosseno de Fourier não estão. Esta característica de localização no espaço juntamente com localização de wavelets de freqüência, faz muitas funções e operadores usarem wavelets "esparsas" quando transformadas no domínio 


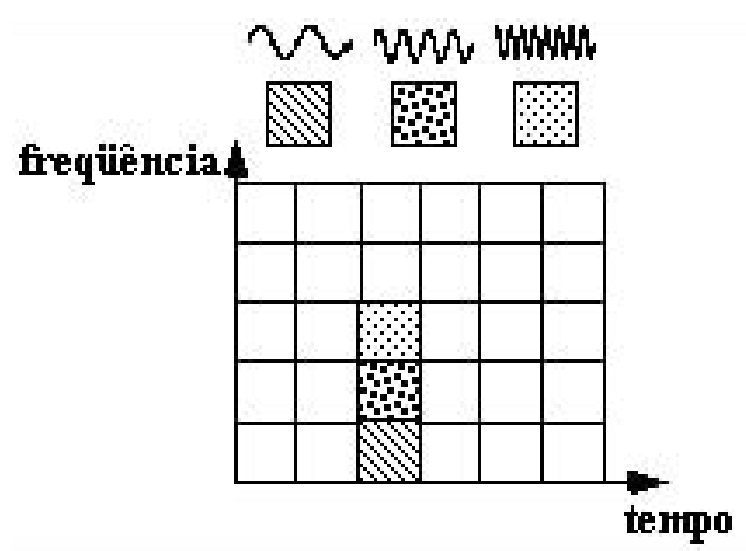

Figura 3.1: Funções base de Fourier, cobertura do plano de tempo-freqüência.

wavelet. Esta característica de ser esparsa resulta em um grande número de aplicações como compressão de dados, detecção de características em imagens, e remoção de ruído das séries de tempo.

Uma forma de olhar as diferenças de resolução de tempo-freqüência entre as duas transformadas é notar a cobertura da função base do plano de tempo-freqüência (Graps, 1995; Vetterli e Herley, 1992). A Figura 3.1 ilustra uma transformada de Fourier janelada, onde a janela é simplesmente uma onda quadrada. A janela de onda quadrada trunca a função seno ou cosseno para ajustar uma janela de uma largura particular. Como apenas uma janela é usada para todas as freqüências na WFT, a resolução da análise é a mesma para todas as localizações no plano de tempo-freqüência.

Uma vantagem da transformada wavelet é que a janela varia. Para isolar as descontinuidades do sinal, seria interessante ter algumas funções bases bem curtas. Ao mesmo tempo, para obter análise detalhada de freqüência, a solução seria ter algumas funções base bem longas. Uma maneira para conseguir isto é ter bases de funções curtas de alta-freqüência e longas de baixa-freqüência. Isto é exatamente o que a transformada wavelet faz. A Figura 3.2 mostra a cobertura no plano de tempo-freqüência com uma função wavelet, a wavelet de Daubechies.

Algo a ser lembrado é que as transformadas wavelets não possuem apenas um conjunto de funções base como a transformada de Fourier, que utiliza apenas as funções seno e cosseno. Ao invés disso, transformadas wavelet têm um conjunto infinito de possíveis funções base. Assim, a análise wavelet provê acesso imediato à informação que pode ser obscura por outros métodos tempo-freqüência, como a análise de Fourier.

\subsection{Análise de Wavelet}

Wavelets são "ondas pequenas", funções obtidas a partir de uma função protótipo a wavelet mãe - $\psi(t) \in L^{2}(R)$, por meio de dilatações (contrações ou escalamento) e 


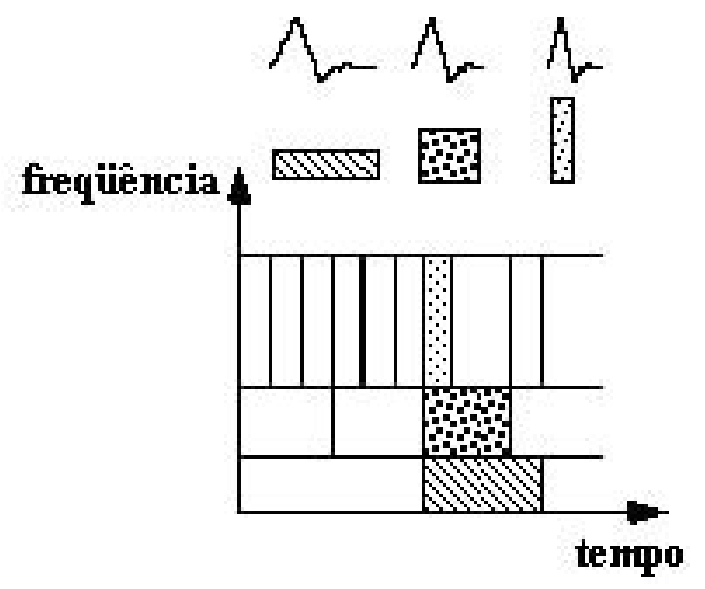

Figura 3.2: Funções base de wavelet de Daubechies e cobertura do plano tempo-freqüência.

translações (deslocamentos). O objetivo primordial em se realizar estas operações é o de se obter uma família de funções base para descrever outras funções pertencentes a $L^{2}(R)$. A Figura 3.3 mostra um exemplo de uma wavelet-mãe, uma versão escalada e uma versão escalada e deslocada, respectivamente. Essa figura é uma wavelet de Morlet, cuja primitiva é a função $\psi(t)=e^{-\alpha t^{2}} \cdot e^{j w t}$.
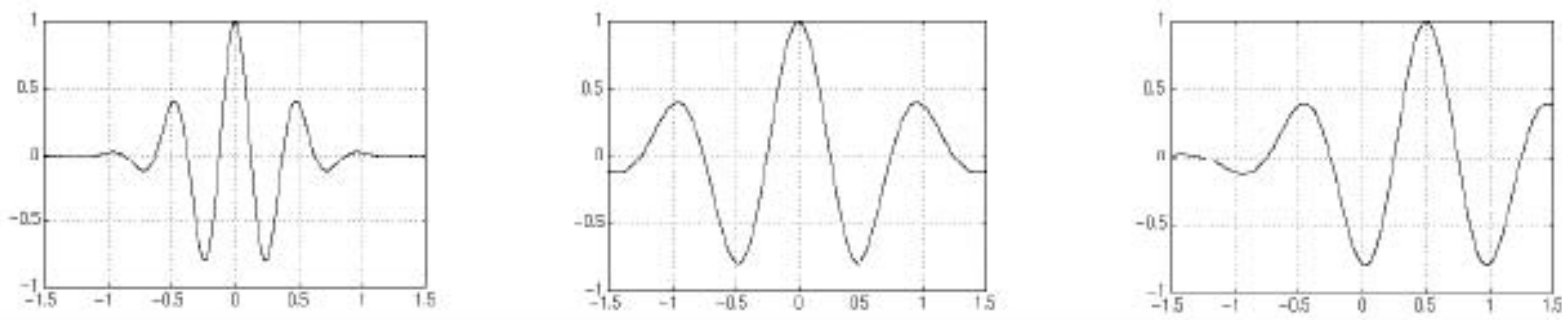

Figura 3.3: Wavelet de Morlet ( não normalizada). À esquerda, a wavelet mãe, no centro a wavelet escalada e à direita a wavelet escalada e deslocada.

Introduzindo dilatações por meio de um fator de escalamento $a$, e translações por meio de uma variável $b$, deduz-se a forma geral de uma família de wavelets:

$$
\psi_{a, b}(t)=\frac{1}{\sqrt{a}} \psi\left(\frac{t-b}{a}\right)
$$

Nesta equação, os parâmetros $a$ e $b$ variam continuamente em $R, a \neq 0$ sendo que a função $\psi_{a, b}$ é denominada wavelet primitiva ou mãe.

A utilidade das wavelets está na sua possibilidade de atuarem como funções base na decomposição de outras funções pertencentes a $L^{2}(R)$. As bases wavelets podem ser redundantes ou ortonormais, cobrindo e descrevendo completamente o espaço $L^{2}(R)$, de uma forma mais sofisticada que as bases senoidais dos métodos de Fourier. Na sua forma contínua, as wavelets são basicamente redundantes. Em forma discreta podem dar origem 
às chamadas "molduras" (frames: bases discretas redundantes), a bases ortonormais, biortogonais, e outras bases wavelets (Daubechies, 1992).

Além desses aspectos, outras propriedades são desejadas e exigidas das famílias wavelets para que sejam úteis em aplicações práticas em processamento de sinais e na análise de espaços funcionais. Neste contexto, wavelets devem satisfazer requisitos como (Meyer, 1993):

- possuirem energia finita, de forma que a análise preserve a energia, e que a síntese leve a uma reconstrução perfeita;

- possuirem certo grau de regularidade (suavidade);

- serem nulas no infinito;

- possuirem um certo número de momentos nulos $\left(f(t)\right.$ quando $\int_{-\infty}^{\infty} f(t) \cdot t^{k} d t=0$ para $k=0,1, \ldots, m)$;

- que sejam funções de classe $C^{k}(0<k<\infty)$;

- que tenham suporte compacto, no tempo e na freqüência.

Existem inúmeras possibilidades de escolha de wavelets para análise, entretanto a escolha não é arbitrária, e obedece a critérios matemáticos bem definidos, como os citados acima. A seguir, analisa-se o caso contínuo (transformada wavelet contínua ou integral).

\subsubsection{Wavelets contínuas}

Seja $\psi \in L^{2}(R)$ uma wavelet mãe. Para que possa dar origem a uma família de wavelets exige-se que (Faria, 1997):

- a wavelet seja absolutamente integrável: $\int_{-\infty}^{\infty} \psi(t) d t<\infty$;

- possui energia finita: $\int_{-\infty}^{\infty}|\psi(t)|^{2}<\infty$;

- satisfaça a uma condição de admissibilidade: $C=2 \pi \int_{-\infty}^{\infty}|\Psi(\omega)|^{2} \frac{d \omega}{|\omega|}$, tal que $\Psi(\omega)$ seja a transformada de Fourier da função $\psi(t), C<\infty$ e $C>0$.

\subsubsection{Transformadas Wavelets}

A definição de uma transformada de wavelets considerando um sinal contínuo, com respeito à família de wavelets da Equação 3.1 é dada por :

$$
F(a, b)=\int f(t) \psi_{a, b}(t) d t
$$


A transformada de wavelets para sinais discretos é definida como

$$
F_{m, n}(a, b)=a_{0}^{-m / 2} \int f(t) \psi\left(a_{0}^{-m} t-n b_{0}\right) d t
$$

Pode-se perceber que o comportamento desta função está baseado em dilatações e translações a partir de uma wavelet mãe. Em ambos os casos, essa wavelet mãe, deve satisfazer à propriedade :

$$
\int \psi(t) d t=0
$$

Observando a Equação 3.2, percebe-se que a transformada wavelet depende de dois parâmetros $a$ e $b$, que correspondem às informações de escala e tempo respectivamente (Daubechies, 1992; Gomes et al., 1997; Misiti et al., 2001). A transformada de wavelet contínua é análoga à transformada de Fourier e é usada principalmente em análise e caracterização de detalhes de sinais. A transformada de wavelet discreta é análoga à transformada de Fourier discreta e é mais apropriada para a compressão de dados e reconstrução de sinais. Obter os coeficientes de wavelets em cada escala possível requer uma grande quantidade de cálculo, tornando muito tedioso o trabalho (transformada contínua de wavelets). A alternativa natural é procurar abordar a transformada wavelet em sua forma matemática discreta, cuja implementação computacional é direta, dispensando os estágios sensíveis a erros e de difícil implementação em tempo real. A transformada wavelet pode ser tratada sob a forma discreta sem prejuízo de suas qualidades e propriedades, e de maneira numericamente estável.

\subsubsection{Wavelets discretas}

Tradicionamente discretizam-se os parâmetros $a$ (escala) e $b$ (deslocamento), variáveis do sinal transformado $F(a, b)$, os coeficientes wavelet. Para a toma-se valores inteiros (positivos e negativos), potências de um parâmetro fixo $a_{0}$

$$
a=a_{0}^{-j} \quad a_{0}>1 \quad \text { e } j \in Z
$$

A discretização de $b$ deve depender de $j$ tal que wavelets estreitas (de alta-freqüência) sejam deslocadas por passos pequenos, e wavelets largas (de baixa-freqüência) sejam deslocadas por passos maiores. Assim, uma escolha natural é

$$
b=k b_{0} a_{0}^{-j} \quad b_{0}>0, \text { fixo, } \quad j, k \in Z
$$

A wavelet discreta fica então

$$
\psi_{j, k}(t)=a^{j / 2} \psi\left(a_{0}^{j} t-k b_{0}\right)
$$


Existem formas diferentes de se trabalhar com wavelets discretas, e de se implementar a transformada discreta. Uma delas é por meio da utilização de bancos de filtros organizados num esquema piramidal, que levará também a uma representação em multi-resolução do sinal. É importante ressaltar que, neste caso, os requisitos matemáticos já mencionados são traduzidos em restrições impostas sobre os coeficientes dos filtros utilizados na decomposição e reconstrução wavelet. $\mathrm{O}$ fator $a_{0}$ não pode ser arbitrário. Diferentes valores de $a_{0}$ levam a wavelets diferentes, e bases ortonormais de wavelets só são conhecidas para valores racionais de $a_{0}$ (Daubechies, 1992).

Bases ortonormais wavelets permitem a caracterização de um sinal $f(t)$ sem redundância (Daubechies, 1992). A prova deste fato pode ser desenvolvida utilizando-se a análise em multi-resolução como ferramenta, mostrando que qualquer função $f(t)$ pode ser aproximada numa precisão arbitrária por combinações lineares de wavelets ortonormais.

A transformada wavelet discreta e sua inversa podem ser expressas, respectivamente, na seguinte forma:

$$
\begin{gathered}
d_{j, k}=\left\langle\psi_{j, k}(t), f(t)\right\rangle=\int f(t) \psi_{j, k}(t) d t \\
f(t)=\sum_{j=-\infty}^{\infty} \sum_{k=-\infty}^{\infty} \psi_{j, k}(t) \cdot d_{j, k}
\end{gathered}
$$

onde $d_{j, k}$ são os coeficientes wavelets, correspondentes a $F(a, b)$ da transformada integral.

\subsubsection{Tipos de Wavelets}

Existem vários tipos de wavelets citados na literatura. O uso de um ou outro está associado à aplicação. Regras de construção de wavelets estão sendo propostas por vários pesquisadores, segundo as restrições e necessidades que cada aplicação específica impõe. Isto nos leva a concluir que podemos gerar uma infinidade de wavelets diferentes, e particularmente construir um conjunto de wavelets adequado ao processamento de um tipo de sinal ou aplicação específica, levando à obtenção de resultados melhores.

Entre as wavelets mais conhecidas podemos citar:

- Haar, que pode ser considerada uma $D_{2}$ (Daubechies 2): a primeira wavelet, com um único momento nulo (Chui, 1992; Meyer, 1993; Vetterli e Herley, 1992);

- Daubechies, de suporte compacto e suavidade "regulável" (Chui, 1992; Daubechies, 1992), (Sweldens, 1995);

- Coiflets, projetada para satisfazer certo número de momentos nulos (Wei et al., 1997);

- Coifman, cujos "filtros foram projetados tal que tanto a wavelet quanto a função escaladora tenham momentos nulos" (Jiang e Guo, 2004); 
- Beylkin, cujos filtros apresentam raízes na proximidade da freqüência de Nyquist (Ojanen, 1998; Wickerhauser, 1994);

- Vaidyanathan, cujo filtro exibe reconstrução exata apesar de não satisfazer nenhuma condição de momentos, incluindo a normalização (Wickerhauser, 1994);

- Meyer, que derivam das chamadas wavelets de Shannon, ou Sinc wavelets, que são suavemente enjaneladas na freqüência tal que o decaimento no tempo $(t)$ possa ser mais rápido que qualquer potência de $t$ (Meyer, 1993);

- Malvar, wavelets ortonormais cuja descoberta se insere na estrutura geral de referência da análise enjanelada de Fourier, vindo a constituir um algoritmo de análise em tempo-freqüência, em oposição à análise tempo-escala (Meyer, 1993);

- wavelets biortogonais, para as quais a restrição da ortogonalidade é relaxada (Meyer, 1993);

- wavelets simétricas ou Simlets (symmlets), ou wavelets "menos assimétricas", de suporte compacto e número de momentos nulos variando de 4 a 10 (Faria, 1997; Wickerhauser, 1994);

- bases wavelets ótimas, que fornecem a decomposição mais compacta (comprimida) de um sinal (Meyer, 1993) (Wickerhauser, 1994),

e mais uma diversidade de variantes, que usualmente recebem os nomes de seus desenvolvedores ou das técnicas que lhes dão origem, como é o caso com as novas "wavelets de segunda geração" (usando a terminologia de Sweldens (1995)), obtidas pelo esquema de lifting, o qual não leva necessariamente a wavelets que sejam dilatações e translações de uma matriz (Sweldens, 1995).

A seguir serão descritas algumas wavelets.

\section{Wavelet de Haar}

A wavelet de Haar é a mais simples das wavelets, introduzida por volta de 1910. A construção de Haar é a seguinte:

$$
\begin{gathered}
W(t):= \begin{cases}1, & t \in[0,1 / 2) \\
-1, & t \in(1 / 2,1] \\
0, & \text { caso contrário }\end{cases} \\
W_{j, k}(x)=2^{j / 2} h\left(2^{j} x-k\right), \quad j, k \in Z
\end{gathered}
$$

para um $j$ inteiro não negativo e $0 \leq k \leq 2^{j}-1$ 


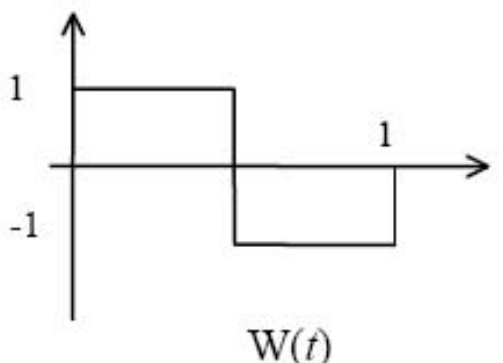

$\mathrm{W}(t)$

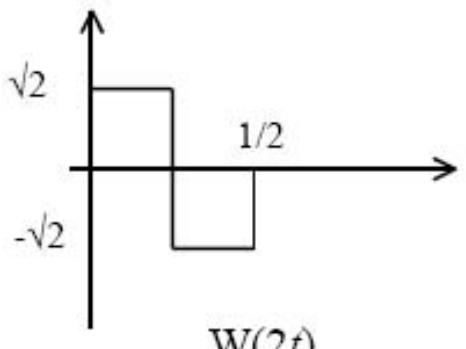

$\mathrm{W}(2 t)$

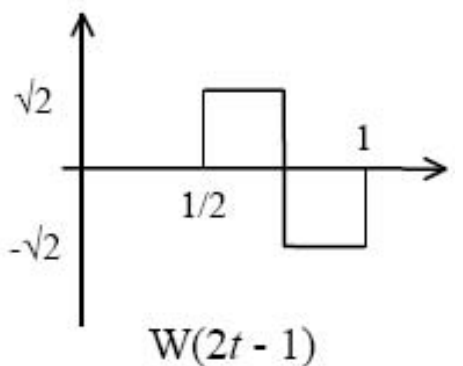

Figura 3.4: Wavelet de Haar

A Figura 3.4 mostra graficamente as operações essenciais de contração (dilatação) e deslocamento, gerando $W(2 t)$ e $W(2 t-1)$.

O próximo nível (não mostrado) contém $W(4 t), W(4 t-1), W(4 t-2)$ e $W(4 t-3)$, de onde exprimimos a forma geral para esta família de wavelets, como na Equação 3.9. Estas wavelets são contínuas por partes e constituem uma base para $L^{2}(R)$. Isto significa que as translações e deslocamentos de $W$ são mutuamente ortogonais para todos os $j$ e $k$.

Segundo Chung e Wang (2001), existem limitações no uso da construção de Haar. Como as funções base de Haar são funções de passos descontínuos, não são muito adequadas para a análise de funções estáveis com derivações contínuas. Visto que as imagens geralmente contêm regiões estáveis, a transformada wavelets de Haar não provê resultados satisfatórios em muitas aplicações com imagens.

\section{Wavelet de Daubechies}

Ingrid Daubechies, uma das mais brilhantes pesquisadoras sobre wavelet no mundo, criou o que é chamado "wavelet ortonormal com suporte compacto". As wavelets de Daubechies são numeradas em função do número de momentos nulos que possuem. O índice em si corresponde ao número de coeficientes que os filtros associados possuem, que também é o número de derivadas nulas do filtro associado a função escaladora em $\omega=\pi$ (o filtro tem um zero em $\omega=\pi$ de ordem $N-1$ ). Assim, a wavelet $D_{4}$ possui 2 momentos nulos, e os filtros associados possuem 4 zeros em $\omega=\pi$, e 4 coeficientes.

A notação usada pela ferramenta Matlab Wavelet Toolbox ${ }^{1}$ para esses filtros é:

$$
d b 1, d b 2, d b 3, d b 4, d b 5, \ldots
$$

Note que a notação utilizada pela ferramenta usa a metade do número dos coeficientes na notação $D_{j}$. As wavelets de Daubechies sempre têm um número par de coeficientes (Meyer, 1993; Ward, 2000).

A wavelet $D_{2}$ é semelhante à de Haar. A Figura 3.5 mostra alguns modelos de wavelet mães da família Daubechies com a notação utilizada pela ferramenta Matlab Wavelet

\footnotetext{
${ }^{1}$ http://www.mathworks.com/products/wavelet
} 

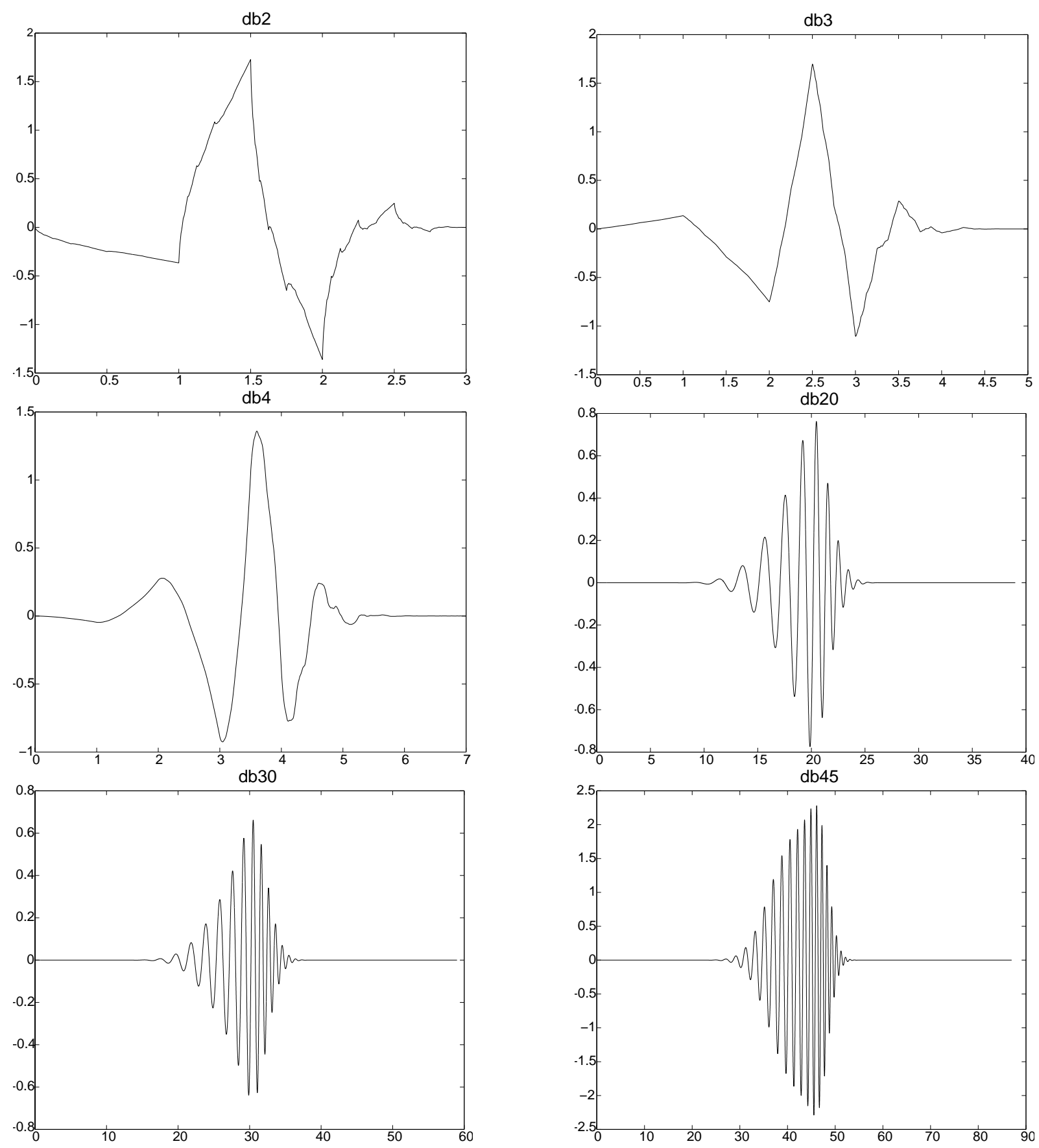

Figura 3.5: Família Daubechies.

Toolbox. Pode-se perceber que conforme a ordem da wavelet mãe aumenta, seu suporte compacto também sofre um aumento significativo. Estas wavelets não têm nenhuma expressão explícita, à exceção de db1, que é a wavelet de Haar. Elas também não são simétricas.

As wavelets de Daubechies apresentam uma capacidade de análise e síntese muito mais efetiva do que as de Haar por possuírem maior regularidade (suavidade) e por melhor aproximarem funções (suaves) em $L^{2}(R)$ (Faria, 1997; Meyer, 1993). As wavelets de 
Daubechies obtêm excelentes resultados no processamento de imagens devido às suas propriedades (Wang et al., 2001).

Segundo Daubechies (1992), dentro da transformada discreta de wavelets distinguem-se duas abordagens: sistemas redundantes discretos (frames) e bases de wavelets ortonormais. A segunda abordagem considera a estratégia de análise de multi-resolução, desenvolvida por (Mallat, 1989), a qual será tomada como base do presente trabalho.

\subsection{Métodos Multi-resolução}

A análise de multi-resolução foi formulada em 1986 por Mallat e Meyer, por meio da construção de bases ortonormais. A multi-resolução, ou multi-escala como é denominada por outros autores, fornece um referencial onde as bases de wavelets estão naturalmente compreendidas, bem como permite a construção de novas bases. Quando Mallat trabalhou com wavelets de Meyer pela primeira vez, ele estava interessado na análise de imagens, em que a idéia de se estudar imagens em várias escalas simultaneamente era popular. Isto o estimulou a ver bases ortonormais de wavelets como uma ferramenta para descrever matematicamente o "incremento na informação" necessário para se ir de uma aproximação grosseira para uma aproximação com maior resolução (Daubechies, 1992).

Uma decomposição multi-escala permite obter uma interpretação invariante da escala da imagem. A escala de uma imagem muda em razão da distância entre a cena e o centro óptico da câmera. Quando a escala da imagem é modificada, a interpretação da imagem não deveria mudar. Uma representação multi-escala pode ser parcialmente invariante a transformações de escala, se a seqüência de parâmetros da resolução $\left(V_{j}\right)_{j \in Z}$ variar exponencialmente (Castañón e Traina, 2003; Mallat, 1989).

Para um melhor entendimento, utiliza-se o conceito de espaço vetorial da álgebra linear. Um espaço vetorial $V$ é basicamente uma coleção de "objetos" (chamados de vetores, neste contexto) para os quais a adição e o produto escalar estão definidos. Assim, é possível adicionar dois vetores, escalar um vetor por alguma constante e assim sucessivamente (Stollnitz et al., 1996).

Agora é preciso definir uma base para cada espaco vetorial $V_{j}$. As funções base para o espaco $V_{j}$ são denominadas funções escalares e são usualmente denotadas pelo símbolo $\phi$.

Uma base simples para $V_{j}$ é dada pelo conjunto de funções caixa escaladas e transladadas:

$$
\phi_{i}^{j}(x):=\phi\left(2^{j} x-i\right) \quad i=0, \ldots, 2^{j}-1
$$

onde

$$
\phi(x):=\left\{\begin{array}{l}
1, \quad \text { se } 0 \leq x<1 \\
0, \quad \text { caso contrário }
\end{array}\right.
$$



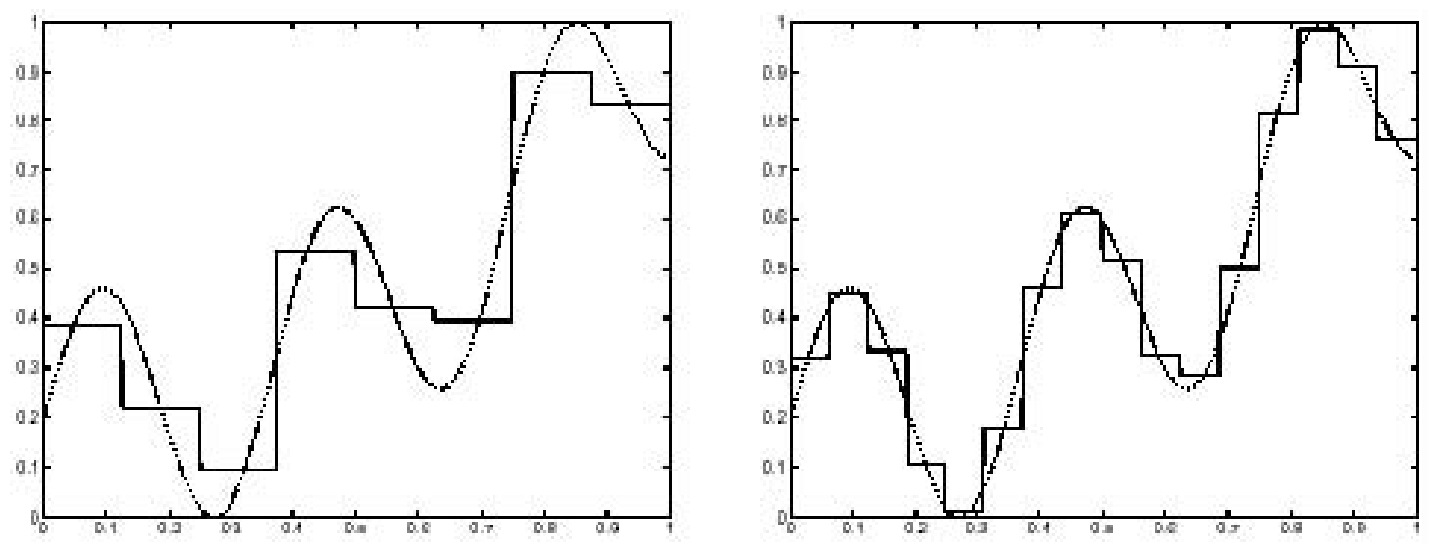

Figura 3.6: Uma função contínua $f(x)$ (linhas pontilhadas) e a função de aproximação caixa (linhas sólidas) em duas resoluções. À esquerda a aproximação grosseira $A_{0} f(x)$ e à direita a aproximação de maior resolução. $A_{1} f(x)$

A Figura 3.6 mostra duas aproximações de uma função contínua por funções caixa.

O passo seguinte na construção da análise de multi-resolução consiste em escolher um produto interno definido sobre os espaços de vetores $V_{j}$. Para o exemplo mostrado, o produto interno "padrão" é dado por:

$$
\langle f, g\rangle:=\int_{0}^{1} f(x) g(x) d x
$$

Dois vetores $f$ e $g$ são ditos ortogonais sob um produto interno escolhido se $\langle f, g=0\rangle$. Então, agora é possível definir um novo espaço vetorial $W_{j}$ como o complemento ortogonal de $V_{j}$ em $V_{j+1}$. Em outras palavras, $W_{j}$ é o espaço de todas as funções em $V_{j+1}$ que são ortogonais a todas as funções em $V_{j}$ no produto interno escolhido. Esse processo é ilustrado em forma gráfica na Figura 3.7.
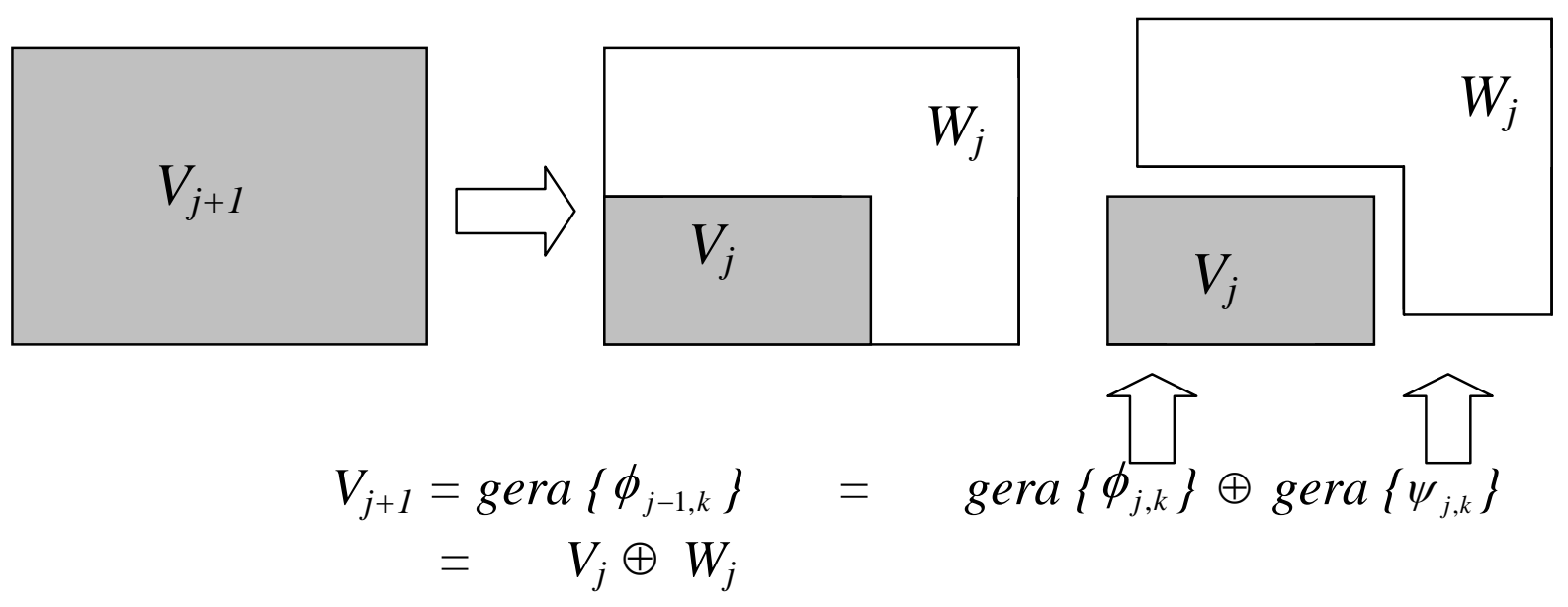

Figura 3.7: Geração do espaço superior em função de $\phi(x)$ e $\psi(x)$.

Em resumo, a análise de multi-resolução consiste de uma seqüência de espaços de aproximação sucessivos $V_{j}$. Mais precisamente, os subespaços fechados $V_{j}$ satisfazem: 


$$
\ldots V_{-1} \subset V_{0} \subset V_{1} \subset \ldots \subset V_{j} \subset V_{j+1}
$$

Uma função $f(t)$ decomposta nestes espaços tem um pedaço em cada subespaço. Este pedaço - a projeção de $f(t)$ em $V_{j}$ - é $f_{j}(t)$. A união de todos os subespaços é $L^{2}(R)$, e as interseções entre eles é o elemento neutro $\left(\bigcap_{j \in Z} V_{j}=0\right)$.

Há ainda requisitos adicionais para haver multi-resolução:

- Completeza: $f_{j}(t) \rightarrow f(t)$ para $j \rightarrow \infty$, e nulidade: $\left\|f_{j}(t)\right\| \rightarrow 0$ para $j \rightarrow-\infty$.

- $V_{j+1}$ compõe-se de todas as funções reescaladas em $V_{j}: f(t) \in V_{j} \Rightarrow f(2 t) \in V_{j+1}$.

- Invariância ao deslocamento: $f(t) \in V_{j} \Rightarrow f\left(t-2^{-j} \cdot k\right) \in V_{j}$.

- Há uma base ortonormal $\phi_{j, k} \mid j, k \in Z$ para cada subespaço $V_{j}$, isto é, as funções $f_{j}(t)$ - projeções de $f(t)$ no nível $j$ - podem ser descritas como combinações lineares de $\phi_{j, k}$.

\subsubsection{Algoritmo de Decomposição e Reconstrução Wavelet}

Definidos os espaços vetorias $V_{j}$ e $W_{j}$, os algoritmos de decomposição (análise) e reconstrução podem ser desenvolvidos.

Precisamos obter uma descrição de $f(t)$ em diferentes escalas. É desejada a habilidade de se trafegar de uma aproximação de baixa resolução de $f(t)$ em direção às mais finas, onde mais detalhes estejam disponíveis (melhor resolução) e vice-versa, bem como ter acesso aos sinais em qualquer escala. A estrutura de referência da multiresolução, agora confinada entre o nível de mais alta resolução $j=J$ e o de mais baixa $j=0$, oferece o meio necessário para se implementar esse processamento. Neste esquema, as projeções de $f(t)$ nos subespaços $V_{j}$ e $W_{j}$ para $j \in[0, J]$ (intervalo finito) são relacionadas por:

$f_{J}=f_{J-1}+\Delta f_{J-1}$, o que por iteração fornece $f_{J}=\Delta f_{J-1}+\Delta f_{J-2}+\ldots+\Delta f_{0}+f_{0}$.

Há uma relação íntima entre $\phi \in V_{0}$ e $\phi(2 t-k) \in V_{1}$ conhecida por relação entre duas escalas, a qual decorre diretamente do fato de $\phi \in V_{0} \subset V_{1}$. Esta relação é expressa por meio da equação de dilatação (equação 3.11), também chamada de equação de refinamento, porque mostra $\phi(t)$ num espaço mais fino $V_{1}$.

$$
\phi=\sum_{n} h_{n} \phi_{1, n}=\sum_{n} 2^{1 / 2} h(n) \phi(2 t-n)
$$

Uma relação semelhante entre duas escalas também ocorre entre $\psi(t) \in W_{0}$ e $\phi(2 t-$ $k) \in V_{1}$, a qual dá origem à equação wavelet (equação 3.12), decorrente de $\psi \in W_{0} \subset V_{1}$. 


$$
\psi=\sum_{n} g_{n} \phi_{1, n}=\sum_{n} 2^{1 / 2} g(n) \phi(2 t-n)
$$

Destas relações, derivam duas novas seqüências: $h(n)$ e $g(n)$, que vêm a ser os coeficientes dos filtros associados respectivamente à função escaladora $\phi(t)$ e à wavelet $\psi(t)$ (Faria, 1997).

Imediatamente, segue-se que uma função $f_{1}(t) \in V_{1}$, pode ser descrita como combinação de duas versões um nível de resolução abaixo, porque $V_{1}=V_{0} \oplus W_{0}$. Isto, juntamente com as relações de duas escalas acima, leva às fórmulas de decomposição (Strang e Nguyen, 1996):

$$
\begin{aligned}
& c_{j-1, k}=\left\langle f, \phi_{j-1, k}\right\rangle=\sum_{n} h_{n-2 k} c_{j, n} \\
& d_{j-1, k}=\left\langle f, \psi_{j-1, k}\right\rangle=\sum_{n} g_{n-2 k} c_{j, n}
\end{aligned}
$$

onde $d_{j, k}$ são os coeficientes wavelet de $f(t)$. Definimos agora $f_{j}(t)$ e $\Delta f_{j}(t)$ como

$$
f_{j}(t)=\sum_{k} c_{j, k} \phi_{j, k}(t) \text { e } \Delta f_{j}(t)=\sum_{k} d_{j, k} \psi_{j, k}(t)
$$

onde $c_{j, k} \in V_{j}$ e $d_{j, k} \in W_{j}$. Sendo $f_{j}=f_{j-1}+\Delta f_{j-1}$, a expressão de reconstrução fica (Strang e Nguyen, 1996):

$$
c_{j+1, n}=\sum_{k}\left[\overline{h_{n-2 k} c_{j, k}}+\overline{g_{n-2 k} d_{j, k}}\right]
$$

Estas expressões são o cerne da decomposição (transformada direta) e reconstrução (transformada inversa) wavelet, e podem ser esquematizadas de forma análoga aos algoritmos piramidais e de codificação sub-banda, como na Figura 3.8.

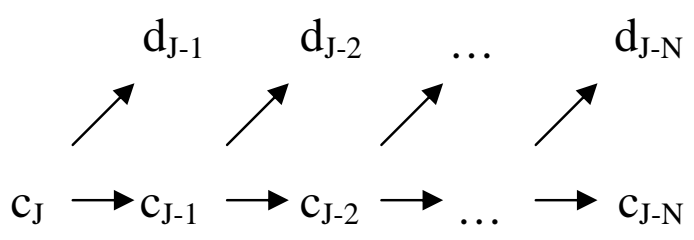

decomposição

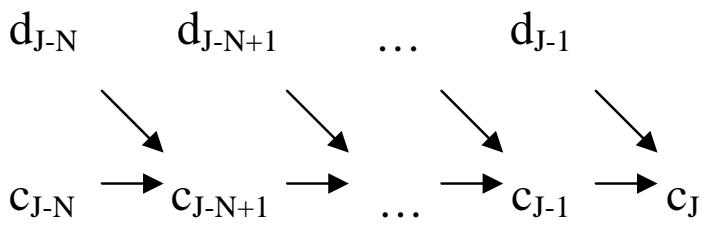

reconstrução

Figura 3.8: Esquema de decomposição e reconstrução wavelet.

A Figura 3.8 sugere um esquema hierárquico para se obter todos os coeficientes wavelet de um sinal eliminando a necessidade de se calcular o produto interno $\left\langle f, \psi_{j, k}(t)\right\rangle$ para cada $d_{j, k}$. É a natureza recursiva deste algoritmo wavelet que o torna computacionalmente 
veloz e eficiente, atraindo a atenção da comunidade de processamento de sinais. Um maior detalhamento do desenvolvimento das fórmulas pode ser encontrado em (Daubechies, 1992; Mallat, 1999; Strang e Nguyen, 1996).

A introdução da teoria da multi-resolução abriu o caminho para descobrir-se as conexões entre os algoritmos piramidais, as estruturas de codificação sub-banda, os filtros de espelhamento de quadratura (QMF) e a teoria wavelet (Meyer, 1993).

\subsection{Wavelets em Processamento de Sinais e Imagens}

Wavelets têm sido amplamente exploradas em um grande número de aplicações em processamento de sinais. Talvez as wavelets mais populares têm sido as de Daubechies, pela sua ortogonalidade e suporte compacto. As wavelets de Gabor também se mostram populares em aplicações em segmentação de imagens e aplicações de reconhecimento de textura e objetos (Shen e Bai, 2006; Zhang et al., 2007; Zheng et al., 2007). As ferramentas de implementação variam de aplicação para aplicação, entretanto nota-se uma grande utilização de bancos de filtros e de algoritmos piramidais de filtragem para implementação da transformada wavelet.

Em processamento de imagens há versões naturalmente extrapoladas para 2 dimensões dos algoritmos wavelets, empregando, em especial, os esquemas piramidais baseados em implementações em multi-resolução. Em computação gráfica, wavelets têm sido usadas para edição de curvas, manipulação de superfícies (Yin et al., 2006), análise de textura, compressão de imagens (Zhao et al., 2006), segmentação, segmentação de imagens texturizadas (Kim e Kang, 2007), enfoque, magnificação, interpolação, pintura em multi-resolução, representação de curvas, análise de superfícies, representação de fluxo de luz, radiosidade, modelamento geométrico, modelos fractais (Yuan et al., 2005), visão computacional e óptica empregadas em interpretação de imagens e sinais biomédicos.
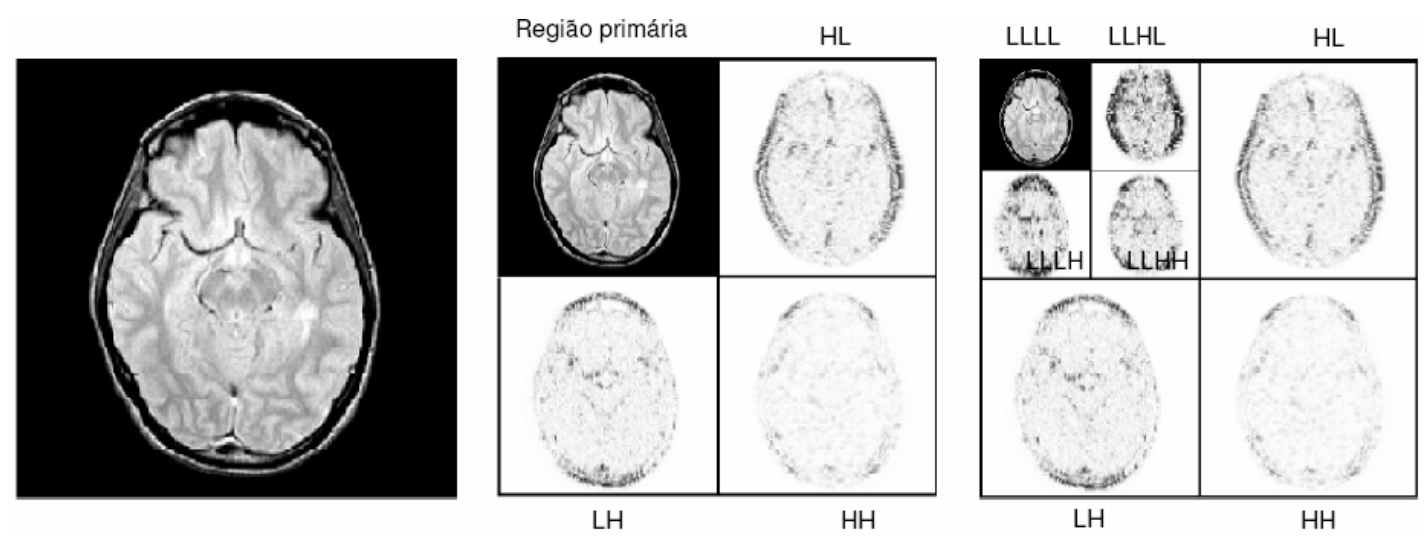

Figura 3.9: Decomposição wavelet 2D. (a) Imagem original. (b) Primeiro e (c) segundo nível de decomposição (Castañón, 2002; Wang et al., 2001). 
Um exemplo de uma representação de uma imagem utilizando três níveis de escala é apresentada na Figura 3.9, na qual uma imagem de ressonância magnética é decomposta utilizando wavelet, através do método de Daubechies.

\subsection{Wavelet de Gabor}

A wavelet de Gabor foi originalmente apresentada por Gabor (1946) quando propôs representar sinais como uma combinação de funções elementares. Granlund (1978) introduziu as funções elementares de Gabor em 2D. Daugman (1985)(Shen e Bai, 2006) evidenciou que neurônios visuais podem otimizar relações gerais da incerteza para resolução no espaço, freqüência espacial e orientação. Acredita-se que filtros de Gabor são similares aos neurônios visuais do sistema de visão humano.

Do ponto de vista teórico, Okajima (1998) deriva funções Gabor como soluções para problemas de maximização de informação mútua. Isto mostra que o campo receptor Gabor pode extrair o máximo de informações de regiões locais da imagem. Pesquisadores têm mostrado que características de Gabor, quando projetadas apropriadamente, são invariantes a translação, rotação e escala.

Em reconhecimento de face muitas aplicações têm obtido sucesso com filtros de Gabor. Os dois melhores métodos de verificação em reconhecimento de padrões, até 2004, usam filtros de Gabor (Phillips et al., 2000)(Messer et al., 2004). Recentemente, o algoritmo AdaBoost tem sido usado para selecionar características para detecção de face e para aprendizagem das características mais discriminantes de Gabor para classificação (Shen e Bai, 2006). Uma vez que o processo de aprendizagem termina, filtros de Gabor de diferentes freqüências e orientações são aplicados em diferentes locais da imagem para extração de característica (Shen e Bai, 2006).

Devido a utilidade das funções de Gabor, elas têm sido muito aplicadas e com sucesso em segmentação de imagens na textura (Jain e Farrokhnia, 1991; Shen e Bai, 2006; Weldon et al., 1996), reconhecimento de números escritos a mão (Hamamoto et al., 1998), reconhecimento de impressões digitais (Lee e Wang, 1999) e reconhecimento de face (Liu e Wechsler, 2002; Shen, 2005; Shen e Bai, 2004; Shen et al., 2007).

A larga aplicação das funções de Gabor tem também resultado em diferentes terminologias, o que pode causar confusões entre pesquisadores. Alguns exemplos são wavelet de Gabor (Gabor wavelet), filtros de Gabor (Gabor filter), expansão de Gabor (Gabor expansions), transformada de Gabor (Gabor transform) e função de Gabor (Gabor function) (Shen, 2005), etc. Como este estudo inicia a partir da junção tempo-freqüência da análise de sinais, a terminologia de wavelet de Gabor é usada neste trabalho. Também será utilizado, do trabalho de Ma e Manjunath (1996) o conceito de transformada wavelet de Gabor, o qual está baseado na ortogonalização dos filtros de Gabor e o aproveitamento 
da abordagem de multi-escala. Esta abordagem é utilizada para caracterizar as imagens médicas que são motivo do presente trabalho.

A transformada wavelet de Gabor (Gabor Wavelets Transform - GWT) originalmente proposta como funções Gabor por Gabor (1946), tem conseguido resultados promissores quando utilizadas em aplicações de reconhecimento de textura e objetos (Zheng et al., 2007). As wavelets de Gabor são especialmente apropriadas para representação de características locais pelo fato de apresentar as seguintes propriedades: (a) as wavelets de Gabor são as wavelets melhores localizadas, i.e., as wavelets de Gabor fornecem o melhor custo-benefício entre a resolução espacial e a resolução de freqüência, (b) as wavelets de Gabor contêm um maior número de parâmetros, e (c) pesquisas em psicologia mostram que reações de células simples no córtex visual podem ser modeladas mediante as funções Gabor (Daugman, 1988; Shen, 2005).

A utilização das wavelets de Gabor na extração de características está motivada por vários fatores. A representação de Gabor tem sido demonstrada como ótima no sentido de minimizar a incerteza das articulações bi-dimensionais no espaço e freqüência (Daugman, 1985). Estes filtros podem ser considerados tonalizáveis na orientação e na escala. Dessa forma, detectores de linhas e bordas, e cálculos estatísticos sobre estas micro-características em uma determinada região são usualmente efetuados para caracterizar a informação de textura subjacente (Manjunath e Ma, 1996; Turner, 1986).

As funções Gabor têm sido utilizadas no processamento de imagens em diversas formas, como na representação total da imagem mediante a definição de um conjunto de wavelets de Gabor 2D, que fornecem uma representação completa de uma imagem qualquer. Em Manjunath e Ma (1996) e Jain e Vailaya (1998) a média e o desvio-padrão dos coeficientes das GWT foram usados com sucesso na recuperação de imagens baseadas na textura. Utilizando esta técnica, pôde-se efetuar o reconhecimento de íris com grande sucesso, como é demonstrado no trabalho de Daugman (2002), assim como em impressões digitais (Jain et al., 2001). Na área de reconhecimento de faces, Feris et al. (2001) desenvolveu uma técnica que analisa os subespaços wavelets gerados pela GWN (Gabor Wavelets Network) (Krueger e Sommer, 1999), para o reconhecimento de faces em seqüências de vídeo.

A seguir apresentaremos a técnica de GWT para caracterização de imagens baseadas na textura, descrevendo suas principais características.

\subsubsection{Funções Gabor e Wavelets}

Uma função bi-dimensional de Gabor $\psi(x, y)$, usada como wavelet mãe, é definida como (Manjunath e Ma, 1996)(Ma e Manjunath, 1996):

$$
\psi(x, y)=\left(\frac{1}{2 \pi \sigma_{x} \sigma_{y}}\right) \exp \left(-\frac{1}{2}\left(\frac{x^{2}}{\sigma_{x}^{2}}+\frac{y^{2}}{\sigma_{y}^{2}}\right)+2 \pi j W x\right)
$$




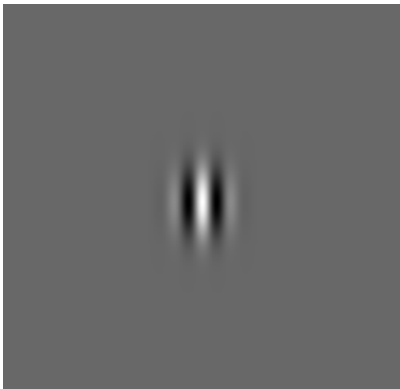

(a)

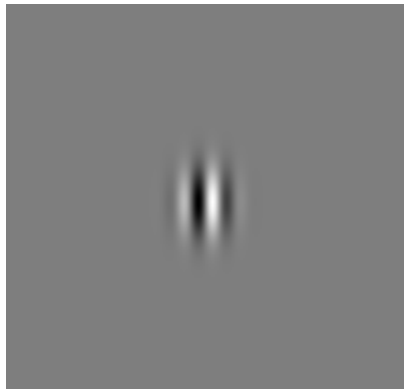

(b)

Figura 3.10: Componentes (a) real e (b) imaginário de $\psi(x, y)$ gerados com os parâmetros $S=4$ e $K=6$.

onde $\sigma_{x}$ e $\sigma_{y}$ são os desvios-padrões de $\psi(x, y)$ ao longo dos eixos $x$ e $y$, respectivamente. A constante $W$ determina o comprimento de banda de freqüência dos filtros. As partes real e imaginária de $\psi(x, y)$ são mostradas na Figura 3.10.

As funções de Gabor formam um completo, mas não ortogonal, conjunto de bases. Exemplo de uma classe particular de wavelets de Gabor 2D são apresentadas na Figura 3.11. Usando estas bases, expande-se o sinal que fornece uma descrição de freqüência localizada. Isto faz com que as funções Gabor sejam bem reconhecidas por terem o melhor custo-benefício entre a localização de tempo-freqüência (Mallat, 1999).

Uma classe de funções auto-similares, nomeadas como Gabor wavelets são geradas a partir da função $\psi(x, y)$, a wavelet de Gabor mãe. Então o dicionário de filtros auto-similares pode ser obtido mediante dilatações e rotações apropriadas de $\psi(x, y)$ através da função geradora:

$$
\begin{gathered}
\psi_{m, n}(x, y)=a^{m} \psi\left(x^{\prime}, y^{\prime}\right), \quad a>1, m=1: M, n=1: N \\
x^{\prime}=a^{m}\left(x \cos \theta_{n}+y \sin \theta_{n}\right) \text { e } y^{\prime}=a^{m}\left(-x \sin \theta_{n}+y \cos \theta_{n}\right), \quad \theta_{n}=n \pi / N
\end{gathered}
$$

onde $a^{m}$ é o parâmetro de escala que tem como objetivo assegurar que a energia é independente de $m$.

As wavelets de Gabor podem ser interpretadas como um conjunto de funções Gabor com distintos centros de freqüência e orientações (Figura 3.11). O tamanho ou o comprimento de banda das wavelets de Gabor é também controlado por $\theta$. Pelo fato das wavelets Gabor serem simétricas, só precisa-se especificar o valor de $\theta$ para montar um espaço uniformemente amostrado em $[0, \pi]$. Dessa forma, o conceito de localização das wavelets de Gabor estendeu-se para o tempo, freqüência e orientação.

A não ortogonalidade das wavelet de Gabor pode implicar que existe informação redundante nas imagens filtradas (Castañón e Traina, 2003; Ma e Manjunath, 1996). Isto é verificado na Figura 3.11, na qual as elipses (correspondente a cada filtro) possuem interseção entre si. Manjunath e Ma (1996) define uma estratégia para reduzir esta redundância, que segue os seguintes princípios (Rubner e Tomasi, 2001): 

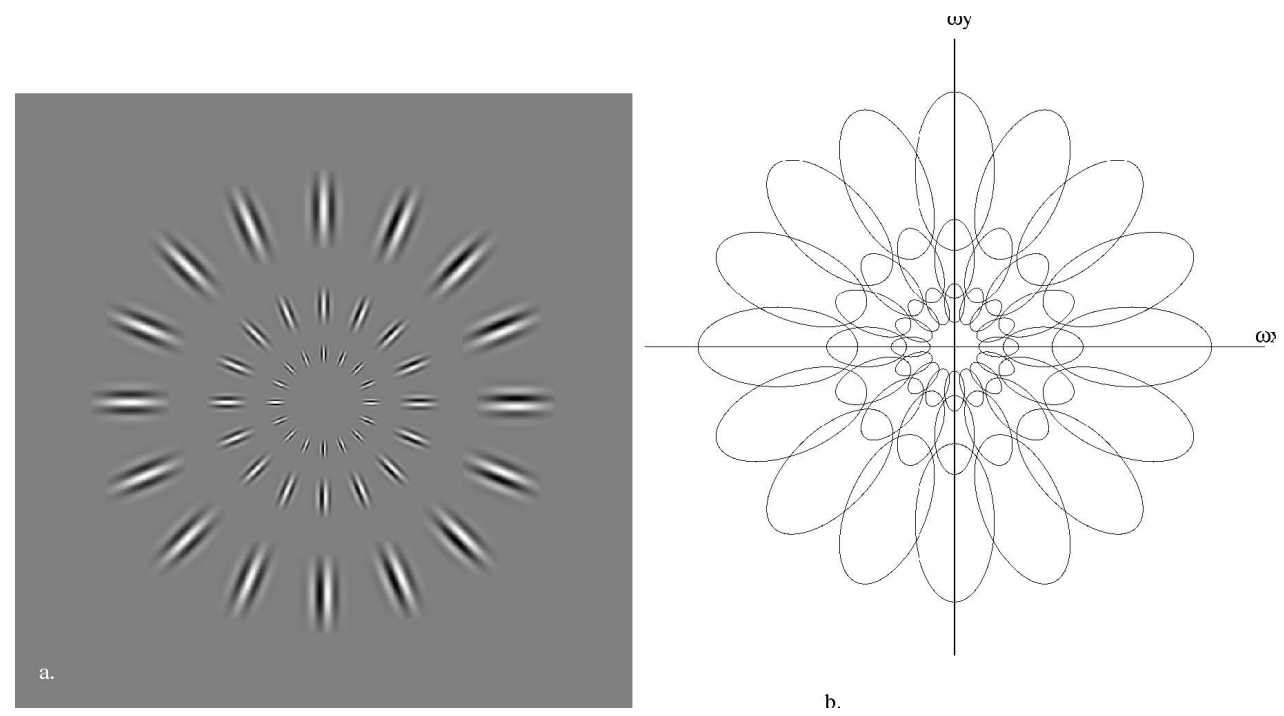

Figura 3.11: (a) Conjunto de wavelets Gabor (comprimento de banda octal de 1.5) (b) sua cobertura no plano de freqüência espacial (Lee, 1996).

- Separação uniforme na orientação. Assumindo a simetria rotacional, todos os filtros em uma escala específica deveriam ter o mesmo desvio-padrão angular e deveriam estar igualmente espaçados no eixo de orientação.

- Separação exponencial na escala. Os comprimentos dos filtros deveriam acrescentar exponencialmente com distância a partir do centro do plano. Isto quer dizer que a diferença entre uma escala e outra está dada pela multiplicação por um parâmetro escalar.

- Cobertura contínua do espaço de freqüência. O contorno de dois filtros vizinhos tocam um a outro nos eixos de escala e orientação.

Essa estratégia para reduzir redundância está definida por $U_{h}$ e $U_{l}$ que denotam os centros de freqüência de interesse superior e inferior, respectivamente. Sejam $K$ o número de orientações e $S$ o número de escalas na decomposição multi-resolução, então a estratégia consiste em assegurar que o suporte da magnitude do pico médio (half-peak) dos filtros de resposta no espectro de freqüência toquem-se uns aos outros, como é mostrado na Figura 3.12. Seja $\sigma_{u}=1 /\left(2 \pi \sigma_{x}\right)$ e $\sigma_{v}=1 /\left(2 \pi \sigma_{y}\right)$. O processo anteriormente descrito é produto das seguintes fórmulas para o cálculo dos parâmetros dos filtros $\sigma_{u}$ e $\sigma_{v}$ (e assim $\sigma_{x}$ e $\left.\sigma_{y}\right)$ :

$$
\begin{gathered}
a=\left(U_{h} / U_{l}\right)^{1 /(S-1)}, \quad \sigma_{u}=\frac{(a-1) U_{h}}{(a+1) \sqrt{2 \ln 2}} \\
\sigma_{v}=\tan \left(\frac{\pi}{2 \pi}\right)\left[U_{h}-2 \ln 2\left(\frac{\sigma_{u}^{2}}{U_{h}}\right)\right]\left[2 \ln 2-\frac{(2 \ln 2)^{2} \sigma_{u}^{2}}{U_{h}^{2}}\right]^{-\frac{1}{2}}
\end{gathered}
$$


onde $W=U_{h}$ e $m=0,1, \ldots, S-1$. Para o presente trabalho foram utilizadas $U_{h}=0.4$ e $U_{l}=0.05$. A Figura 3.12 mostra a localização e comprimento dos filtros resultantes de Gabor, usando quatro escalas e seis orientações.

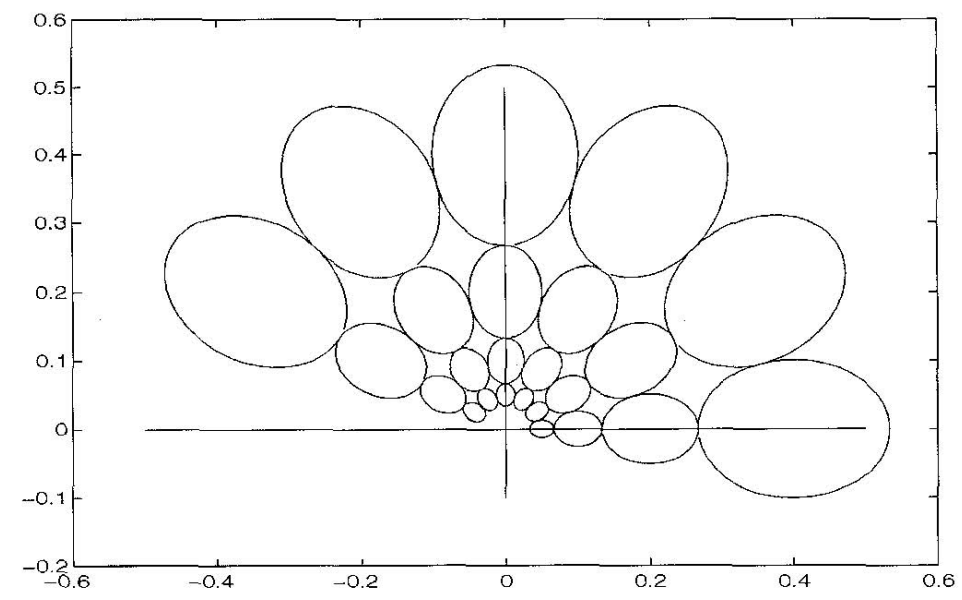

Figura 3.12: Os contornos indicam a magnitude do pico médio do filtro de resposta no dicionário dos filtros de Gabor. Os parâmetros usados são $U_{h}=0.4$, $U_{l}=0.05, K=6$ e $S=4$.

\subsubsection{O vetor de Características}

Neste trabalho, o vetor de características de uma dada imagem foi baseado no vetor proposto por Ma e Manjunath (1996). No trabalho de Ma e Manjunath (1996), dada uma imagem $I(x, y)$, sua transformada wavelet de Gabor é definida como

$$
W_{m n}(x, y)=\int I\left(x_{1}, y_{1}\right) \psi_{m n}^{*}\left(x-x_{1}, y-y_{1}\right) d x_{1} d y_{1}
$$

onde $*$ indica o complexo conjugado. A região de textura é agora caracterizada pela média $\mu_{m n}$ e pelo desvio-padrão $\sigma_{m n}$ da distribuição de energia dos coeficientes da transformada.

$$
\begin{gathered}
\mu_{m n}=\iint\left|W_{m n}(x, y)\right| d x d y \\
\sigma_{m n}=\sqrt{\iint\left(\left|W_{m n}(x, y)\right|-\mu_{m n}\right)^{2} d x d y}
\end{gathered}
$$

Um vetor de característica agora é construído usando $\mu_{m n}$ e $\sigma_{m n}$ como atributos. Ma e Manjunath (1996) propõe $S=4$ e $K=6$, resultando em um vetor de características

$$
\bar{f}=\left[\begin{array}{llll}
\mu_{00} \sigma_{00} & \mu_{01} \sigma_{01} & \ldots & \mu_{S-1 K-1} \sigma_{S-1 K-1}
\end{array}\right]
$$




\subsection{Considerações finais}

Neste capítulo foram mostradas as wavelets considerando sua evolução a partir da transformada de Fourier e a sua posterior formalização matemática.

É importante observar que as transformadas wavelets permitem a análise local do sinal. Isso ocorre devido às funções base de suporte compacto. As wavelets têm se mostrado como uma ferramenta adequada para o processamento de imagens. Neste trabalho, as wavelets serão utilizadas para extrair características das imagens e assim gerar uma representação reduzida das mesmas por meio do vetor de características. 


\section{Capítulo \\ 4 \\ Busca e Recuperação de Imagens por Conteúdo}

\subsection{Considerações iniciais}

Tradicionalmente, as imagens de uma base são catalogadas utilizando-se informação textual. Neste caso, a recuperação é realizada por meio de comandos interpretados pelo sistema de gerenciamento do banco de dados (por exemplo, comandos SQL). Embora prática e simples, esta abordagem apresenta determinadas limitações. Uma delas consiste no fato de que é praticamente inviável fazer anotações manuais para todas as imagens do banco, considerando-se uma aplicação de grande porte. Além disso, a essência semântica do conteúdo visual das imagens, principalmente aquelas que possuem mais detalhes, dificultam a descrição textual das mesmas (Zhang e Lu, 2002). Diferentes pessoas, inclusive, podem fornecer descrições diferentes da mesma imagem, causando ambigüidades e gerando resultados pouco interessantes para uma operação de consulta.

Dentro deste contexto, surgiu a necessidade de se estender as técnicas tradicionais de recuperação de imagens em bancos de dados multimídia, incluindo também informações visuais das imagens que podem ser obtidas por meio de um processo automático. A essa abordagem, dá-se o nome de "Recuperação de Imagens Baseada em Conteúdo" (Content-Based Image Retrieval - CBIR). O objetivo principal da abordagem de recuperação de imagens baseada em conteúdo consiste em extrair informações das imagens que possam caracterizar adequadamente o seu conteúdo. 
A busca de imagens por conteúdo envolve várias etapas. Inicialmente, as imagens são processadas e as características visuais das mesmas são extraídas, como descrito no Capítulo 2. Para a construção da estrutura de índices, a similaridade entre as imagens da base é avaliada. As características da imagem de consulta são extraídas e comparadas com as características das demais imagens da base para a execução de uma consulta. Neste capítulo são discutidos os conceitos envolvidos em cada etapa da busca de imagens por conteúdo.

\subsection{Atributos para consultas de imagens}

Para Roden et al. (1999) existem três níveis de critérios usados na recuperação de imagens: características físicas da imagem, parâmetros derivados a partir das características físicas e parâmetros abstratos. Mais detalhadamente, segundo Eakins (1996) (Balan, 2004):

- Nível 1 - Compreende pesquisas que levam em consideração apenas atributos denominados primitivos, sendo que os mais importantes são: cor, textura e forma. Um exemplo de tal pesquisa inclui de maneira mais comum: "encontre imagens que possuam certo tipo de semelhança com esta imagem". Tais atributos primitivos são objetivos e diretamente derivados do próprio conteúdo da imagem.

- Nível 2 - Envolve pesquisas com atributos que possuem certo grau de inferência lógica acerca da identidade, localização e disposição dos objetos presentes na imagem. Tais atributos são denominados "atributos lógicos". Como exemplo de busca pode-se citar "encontre imagens do Coliseu", sendo que no exemplo é necessário ter, a priori, um conhecimento acerca da identidade dos objetos contidos na imagem.

- Nível 3 - Envolve a busca por elementos de caráter puramente abstrato, como por exemplo, emoções, eventos ou tipos de atividade em específico.

É possível perceber entre os níveis de pesquisa citados, um aumento brusco do nível de abstração, ocorrendo de maneira mais acentuada entre os níveis 1 e 2. Alguns autores definem esse aumento brusco de abstração com a expressão "gap semântico" (semantic gap) (Smeulders et al., 2000).

\subsection{Extração de Características}

O "gap semântico" representa, de fato, uma barreira a ser transposta por pesquisas que têm como objetivo desenvolver mecanismos de recuperação de imagens baseados em atributos semânticos, sendo que poucas abordagens têm sido propostas para contornar este problema (Müller et al., 2004; Smeulders et al., 2000; Vailaya et al., 2001). Por esse motivo, 
a grande maioria dos sistemas CBIR utiliza características primárias para descrever elementos relevantes da imagem e proporcionar recuperação baseada em conteúdo. Conforme já mencionado, as características primitivas são derivadas de três elementos fundamentais da imagem: cor, textura e forma. O Capítulo 2 apresenta uma visão geral do tipo de análise realizada para cada um destes atributos.

\subsection{Consultas por Similaridade em Imagens}

A busca por similaridade consiste na recuperação de imagens semelhantes à especificada segundo algum critério especificado pelo usuário. A avaliação da similaridade entre dois objetos é feita por meio de funções de dissimilaridade, que são algoritmos computacionais que recebem dois objetos de um mesmo domínio e retornam a "distância", ou grau de dissimilaridade, entre os mesmos. As funções de dissimilaridade são dependentes do modelo utilizado para representar os objetos. Na literatura existem duas abordagens principais para a representação de objetos levando em consideração o domínio dos dados onde as comparações são feitas (Chávez et al., 2001):

- Modelo de Espaço Vetorial: os objetos são descritos por meio de vetores de características. Por exemplo: representação de imagens em relação ao espaço de cores, utilizando histogramas de cores (R, G, B) ou níveis de cinza.

- Modelo de Espaço Métrico: é voltado para situações em que a noção de similaridade é complexa e altamente dependente do domínio, onde a dissimilaridade é avaliada a partir de uma função de distância métrica.

Várias técnicas de indexação, também chamadas de métodos de acesso, foram propostas na literatura. Dependendo do modelo utilizado para representar os objetos, existem os seguintes tipos de métodos de acesso (Santos Filho et al., 1999):

- Métodos de Acesso Espaciais (MAEs): voltados para o modelo no qual os objetos são representados por vetores em um espaço multidimensional. Exemplos de MAEs dinâmicos são: a R-tree (Guttman, 1984), a TV-Tree (Lin et al., 1994) e a SR-Tree (Katayama e Satoh, 1997).

- Métodos de Acesso Métricos (MAMs): voltados para o modelo no qual apenas a distância entre os objetos é levada em consideração. Exemplos conhecidos de MAMs dinâmicos são: a M-Tree (Ciaccia et al., 1999) e a Slim-Tree (Traina Jr. et al., 2002).

Estruturas de indexação para espaços métricos (ou MAMs, os quais englobam tanto dados espaciais com dimensão definida quanto dados adimensionais) foram propostas para suportar buscas por similaridade. Com base nas características extraídas previamente da 
imagem, um MAM constrói a estrutura de índices calculando as distâncias entre elas, procedimento que deve corresponder à comparação entre as imagens originais.

Formalmente, um espaço métrico é um par $M=(D, d)$, onde $D$ é o domínio do vetor de características - que são as chaves de indexação, e $d$ é uma função de distância, também chamada de métrica, que satisfaz as seguintes propriedades:

1. Simetria: $d\left(O_{i}, O_{j}\right)=d\left(O_{j}, O_{i}\right)$

2. Não negatividade: $0<d\left(O_{i}, O_{j}\right)<\infty, O_{i} \neq O_{j}$ e $d\left(O_{i}, O_{i}\right)=0$

3. Desigualdade triangular: $d\left(O_{i}, O_{j}\right) \leq d\left(O_{i}, O_{k}\right)+d\left(O_{k}, O_{j}\right)$,

onde $O_{i}, O_{j}$ e $O_{k}$ são elementos pertencentes ao espaço $D$.

Os tipos mais comuns de consultas, usando o critério de similaridade, são a consulta por abrangência (Range query) e a consulta aos $k$ vizinhos mais próximos ( $k$-Nearest Neighbor query). A consulta por abrangência consiste em encontrar todas as imagens da base que se diferenciam em no máximo um dado grau da imagem alvo de análise. A consulta aos k-vizinhos mais próximos consiste em encontrar as $k$ imagens que mais se aproximam da imagem alvo de análise. Tais consultas são detalhadas a seguir.

\subsubsection{Consulta por Abrangência}

Para este tipo de consulta são fornecidos um elemento de referência $O$ e um raio de cobertura $r$. O conjunto resposta $R_{r q}$ inclui todos os elementos $s \in S$ da base que se encontram a uma distância menor ou igual a $r$ do elemento $O$. Ou seja:

$$
R_{r q}=\{S \mid d(S, O) \leq r\}
$$

A Figura 4.1 ilustra um exemplo de consulta por abrangência no domínio bidimensional, onde o conjunto resposta contém sete elementos. A função de distância utilizada neste caso é a função Euclidiana $\left(L_{2}\right)$.

Vale mencionar que, dependendo da implementação, o elemento de busca também pode estar contido no conjunto resposta.

\subsubsection{Consulta aos $\mathrm{k}$ vizinhos mais próximos ( $\mathrm{kNN}$ query)}

Neste tipo de consulta são fornecidos um elemento de referência $O$ e um número inteiro $k \geq 1$ referente ao número de elementos mais próximos do elemento $O$ que se deseja obter como conjunto resposta $R_{k N N}$. Formalmente tem-se:

$$
R_{k N N}=\left\{S\left|\forall P \in\left\{\Omega-R_{k N N}\right\}, d(O, S) \leq d(O, P),\right| R_{k N N} \mid=K\right\}
$$




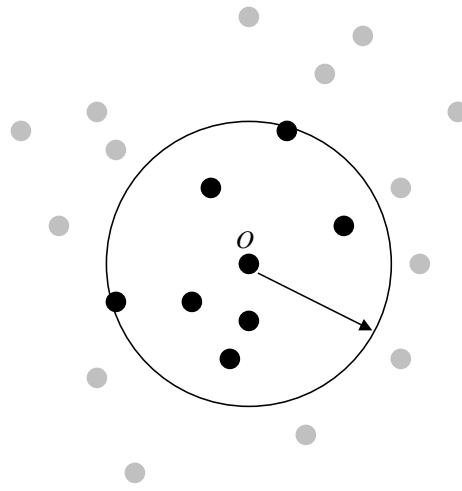

Figura 4.1: Exemplo de uma consulta por abrangência onde o conjunto resposta contém 7 elementos sem contar o elemento de busca $O$.

onde $\Omega$ representa o conjunto de todos os elementos contidos na base de dados, isto é, $S$.

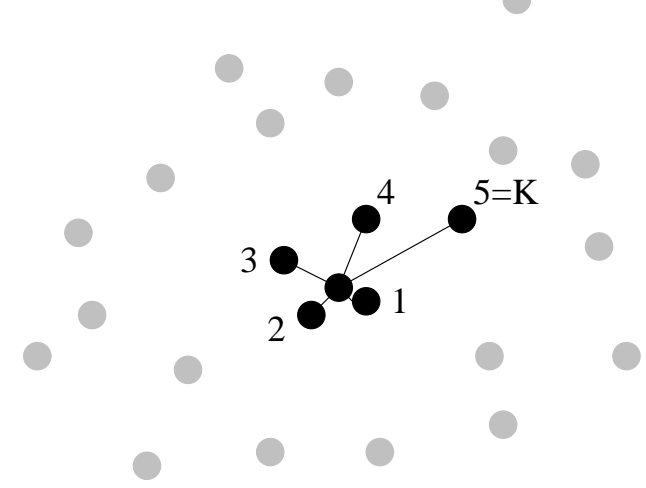

Figura 4.2: Exemplo de uma consulta do tipo $k N N$ onde o conjunto resposta contém 5 elementos, sem contar o elemento de busca $O$.

A avaliação de similaridade entre os elementos da base é feita por meio de funções de distância.

\subsection{Funções de distância}

Idealmente, uma função de distância deve refletir matematicamente a percepção humana de similaridade entre duas imagens. A fórmula de distância é aplicada sobre o conjunto de características extraídas das imagens. Diversas funções têm sido exploradas em CBIR, destacando-se entre elas (Smith, 1997): a família de distâncias de Minkowski (família $L_{p}$ ); a função de distância de Mahalanobis; a função de distância Cosseno; a função de distância quadrática e a função de distância de interseção de histogramas. Um maior detalhamento pode ser encontrado em Zhang e Lu (2002) para função distância Minkowski e para a função distância quadrática, Salton e McGill (1983) e Smith (1997) para função de distância Cosseno, Theodoridis e Koutroumbas (1999) para função distância 
de Mahalabobis e Swain e Ballard (1991) (Campo, 2002) para a função de distância de interseção de histogramas.

\subsection{Avaliação de eficiência}

Assim como as curvas de ROC (Receiver Operating Characteristic - medem a sensibilidade e a especificidade dos dados) são usadas para avaliar o desempenho de sistemas de auxílio ao diagnóstico (Marques, 2001)(Müller et al., 2004), um dos métodos mais usados para a avaliação de eficiência de sistemas de busca é o gráfico de precisão e revocação (precision vs. recall) (Baeza-Yates e Ribeiro-Neto, 1999)(Müller et al., 2004)(Alto et al., 2005).

Considere que para uma determinada requisição de informação $I$ existe um conjunto $R$ de elementos relevantes. Um determinado sistema de busca processa a requisição $I$ retornando um conjunto $A$. A interseção dos conjuntos $R$ e $A$ compreende os elementos relevantes à requisição $I$ que foram recuperados na operação de busca realizada. Vamos denotar a cardinalidade dos conjuntos $R, A$ e $R \backslash A$ como sendo, respectivamente, $|R|,|A|$ e, $|R a|$. A Figura 4.3 ilustra tais conjuntos. As medidas precision e recall são definidas da seguinte maneira:

- Recall é a porção do conjunto de elementos relevantes $(R)$ que foram recuperados pela operação de busca.

$$
\text { Recall }=|R a| /|R|
$$

- Precision é a porção do conjunto de elementos recuperados $(A)$ que são relevantes à requisição $I$.

$$
\text { Precision }=|R a| /|A|
$$

A avaliação das medidas é realizada construindo-se o gráfico precision versus recall para vários pares de medidas. O primeiro passo para a obtenção desse conjunto de pares consiste em ordenar elementos do conjunto $A$ (elementos recuperados) de acordo com seu grau de relevância. Cada elemento de $A$ que é relevante à consulta é então examinado e as medidas precision e recall vão sendo computadas a partir desta verificação.

Como um exemplo prático, considere que para uma determinada operação $q$ de consulta na base existe um conjunto $R q$ de 10 elementos relevantes, composto da seguinte maneira:

$$
R q=e 5, e 13, e 17, e 20, e 31, e 36, e 42, e 47, e 55, e 61
$$




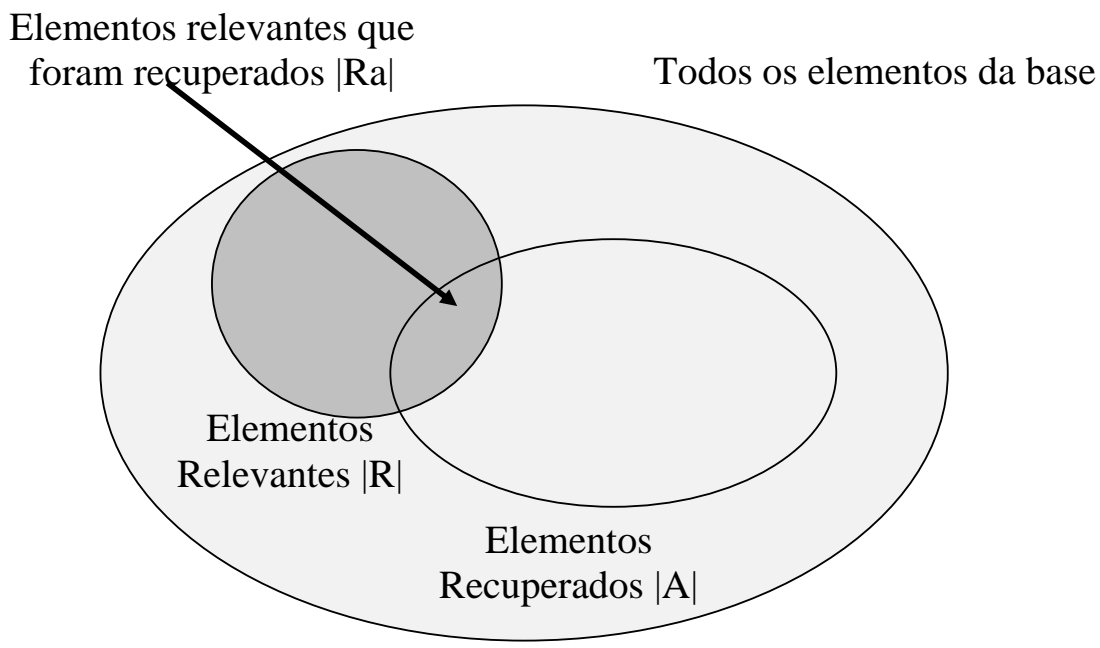

Figura 4.3: Conjuntos referentes às medidas precision e recall para uma determinada operação de busca.

É importante mencionar que o conjunto de elementos relevantes a uma consulta é previamente estabelecido com a ajuda de um ou mais especialistas da área. Para uma base de imagens médicas, por exemplo, o auxílio à determinação de conjuntos de imagens relevantes às operações de busca previstas deve ser assistido por especialistas da área médica.

Considere agora que um algoritmo de busca tenha retornado um conjunto de elementos $A q$, referente à consulta $q$, cujos elementos e sua respectiva classificação é dada por:
1. $e 42$
2. e 54
3. $e 17$
4. $e 15$
5. $e 2$
6. $e 5$
7. e 25
8. $e 27$
9. e13
10. e54
11. e55
12. $e 67$

Os elementos que são relevantes à consulta $q$ estão marcados com • Examinando o conjunto $A q$ dos elementos recuperados, verifica-se que o primeiro elemento (e42) é um dos elementos relevantes à consulta. Neste caso, o valor de precision é de 100\%, pois de todos os elementos analisados (apenas o primeiro até aqui), todos são relevantes à consulta. Neste ponto, o valor de recall é $10 \%$ pois um elemento relevante, dentro de um conjunto de dez elementos, foi recuperado até esse ponto. O próximo elemento relevante da lista é o terceiro elemento (e17). Para este elemento o valor de precision é de aproximadamente $66 \%$ (dois elementos relevantes em três verificados) e o valor de recall é de $20 \%$ (dois entre dez elementos relevantes já verificados). A análise prossegue desta maneira até que todos os elementos relevantes sejam verificados. Para o valor zero de recall, definimos para 
precision o valor 100. Os valores de precision e recall são então visualizados graficamente, conforme o exemplo ilustrado na Figura 4.4.

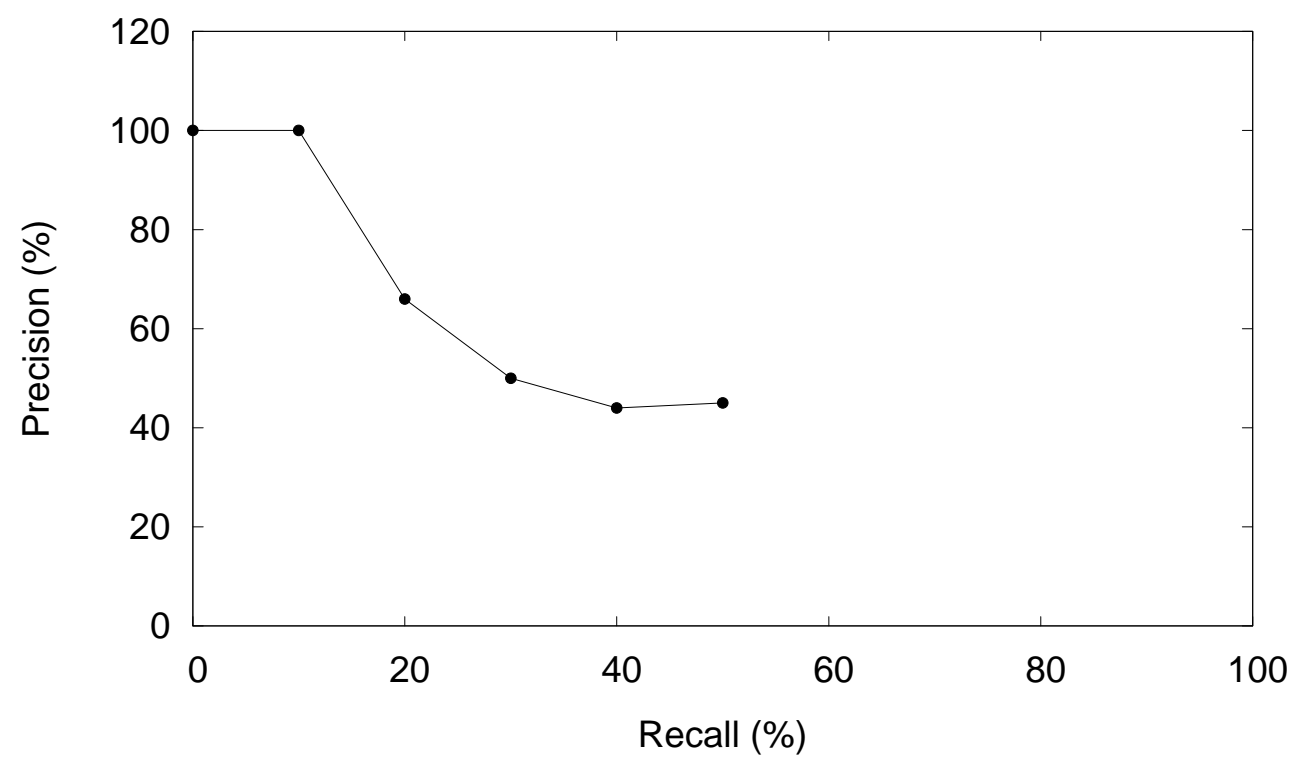

Figura 4.4: Exemplo de um gráfico de medidas precision $\times$ recall para uma operação de busca.

Para uma avaliação confiável dos resultados obtidos por um determinado sistema de recuperação, é necessário que diversas operações de consultas sejam realizadas e consideradas na avaliação. Para isso, é preciso construir um gráfico precision $\times$ recall que represente a média dos desempenhos das diversas consultas realizadas. Isto é feito, geralmente, calculando-se valores de precision para escalas determinadas de recall, como por exemplo, nas dezenas. Calcula-se então, para os diversos valores de precision obtidos em cada escala de recall, a média aritmética dos mesmos.

A avaliação do desempenho é realizada de maneira prática, verificando-se o formato da curva obtida. Quanto mais próxima do topo do gráfico a curva estiver, melhor será o resultado da operação de busca. Sendo assim, a curva obtida em uma busca cujo resultado é o ideal, ou seja, contém todos os elementos relevantes à busca e nenhum outro mais, é a curva constante com valor um em todos os valores do eixo recall.

\subsection{Considerações finais}

Esse capítulo apresentou os principais conceitos relacionados à recuperação de imagens baseada em conteúdo (CBIR) incluindo os principais tipos de consulta, avaliação de similaridade e avaliação de desempenho de consultas. O trabalho desenvolvido nesta pesquisa esteve diretamente ligado a todos estes conceitos, sendo que os resultados obtidos foram analisados segundo os gráficos de precision $\times$ recall gerados a partir da busca aos $k$-vizinhos mais próximos. 


\section{Capítulo}

5

\section{Extração de Conhecimento e Mineração de Imagens}

\subsection{Considerações Iniciais}

A mineração de dados refere-se à lógica e ao processamento aplicados sobre os dados preparados para a obtenção de conhecimento útil. A informação extraída por meio da mineração pode ser usada em uma grande variedade de aplicações, tais como análise de mercado, controle de produção e análises de dados biomédicos. Considerando os sistemas médicos, devido à complexidade e à enorme quantidade de imagens geradas, buscam-se técnicas automáticas ou pelo menos semi-automáticas, para auxiliar a extração de características das imagens e também do conhecimento trazido por elas.

A mineração de imagens busca a extração de conhecimento implícito, de relacionamentos em dados do tipo imagem, além de relacionamentos entre os dados pictóricos presentes nas imagens e suas descrições alfa-numéricas feitas por especialistas (por exemplo, em seu laudo). É portanto um campo multi-disciplinar envolvendo: visão computacional, processamento de imagens, recuperação de imagens por conteúdo, recuperação de informação, mineração de dados, descoberta de conhecimento em banco de dados e inteligência artificial (Roden et al., 1999). Um exemplo da aplicação da mineração de imagens no campo da medicina é descobrir que tipos de tumores acontecem concomitantemente. 


\subsection{Etapas da Mineração de Imagens}

A mineração de imagens não é simplesmente a aplicação de técnicas de mineração usadas no domínio alfa-numérico migradas para o domínio de imagens: ela envolve um conjunto de requisitos que tornam a tarefa bem mais complexa. Alguns fatores que fazem a mineração de imagens ser mais complexa do que a mineração de dados do domínio alfa-numérico são (Hsu et al., 2002):

- Presença de valores relativos: atributos em bases de dados relacionais geralmente têm um significado semântico facilmente compreendido como, por exemplo, idade = 35. No entanto, no caso de imagens, o significado de um atributo freqüentemente depende do contexto no qual ele acontece. Por exemplo, a mesma coloração de um objeto da imagem pode parecer mais clara ou mais escura dependendo do contexto em que o mesmo está inserido;

- Importância da informação espacial: muitas vezes, a informação espacial é crítica para a interpretação correta de uma imagem. Assim, uma alteração (mancha) no centro de uma imagem pode ter significado diferente de uma mancha numa extremidade da mesma;

- Presença de Múltiplas Interpretações: o significado semântico do mesmo objeto pode variar, podendo acarretar distorções na mineração.

As fases da mineração de imagens são ilustradas na Figura 5.1 e a descrição das mesmas é apresentada na Tabela 5.1.

\begin{tabular}{|l|l|}
\hline \multicolumn{1}{|c|}{ Etapa } & \multicolumn{1}{c|}{ Objetivo } \\
\hline 1) Pré-processamento & $\begin{array}{l}\text { Aumentar a qualidade da imagem a ser analisada, } \\
\text { ressaltando determinadas particularidades. }\end{array}$ \\
\hline 2) Extração de características & $\begin{array}{l}\text { Obtenção das características a serem usadas na } \\
\text { mineração. Criação de estruturas de representação } \\
\text { das imagens e índices que facilitem o acesso e } \\
\text { manipulação das características extraídas. }\end{array}$ \\
\hline 3) Mineração & $\begin{array}{l}\text { Aplicação de algoritmos sobre as estruturas obtidas } \\
\text { na etapa anterior para a descoberta de padrões } \\
\text { sobre as características da imagem. }\end{array}$ \\
\hline 4) Apresentação & $\begin{array}{l}\text { Apresentação dos padrões obtidos de uma maneira } \\
\text { inteligível para que sejam possíveis o entendimento, } \\
\text { interpretação e uso dos mesmos. }\end{array}$ \\
\hline
\end{tabular}

Tabela 5.1: Descrição das fases da mineração de imagens. 

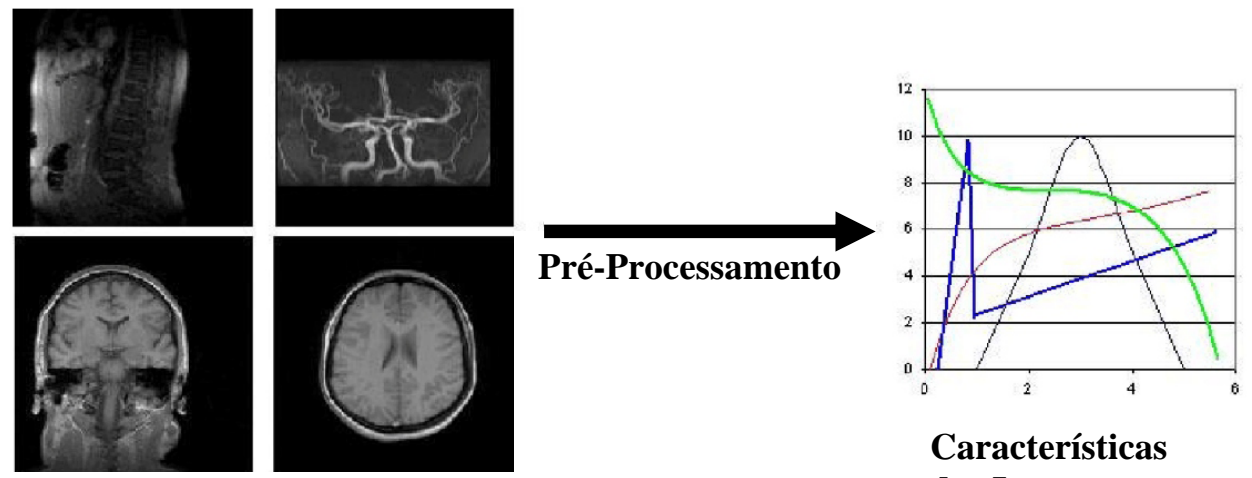

Características

Base de Imagens das Imagens

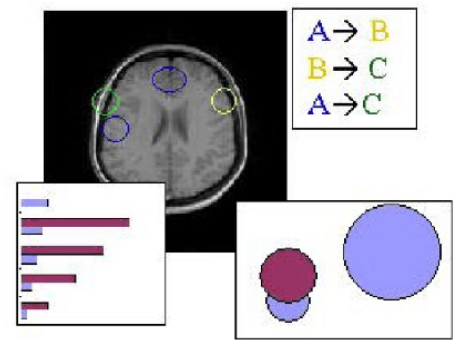

Apresentação do Conhecimento obtido

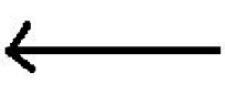

Mineração

Figura 5.1: Fases da Mineração de Imagens

\subsection{Pesquisas envolvidas}

A mineração de imagens é foco de pesquisas recente. Existem ainda muitas lacunas a serem preenchidas para permitir o desenvolvimento de processos e de algoritmos de mineração eficazes e eficientes para descoberta de padrões em imagens (Hsu et al., 2002; Zaiane et al., 1998). Dentre as carências que envolvem o processo de mineração de imagens, pode-se citar:

- Seleção das características da imagem: técnicas para determinar um conjunto de características de cada imagem que sejam úteis em vários domínios de aplicações;

- Determinação de padrões de representação da imagem: devem ser pesquisados modos eficientes de representar uma imagem por uma coleção reduzida de características, contendo informações para todas as análises necessárias ao processo de mineração, como por exemplo, contexto, objetos, coloração e informações espaciais;

- Determinação das estruturas de índices para mineração: estruturas de índice devem ser criadas para permitir acesso e comparação rápidos de todas as características das imagens usadas no processo de mineração.

As pesquisas em mineração de imagens estão sendo desenvolvidas em duas direções. A primeira diz respeito a aplicações de domínios específicos, onde o foco é extrair as características mais relevantes de um modo adequado para a tarefa de mineração de dados 
(Datcu e Seidel, 2000; Hsu et al., 2000). A segunda direção diz respeito a aplicações genéricas, onde o foco é gerar padrões que relacionem as características de baixo nível da imagem deixando a percepção de alto nível sobre as imagens para os seres humanos (Zaiane et al., 1998). O presente projeto visa pesquisar conjuntamente ambas as direções.

O algoritmo StARMiner - (Statistical Association Rule Miner) foi desenvolvido por Ribeiro et al. (2006) para determinar o conjunto mínimo de características que devem ser usadas para representar as imagens. Por meio da mineração das regras de associação estatísticas, este algoritmo identifica as características mais relevantes para manter o poder de discriminação ao classificar as imagens em categorias (por exemplo, tumor benigno e tumor maligno). O algoritmo usa medidas estatísticas que descrevem o comportamento do atributo considerando as categoriais das imagens para encontrar regras de interesse, e será detalhado na próxima seção.

\subsection{StARMiner - Técnica Proposta para a Mineração de Regras de Associação Estatísticas e Seleção de Características}

A tarefa de associação é uma das atividades de mineração de dados mais exploradas (Agrawal et al., 1993). Ela foi inicialmente motivada por aplicações comercias tais como, análise de mercado, análise de cesta de compras e classificação de clientes. Entretanto, a extração de regras de associação também tem sido intensamente usada em outras aplicações, tais como sumarização e classificação de imagens.

Características de baixo nível das imagens são extraídas e organizadas em vetores de características, que descrevem as imagens quantitativamente. Por isso, uma maneira adequada para extrair regras de associação envolvendo as características de imagens deve considerar os dados quantitativos (contínuos), ao invés de dados categóricos (nominais). Muitos trabalhos propostos para a mineração de regras de associação quantitativas requerem a discretização de dados numéricos (Srikant e Agrawal, 1996). O processo de discretização para a mineração de regras de associação quantitativas leva à perda de precisão. Assim, o ideal é trabalhar com os dados contínuos, sem prévia discretização, como é feito em Aumann e Lindell (1999), onde os valores da média e desvio padrão são usados para caracterizar as regras. O algoritmo StARMiner para a mineração de regras de associação estatísticas em imagens é apresentado por Ribeiro et al. (2006). O algoritmo StARMiner é uma extensão das técnicas propostas em Aumann e Lindell (1999) para a discriminação de imagens médicas.

O objetivo do algoritmo StARMiner é implementar a mineração de regras de associação estatísticas para encontrar os atributos que melhor discriminam a imagem em categorias. O formato geral da regra é $x \rightarrow F_{i}$, onde $x$ é uma categoria e $F_{i}$ uma característica da 
5.4 StARMiner - Técnica Proposta para a Mineração de Regras de Associação

Estatísticas e Seleção de Características

imagem (atributo), significando que para a categoria $x$ o atributo $F_{i}$ é relevante. As regras mineradas pelo algoritmo devem satisfazer as seguintes condições:

- A característica $F_{i}$ deve apresentar um comportamento distinto para as imagens da categoria $x$ em relação às demais imagens das outras categorias;

- A característica $F_{i}$ deve apresentar um comportamento uniforme para todas as imagens da categoria $x$.

Essas condições são implementadas no algoritmo StARMiner pela incorporação das restrições de interesse discutidas a seguir. Seja $T$ uma base de imagens médicas, $x$ uma categoria de imagens, $T_{x} \subset T$ o subconjunto de imagens da base da categoria $x, F_{i}$ um atributo da imagem e $\left(F_{i}\right)_{j}$ o valor de $F_{i}$ da imagem $j$. As restrições de interesse usadas no algoritmo StARMiner são:

1. $\left|\mu_{F_{i}}\left(T_{x}\right)-\mu_{F_{i}}\left(T-T_{x}\right)\right| \geq \Delta \mu_{\min }$,

onde:

- $\mu_{F_{i}}(V)=\frac{\sum_{j \in V}\left(F_{i}\right)_{j}}{|V|}$, i.e., $\mu_{F_{i}}(V)$ é a média dos valores da característica $F_{i}$ para o subconjunto de imagens $V$;

- $\Delta \mu_{\text {min }}$ é um parâmetro de entrada que indica a diferença mínima permitida entre a média dos valores de $F_{i}$ para as imagens da categoria $x$ e a média dos valores de $F_{i}$ para as imagens restantes da base de imagens.

2. $\sigma_{F_{i}}\left(T_{x}\right) \leq \sigma_{\max }$

onde:

- $\sigma_{F_{i}}(V)=\sqrt{\frac{\sum_{j \in V}\left(\left(F_{i}\right)_{j}-\mu_{F_{i}}(V)^{2}\right)}{|V|}}$, i.e., $\sigma_{F_{i}}(V)$ é o desvio padrão dos valores do atributo $F_{i}$ no subconjunto $V$;

- $\sigma_{\max }$ é um parâmetro de entrada que indica o máximo de desvio padrão permitido aos valores de $F_{i}$ para as imagens da categoria $x$.

3. Testes de hipóteses. $H 0$ deve ser rejeitada com confiança maior ou igual a $\gamma_{\min } \mathrm{em}$ favor de $H 1$, onde:

$$
H 0: \mu_{F_{i}}\left(T_{x}\right)=\mu_{F_{i}}\left(T-T_{x}\right) \quad H 1: \mu_{F_{i}}\left(T_{x}\right) \neq \mu_{F_{i}}\left(T-T_{x}\right)
$$

$\gamma_{\text {min }}$ é um parâmetro de entrada que indica a confiança mínima com a qual a hipótese $H 0$ deve ser rejeitada. Rejeitando $H 0$, com confiança $\gamma_{\text {min }}$, implica que as médias 
$\mu_{F_{i}}\left(T_{x}\right)$ e $\mu_{F_{i}}\left(T-T_{x}\right)$ são estatisticamente diferentes. Para rejeitar $H 0$ com confiança $\gamma_{\text {min }}$, o valor $Z$, cujo cálculo é apresentado na Equação 5.1, deve estar na região de rejeição ilustrada na Figura 5.2. Os valores críticos de $Z, z 1$ e $z 2$, dependem do valor $\gamma_{\text {min }}$, como mostrado na Tabela 5.2.

$$
Z=\frac{\mu_{F_{i}}\left(T_{x}\right)-\mu_{F_{i}}\left(T-T_{x}\right)}{\frac{\sigma_{F_{i}}\left(T_{x}\right)}{\sqrt{\left|T_{x}\right|}}}
$$

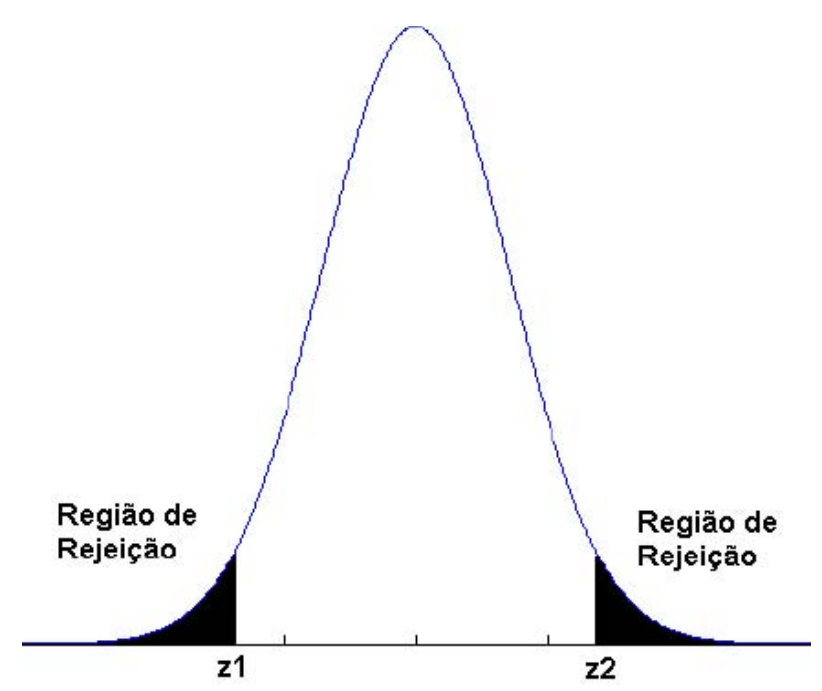

Figura 5.2: Regiões de rejeição.

\begin{tabular}{|l|l|l|l|}
\hline$\gamma_{\min }$ & 0.9 & 0.95 & 0.99 \\
\hline$z 1$ & 1.64 & 1.96 & 2.58 \\
\hline$z 2$ & -1.64 & -1.96 & -2.58 \\
\hline
\end{tabular}

Tabela 5.2: Valores críticos de $Z$.

O algoritmo StARMiner identifica as características com alto poder de discriminação, pois elas apresentam um comportamento particular e uniforme em imagens de uma dada categoria. Isso é importante porque as características que apresentam um comportamento uniforme para todas as imagens da base, independentemente da categoria, não contribuem para discriminá-las e devem ser eliminadas. Os atributos com maior poder de discriminação fazem parte do conjunto de regras mineradas pelo algoritmo StARMiner com maior valor de confiança. Esses atributos são usados para compor vetores de características compactos para a representação das imagens. 


\subsection{Considerações finais}

A mineração de imagens envolve uma série de etapas. Em geral, os algoritmos de mineração de dados alfa-numéricos, que já são bem conhecidos e divulgados na literatura, são aplicados sobre as características extraídas das imagens para a obtenção de padrões.

Neste capítulo foram discutidos o conceito de mineração de imagens, as etapas do processo de mineração e as carências que envolvem o processo de mineração de imagens e o algoritmo StARMiner, desenvolvido por Ribeiro et al. (2006).

Este projeto propõe novos extratores de características que são validados e integrados no sistema de mineração de imagens StARMiner em desenvolvimento no Grupo de Bases de Dados e Imagens (GBdI), o que resultou no artigo Ribeiro et al. (2006) e em outros resultados, como será visto no Capítulo 6. 
Capítulo

6

\section{Extração de Características de Imagens Médicas 2D através de wavelets}

\subsection{Considerações Iniciais}

Neste capítulo, são apresentados os métodos propostos de extração de características de imagens médicas provenientes de exames de ressonância magnética e mamografia. É também apresentada uma descrição detalhada dos experimentos desenvolvidos com as técnicas de extração de características baseada em wavelets detalhadas nos capítulos anteriores. Especificamente, descreve-se os conjuntos de dados usados nos experimentos, as abordagens adotadas na extração de características e as respectivas métricas de distância utilizadas no casamento de imagens similares, além de comparações entre as distintas abordagens.

No desenvolver deste trabalho procuramos responder à questão: dado um repositório de imagens médicas de ressonância magnética de diversos pacientes e diversas partes do corpo, como representar essas imagens em um espaço vetorial de características de modo a possibilitar a realização de consultas de imagem por similaridade? Também aplicamos as técnicas propostas em um conjunto de imagens mamográficas, verificando a precisão do espaço vetorial gerado para caracterizar essas imagens de modo a possibilitar a classificação em tumores benignos ou malignos.

No presente trabalho, o problema de definir o domínio semântico de recuperação de imagens é dado pela semelhança das imagens médicas em conjuntos de exames de mesmo tipo. Por exemplo cortes de cabeça, de abdômen, entre outros (sagital, coronal), podem 
formar um grupo semântico, e cada vez que seja feita uma consulta o sistema deve fornecer como resposta as imagens correspondentes ao mesmo grupo semântico.

Nas seções a seguir, são descritas as abordagens para a extração de características, as bases de imagens usadas nos experimentos, os métodos propostos e os resultados e experimentos para validação dos métodos.

\subsection{Abordagens para a extração de características}

Nessa seção, são introduzidas as técnicas de extração de características de imagens médicas com o objetivo de abstrair as informações relevantes contidas em cada imagem. Basicamente, foram estudadas duas abordagens para extração de características baseadas na transformada wavelet. A primeira, e a mais simples, consiste na aplicação de filtros de Daubechies $\left(D_{2}, D_{4}, D_{6}, D_{8}, D_{16}\right)$, Coifman (coifman1 e coifman2) e Symlets $(2,3$, 4, 5, 15) que são filtros simples de implementar por meio da técnica de multiresolução, descrita na seção 3.6. A segunda abordagem consiste na aplicação da função Gabor como wavelet mãe (seção 3.8), o que é denominado como transformada wavelet de Gabor. Em comparação à primeira abordagem, as wavelets de Gabor são consideradas como as melhores de localização no tempo e na freqüência, por conter maior número de parâmetros e, as mais atrativas, por simular reações simples de células no cortex visual.

As propriedades das wavelets permitem desenvolver uma série de técnicas que visem caracterizar as imagens, entre estas propriedades temos (Albuz et al., 2001; Castañón, 2002):

- Localização: Cada componente wavelet é localizado simultaneamente no tempo e na freqüência. Pelo que as wavelets podem casar uma ampla extensão de componentes do sinal desde transitórios até harmônicos.

- Multiresolução: Os componentes de wavelets esticam-se e dilatam-se para a análise dentro de conjuntos aninhados de escalas. Isto permite que a transformada case tanto com as estruturas do sinal de curta como de longa duração.

- Compressão: As transformadas wavelet de sinais e imagens do mundo real, tendem a ser esparsas. Como resultado a distribuição dos coeficientes de wavelets de sinais e imagens do mundo real podem ser comprimidas.

Uma cuidadosa observação dos subespaços de wavelets (Figura 6.1) indica que existe uma relação hierárquica entre os distintos subespaços, o que forma uma estrutura piramidal de subimagens com várias resoluções correspondentes a diferentes escalas. Por exemplo, o subespaço LLLH tem informação similar ao subespaço LH. Isto porque ambos subespaços são gerados pelo mesmo filtro, mas em escalas distintas. 


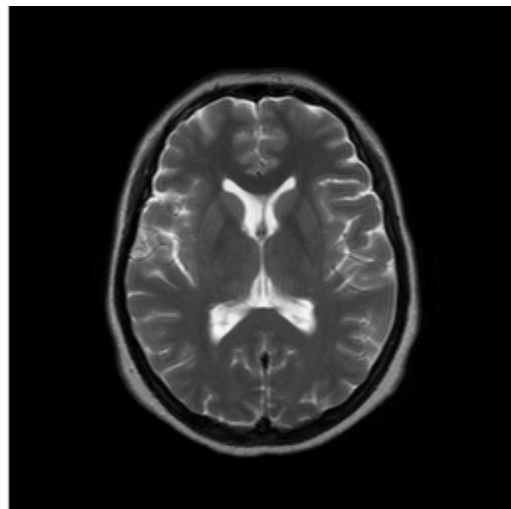

(a)

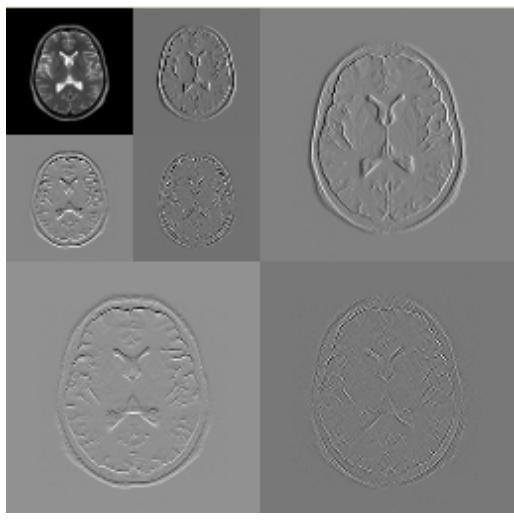

(b)

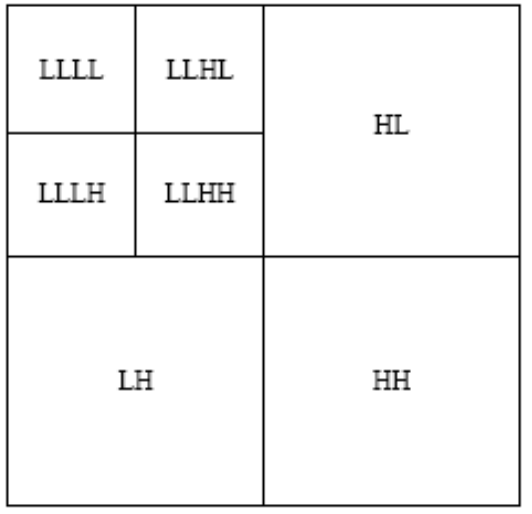

(c)

Figura 6.1: Exemplo de decomposição wavelet. (a) Imagem original; (b) Imagem decomposta em dois níveis de transformação com filtros Haar; (c) Configuração das regiões após a decomposição.

\subsection{Conjunto de Imagens}

As imagens utilizadas no trabalho correspondem a exames de ressonância magnética (RM), angiograma e mamografia. A primeira base preparada para a realização de testes é composta por um conjunto de 704 imagens de ressonância magnética retiradas de vários tipos de exames de diversas partes do corpo adquiridas nas três orientações (axial, coronal e sagital) e exames de angiograma de coração, sendo a profundidade dos pixels de cada imagem de 8 bits, resultando em 256 possíveis tons de cinza, e as dimensões das imagens é $256 \times 256$.

Os exames de ressonância magnética ressaltam melhor os tecidos moles (músculos, gordura, por exemplo), pois esse exame clínico se baseia nas propriedades de relaxamento do núcleo de moléculas de hidrogênio presentes na água e gordura, elementos que constituem a maior parte do corpo humano. Por isso, este exame possibilita diferenciar um número relativamente grande de tecidos com relação aos outros tipos de exame, como a tomografia computadorizada. Já os angiogramas são exames radiológicos onde se utiliza um contraste que permite a visualização dos vasos sangüíneos de alguma região do corpo do paciente, neste caso, foram utilizados angiogramas de coração. A Tabela 6.1 apresenta a distribuição de imagens desta base experimental e a Figura 6.2 mostra um exemplo de cada tipo de exame.

A segunda base de imagens consiste de imagens mamográficas. As características das imagens de mamografia (baixo contraste e diferenças entre os tipos de tecido) fazem com que a detecção e distinção do tumor em maligno e benigno seja uma tarefa bastante difícil, até mesmo para os especialistas. Um método atualmente adotado pela comunidade internacional de radiologistas é o sistema BI-RADS ${ }^{1}$ (Breast Imaging Reporting and Data System). Ele foi elaborado em 1992 pela ACR - American College of Radiology - nos

\footnotetext{
${ }^{1}$ American College of Radiology - Breast Imaging Reporting and Data system - $3^{\text {rd }}$ ed., 1992.
} 


\begin{tabular}{|l|c|}
\hline \multicolumn{1}{|c|}{ Categoria } & $\mathbf{n}^{\mathbf{0}}$ de imagens \\
\hline Angiograma RM & 36 \\
Pélvis Axial & 86 \\
Cabeça Axial & 155 \\
Cabeça Sagital & 258 \\
Abdômen Coronal & 23 \\
Espinha Sagital & 59 \\
Abdômen Axial & 51 \\
Cabeça Coronal & 36 \\
\hline Total & $\mathbf{7 0 4}$ \\
\hline
\end{tabular}

Tabela 6.1: Base de imagens de ressonância magnética e angiograma.

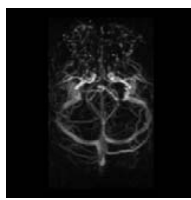

(a)

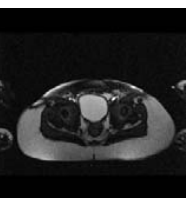

(b)

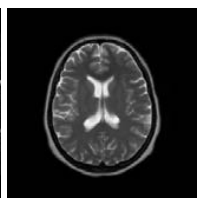

(c)

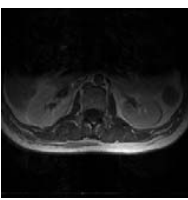

(d)

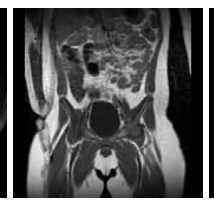

(e)

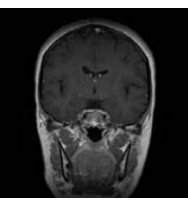

(f)

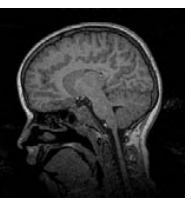

(g)

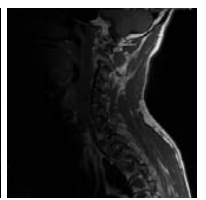

(h)

Figura 6.2: Imagens de exames de ressonância magnética e angiograma. (a) Angiograma, (b) Abdômen Axial, (c) Cabeça Axial, (d) Pélvis Axial, (e) Abdômen Coronal, (f) Cabeça Coronal, (g) Cabeça Sagital e (h) Espinha Sagital.

Estados Unidos da América para a padronização de descrição de laudos em mamografia. O objetivo da sistematização é padronizar a nomenclatura dos laudos, que devem possuir conclusão diagnóstica e propor conduta. Ele contém várias recomendações desde a padronização de termos utilizados no diagnóstico por imagem das doenças da mama, até o enquadramento da composição do corpo mamário e dos achados mamográficos em categorias.

A avaliação da composição do tecido mamário é importante para especificar o grau de sensibilidade que se espera no diagnóstico. Quanto maior a densidade radiológica, menor a sensibilidade diagnóstica. Os casos devem ser classificados em um dos seguintes padrões:

Composição 1: as mamas são quase completamente substituídas por tecidos gordurosos.

Composição 2: Existem tecidos fibro-glandulares dispersos, que podem ocultar lesões na mamografia.

Composição 3: O tecido mamário é heterogeneamente denso. Este fato determina menor sensibilidade diagnóstica do exame.

Composição 4: O tecido mamário é extremamente denso, o que pode obscurecer uma lesão na mamografia. Este fato também determina uma baixa sensibilidade diagnóstica para o exame. 
Para classificar os achados mamográficos, o padrão divide-os nas seguintes categorias:

Categoria 0: necessidade de avaliação adicional de imagem. Esta avaliação inclui incidências localizadas e magnificadas, incidências especiais, e exames de outras modalidades diagnóstica por imagem.

Categoria 1: mamografia normal ou exame negativo. As mamas são simétricas e não apresentam nódulos, distorções arquiteturais ou calcificações suspeitas.

Categoria 2: achados mamográficos benignos. Esta categoria demonstra achados mamográficos com negativos evidentes de malignidade.

Categoria 3: achados provavelmente benignos. São achados que não se espera alterações no decorrer do tempo. Por isso, são acompanhados para controle de sua estabilidade.

Categoria 4: achados suspeitos. Lesões que não têm características malignas, mas que também não podem ser classificadas como benignas. Em edições mais recentes do BI-RADS ${ }^{2}$, recomenda-se subdivisão em categoria 4A (suspeita leve), 4B (suspeita moderada) e 4C (suspeita forte).

Categoria 5: altamente sugestivo de lesão maligna. Devem ser encaminhados para biópsia.

A base de imagens de mamografia construída no presente trabalho está baseada no sistema BI-RADS para classificar os achados mamográficos. As imagens foram classificadas nas Categorias de 2 a 5, sendo um total de 103 imagens. Cada imagem possui dimensão de $1024 \times 1024$ pixels com profundidade de 8 bits. A Tabela 6.2 apresenta o número de imagens por categoria e a Figura 6.3 mostra um exemplo de imagem de cada categoria.

\begin{tabular}{|c|c|}
\hline Categoria & $\mathbf{n}^{\mathbf{0}}$ de imagens \\
\hline 2 & 1 \\
3 & 20 \\
4 & 45 \\
5 & 37 \\
\hline Total & $\mathbf{1 0 3}$ \\
\hline
\end{tabular}

Tabela 6.2: Base de imagens mamográficas. Número de imagens por categoria de acordo com a classificação BI-RADS.

\subsection{Experimentos - considerações gerais}

Para avaliar os métodos propostos, foram empregados os gráficos de precision vs. recall, descritos na Seção 4.6 obtidos a partir dos resultados das consultas por conteúdo de imagens. Considerando o tamanho da base de dados, consultas aos $k$ vizinhos mais

\footnotetext{
${ }^{2}$ American College of Radiology - Breast Imaging Reporting and Data system, $4^{\text {th }}$ ed., 2003
} 


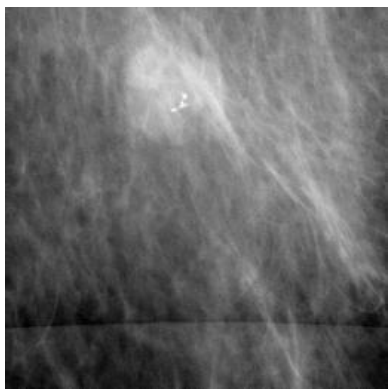

(a) Categoria 2

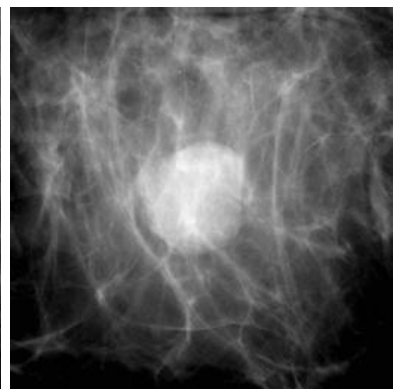

(b) Categoria 3

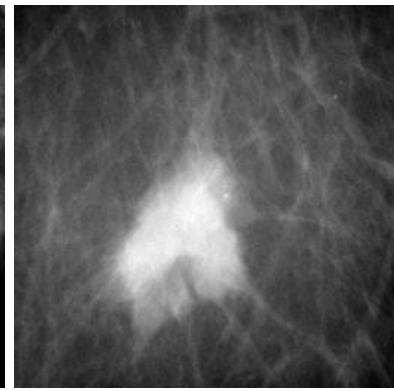

(c) Categoria 4

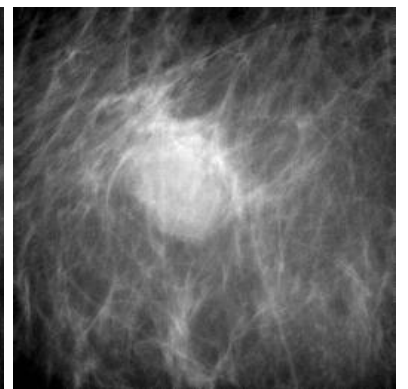

(d) Categoria 5

Figura 6.3: Exemplo de imagens das categorias 2, 3, 4 e 5 de acordo com o sistema BI-RADS.

próximos (Seção 4.4.2) são aplicadas à base de dados. Lembrando que uma consulta $k-$ $N N$ é uma consulta por similaridade executada comparando os vetores de características através de uma função de distância que quantifica o quão perto (ou similar) cada par de vetores estão. Uma maneira direta de analisar as curvas de precision vs. recall é comparar a altura das curvas: quanto mais perto a curva estiver do topo do gráfico melhor a técnica de busca empregada. Nos experimentos foram executadas $k$ séries de consultas $k-N N$, considerando $k$ como o tamanho da base de dados. Então, curvas médias de precision vs. recall geradas a partir destas consultas realizadas foram calculadas e plotadas. A função de distância usada na maioria dos experimentos foi a Euclidiana.

Com relação à base de ressonância magnética e angiograma, para avaliação dos resultados das consultas por meio das curvas de precision vs. recall foram criados subgrupos de imagens similares dentro de cada uma das categorias listadas na Tabela 6.1. Basicamente, os subgrupos comportam imagens similares com relação à parte do corpo examinada, orientação (axial, radial, coronal) e altura do corte. O tamanho dos grupos pode variar de 15 a 40 imagens, sendo que a maioria deles contém imagens de diferentes pacientes e exames. Em nossos experimentos, dada uma imagem chave de busca, as imagens consideradas relevantes para a consulta são todas aquelas pertencentes ao mesmo subgrupo de imagens similares. Assim, o gráfico de precision vs. recall da consulta pode ser computado automaticamente pelo sistema desenvolvido.

Já para a base de imagens de mamografia, cada exame realizado é de uma paciente diferente. Dada uma imagem chave de busca, as imagens consideradas relevantes para a consulta são todas aquelas pertencentes à mesma categoria de imagens similares (ver Tabela 6.2), de acordo com o sistema BI-RADS, descrita na Seção 6.3.

Para um estudo comparativo do vetor de características proposto foi escolhida uma técnica bem conhecida e importante de representação de conteúdo de imagens: os histogramas de brilho ou níveis de cinza. O histograma em níveis de cinza calcula e apresenta o número de pixels de uma imagem para cada nível de cinza. Os histogramas de brilho são muito usados em CBIR devido à facilidade e rapidez com que eles podem ser 
computados. Portanto, os histogramas normalizados de brilho também foram computados para as mesmas imagens, resultando em vetores de características de 256 valores reais.

\subsection{Método 1 - Extraindo a energia dos subespaços gerados por wavelets}

O método proposto é baseado no vetor de características proposto por Castañón (2002). Castañón aplica a transformada wavelet de Daubechies $D_{4}$ em três níveis de decomposição. De cada subespaço wavelet é extraída a medida de energia. Portanto, seu vetor é composto por nove características. Diferentemente da abordagem de Castañón (2002), que extrai medidas estatísticas apenas dos subespaços de alta freqüência gerados pela aplicação da wavelet mãe, o método proposto, além desses subespaços, também considera o subespaço de baixa freqüência. Assim, são aplicados três níveis de decomposição, gerando uma subimagem de baixa freqüência e nove subespaços de wavelets (cada três nas direções horizontal, vertical e diagonal) que correspondem a subimagens direcionais de alta freqüência.

O cálculo dos vetores de características está baseado nas propriedades de energia dos subespaços gerados, assim como na abordagem de Castañón (2002) descrita no parágrafo anterior. Para cada imagem, depois de aplicar a transformada wavelet de Daubechies $D_{4}$, é calculado o valor da energia total do subespaço de wavelets, de acordo com a Equação 6.1, onde $P(i, j)$ é o valor do pixel na posição $(i, j)$ da imagem de $M \times N$ pixels. Aplicando o processo descrito no parágrafo anterior, o vetor de características é composto por dez valores de energia total de cada subespaço de wavelets de alta e baixa freqüência, como é mostrado na Figura 6.4.

$$
E=\sum_{i=1}^{M} \sum_{j=1}^{N} P(i, j)^{2}
$$

\subsubsection{Experimentos e resultados}

Para avaliar e validar a eficiência na tarefa de recuperação de imagens do vetor de característica proposto, foi usada a base de 704 imagens de ressonância magnética e angiograma (Tabela 6.1). A função distância escolhida foi a Euclidiana e também foi implementada a proposta de Castañón (2002) para a representação da imagem. O gráfico da Figura 6.5 apresenta as curvas médias de precision vs. recall das consultas realizadas a todas as imagens da base como objeto de consulta, obtidas pelas técnicas comparadas.

Analisando visualmente o gráfico da Figura 6.5, observa-se que o vetor de características proposto se sobressai com relação ao vetor de Castañón. Numericamente, tem-se 

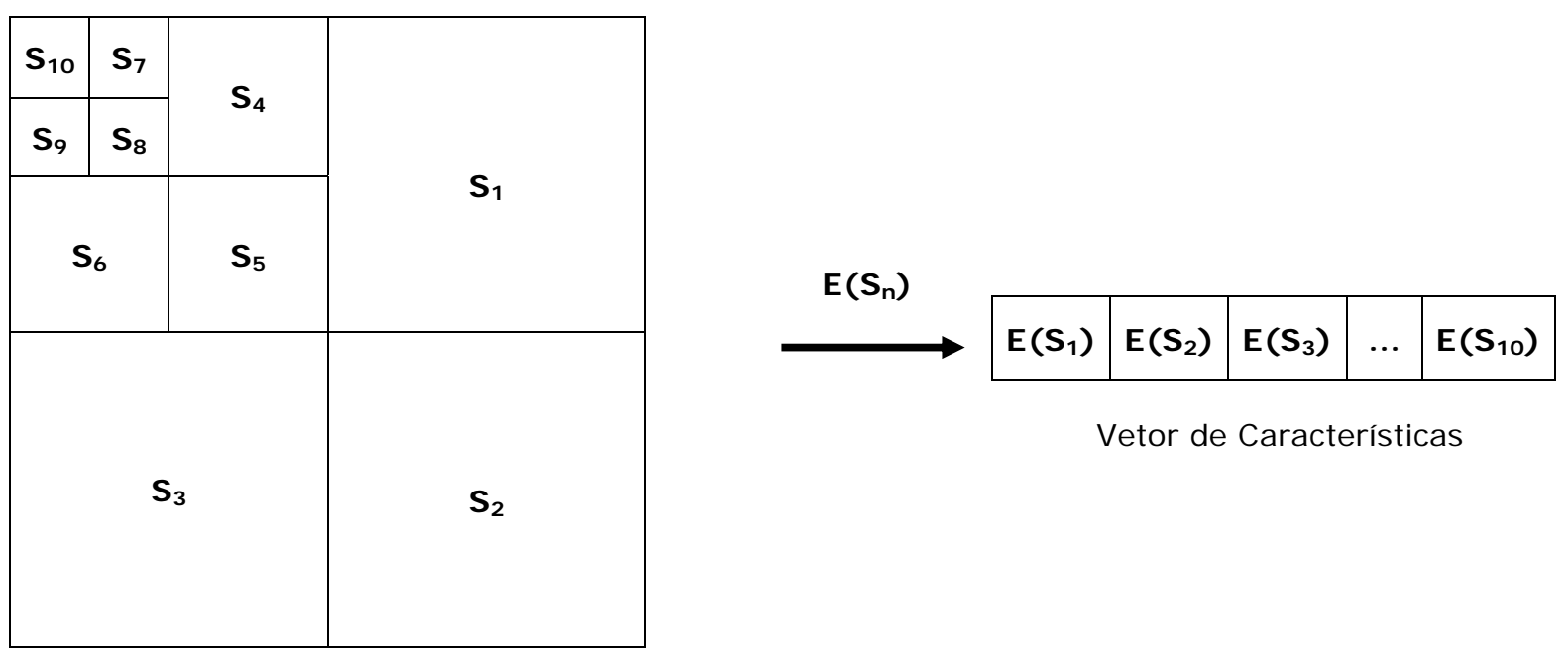

Subespaços de wavelets

Figura 6.4: Geração do vetor de características de uma imagem baseada nos subespaços wavelets considerando três níveis de decomposição e a função $E\left(S_{n}\right)$ corresponde ao extrator aplicado sobre o subespaço $S_{n}$.

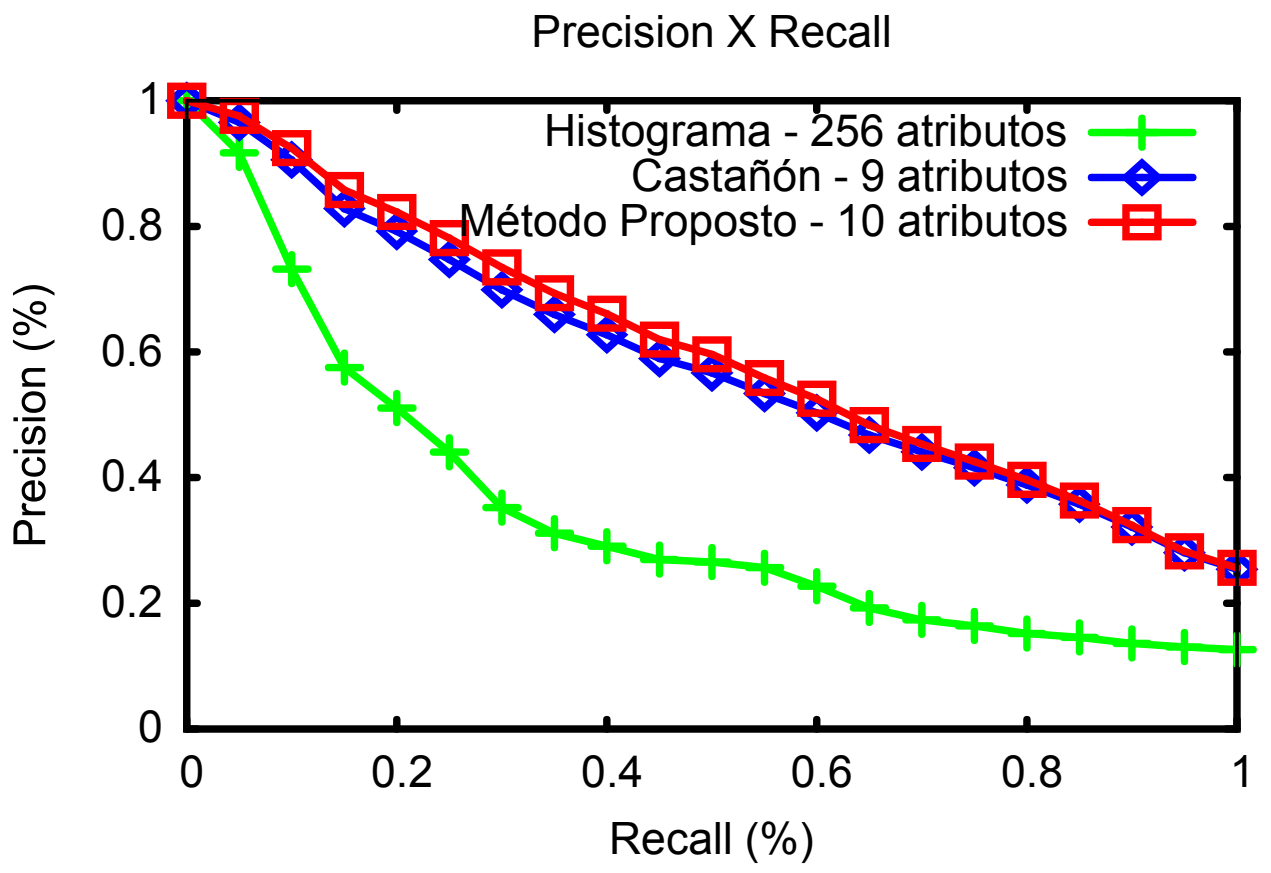

Figura 6.5: Curvas médias de precision vs. recall ilustrando o comportamento na recuperação de imagens do vetor de características composto pela energia dos subepaços de alta freqüência gerados pela wavelet mãe (abordagem de Castañón) e da nossa abordagem, que além desses subespaços, também considera o subespaço de baixa freqüência. 
um ganho de até 5,3\% quando é realizada uma consulta que retorna $40 \%$ das imagens da base. Há também um grande ganho em relação à curva média de precision vs. recall do Histograma, chegando a ser de até $108,98 \%$ para consultas que pedem até $70 \%$ das imagens da base. Este é um ganho considerável tanto em precisão quanto ao analisamos o número de atributos de cada vetor. O vetor de Histograma possui 256 atributos, enquanto que o vetor de característica do método proposto contém 10 atributos. Ou seja, a redução de 256 atributos para 10 é de 96,09\%.

Quanto à análise qualitativa, a Figura 6.6 apresenta as curvas médias de precision vs. recall obtidas separadamente para cada categoria de imagens da base experimental, conforme descrito na Tabela 6.1. O objetivo é ilustrar o comportamento do vetor de características proposto para diferentes tipos de imagens. As categorias que possuem melhor precisão são Angiograma, Abdômen Axial e Pélvis Axial. Podemos notar também que as curvas das categorias Cabeça Axial e Cabeça Coronal são bem próximas. Isto se deve ao fato de muitas imagens de cabeça de corte axial serem bem parecidas com as imagens de corte coronal, assim, ambas as categorias se misturam no resultado de várias operações de consulta por similaridade. A Figura 6.7 ilustra uma consulta às 10 imagens mais semelhantes dada uma imagem de angiograma. Observe que todas as imagens retornadas são relevantes, ou seja, são da mesma classe (angiograma).

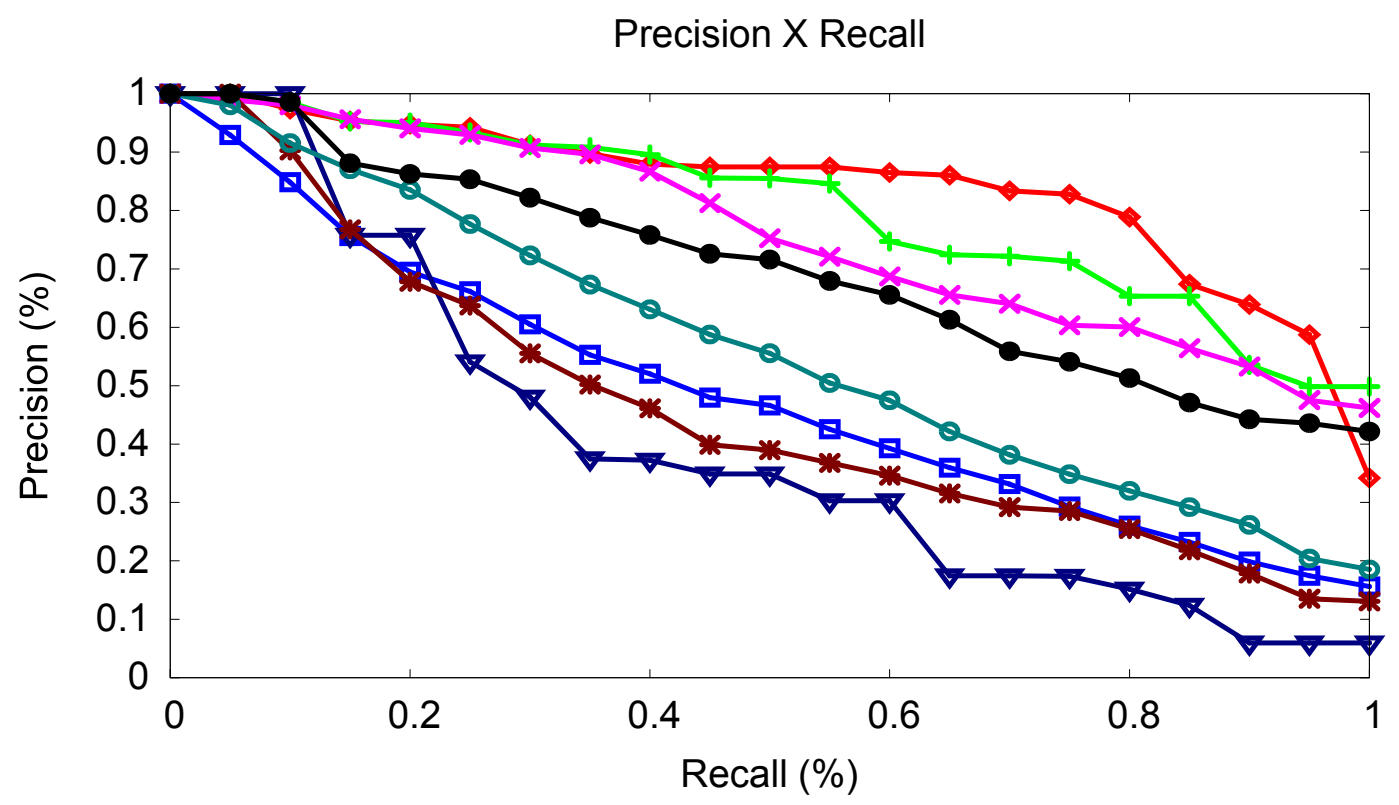
Angiograma
Pélvis Axial $\rightarrow$
Abdômen Axial Abdômen Coronal $\underset{\leftarrow}{\longrightarrow}$
Cabeça Coronal $\rightarrow$ -
Cabeça Sagital $\multimap-$
Espinha Sagital $\longrightarrow-$ Cabeça Axial $\rightarrow$

Figura 6.6: Curvas médias de precision vs. recall para cada categoria de imagens da base experimental da Tabela 6.1. 


\section{Chave de Busca}

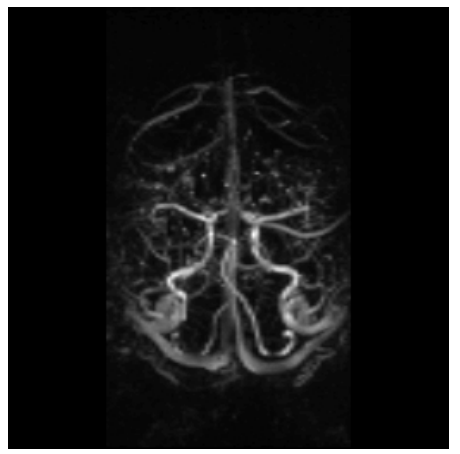

2439.jpg - angiograma
Miniatura dos 10 vizinhos mais próximos
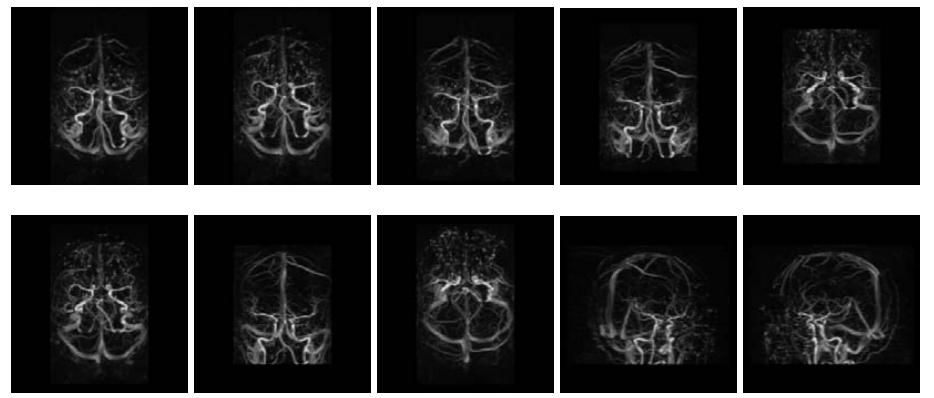

Figura 6.7: Imagens retornadas à consulta das 10 imagens mais próximas.

\subsection{Método 2 - Representação da imagem através do subespaço de baixa freqüência}

Focando na propriedade de compressão de dados das wavelets, o segundo método propõe a caracterização das imagens através de vetores de características compostos pelo subespaço de baixa freqüência gerado por uma transformada wavelet, pela análise de multi-resolução (Seção 3.6).

O subespaço de baixa freqüência foi disposto no vetor de características de acordo com a proposta de Romdhani (1996), na qual a representação de uma imagem é dada como um vetor pelaleitura coluna a coluna da imagem, colocando o valor de cada pixel da imagem em um vetor coluna. Portanto, a dimensão do vetor de características será dada pela multiplicação das dimensões do subespaço de baixa freqüência. A representação do vetor é mostrada na Figura 6.8.

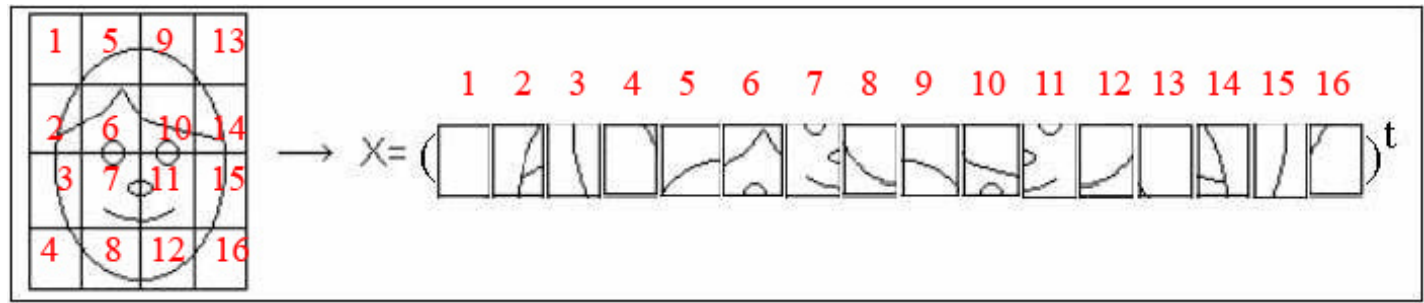

Figura 6.8: Processo de criação de um padrão $x$ a partir de uma imagem (adaptada de Romdhani (1996)).

Como descrito na Seção 6.2, foram utilizados os filtros da família Daubechies $\left(D_{2}, D_{4}\right.$, $D_{6}, D_{8}$ e $D_{16}$ ), Coifman (Coifman 6 e Coifman 12) e Symlets (2, 3, 4, 5 e 15). Os filtros podem ser vistos nos anexos, nas seções A.2, A.1 e A.3, respectivamente.

Foi utilizado o subespaço de baixa freqüência gerado pela decomposição em 4 e 5 níveis por uma das transformadas wavelets descritas no parágrafo anterior. Então, para 
calcular o tamanho do vetor de características, basta dividir por 2 o tamanho da largura e da altura da dimensão da imagem a cada nível de resolução aplicado, como pode ser observado na Figura 6.1, e multiplicar as dimensões do subespaço de baixa freqüência.

Assim, como as imagens possuem $256 \times 256$ pixels, quando aplicada uma decomposição usando transformada wavelet em 4 níveis de resolução, o vetor de características possui $(16 \times 16=256) 256$ características. Quando aplicada uma decomposição em 5 níveis, o vetor possui $(8 \times 8=64) 64$ atributos, que é o número total de pixels do subespaço de baixa freqüência.

\subsubsection{Experimento 1}

As imagens utilizadas no primeiro experimento correspondem a exames de ressonância magnética e angiograma. A profundidade dos pixels das imagens é de 8 bits, resultando em 256 tons de cinza, e as dimensões das imagens são $256 \times 256$. Para realização dos testes, foi preparado um conjunto com 210 imagens de vários tipos de exames realizados no Hospital das Clínicas de Ribeirão Preto. Este conjunto foi dividido em 7 classes, com 30 imagens cada, de acordo com a região do corpo examinada e o tipo de corte tomado: Angiograma, Axial RM Bacia, Axial RM Cabeça, Coronal RM Abdômen, Coronal RM Cabeça, Sagital RM Cabeça e Sagital RM Espinha, como mostra a Figura 6.9.

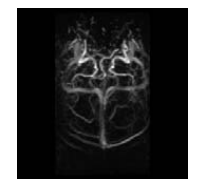

(a)

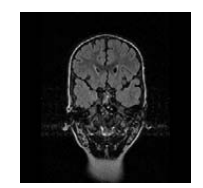

(e)

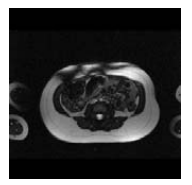

(b)

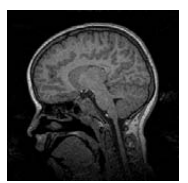

(f)

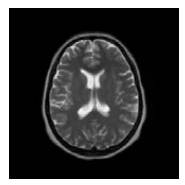

(c)

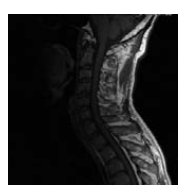

(g)

Figura 6.9: Exemplo de imagens da base de angiograma e ressonância magenética de 210 imagens. (a) Angiograma, (b) Axial RM Bacia, (c) Axial RM Cabeça, (d) Coronal RM Abdômen, (e) Coronal RM Cabeça, (f) Sagital RM Cabeça e (g) Sagital RM Espinha.

Dessas imagens foram obtidos os subespaços de baixa freqüência a partir da decomposição das imagens em 4 níveis de resolução pelas transformadas wavelet Coifman (6 e 12), Daubechies $\left(D_{4}\right.$ e $\left.D_{16}\right)$ e Symlet $(2,3,4,5$ e 15). Assim, a aplicação de cada uma dessas transformadas gera um vetor de características de 256 atributos. O gráfico da Figura 6.10 mostra as curvas médias de precision vs. recall dos nove vetores propostos para representar as imagens. 


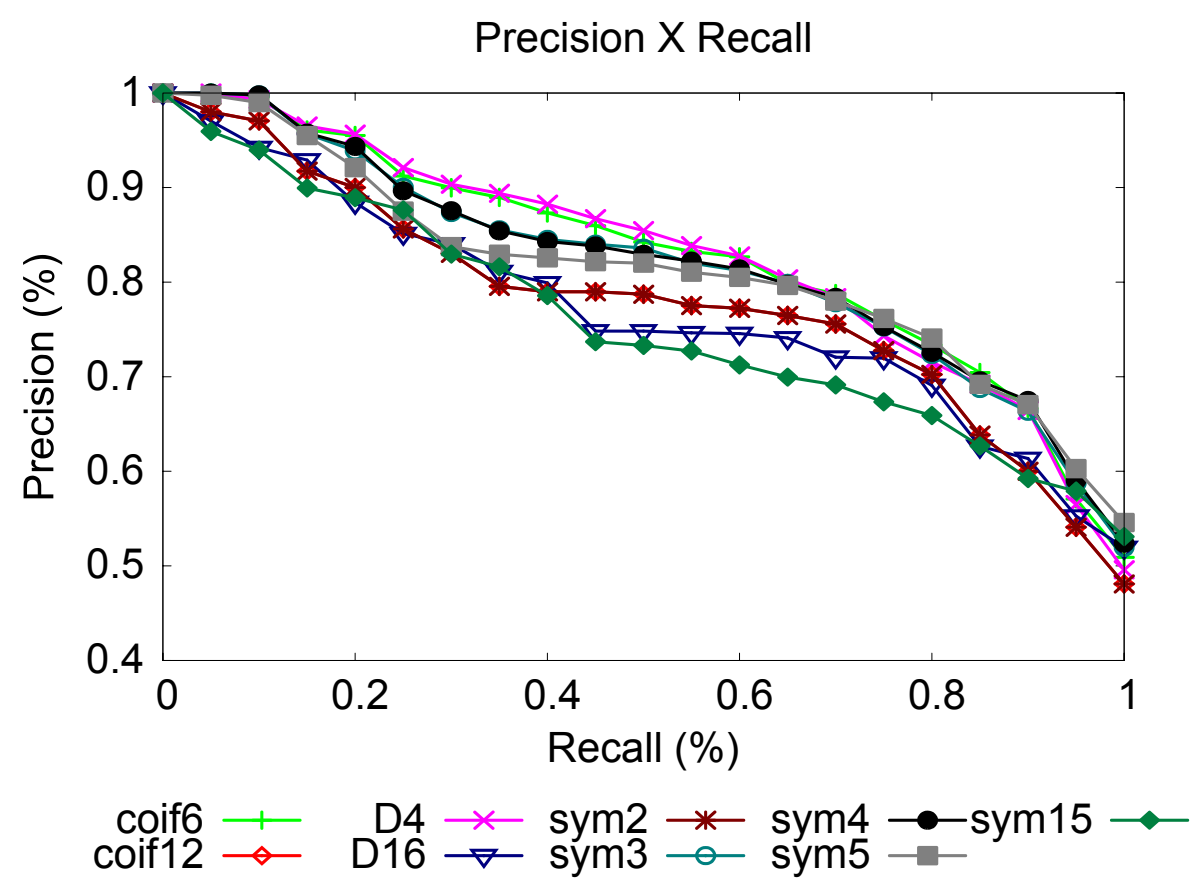

Figura 6.10: Curvas médias de precision vs. recall das consultas realizadas na base de dados com 210 imagens de ressonância magnética e angiograma, representando a imagem pelo subespaço de baixa freqüência gerado pela decomposição em 4 níveis. Cada vetor possui 256 características.

Analisando visualmente o gráfico da Figura 6.10, podemos observar que a wavelet que melhor representou as imagens foi a wavelet de Daubechies $D_{4}$. Também podemos considerar que a curva obtida pela wavelet Coifman 6 é equivalente à $D_{4}$.

\subsubsection{Experimento 2}

O próximo experimento consiste em aplicar a transformada wavelet de Coifman (6 e 12) e Daubechies $\left(D_{2}, D_{4}\right.$ e $\left.D_{16}\right)$ em 5 níveis de resolução e representar a imagem através do subespaço de baixa freqüência. Assim, o vetor de características obtido possui 64 atributos. A Figura 6.11 exibe o gráfico de precision vs. recall obtido realizando consultas sobre a base de 210 imagens representada por esses vetores de características.

Note que a wavelet que melhor representou as imagens desta base de imagens foi a wavelet de Haar, ou $D_{2}$. O gráfico da Figura 6.12 compara os melhores métodos apresentados nos Experimentos 1 e 2, descritos na Seção 6.6.1 e na Seção 6.6.2, com o gráfico gerado pelo Histograma de brilho.

Analisando o gráfico da Figura 6.12, observamos que todos os métodos propostos possuem melhor desempenho nas consultas que o Histograma de brilho. Note também que a curva que possui melhor precisão é a $D_{2}$, com apenas 64 atributos, enquanto que os outros métodos plotados possuem 256 características. Ou seja, há uma redução na dimensionalidade dos dados de $75 \%$. O ganho da curva gerada pela wavelet $D_{2}$ com 


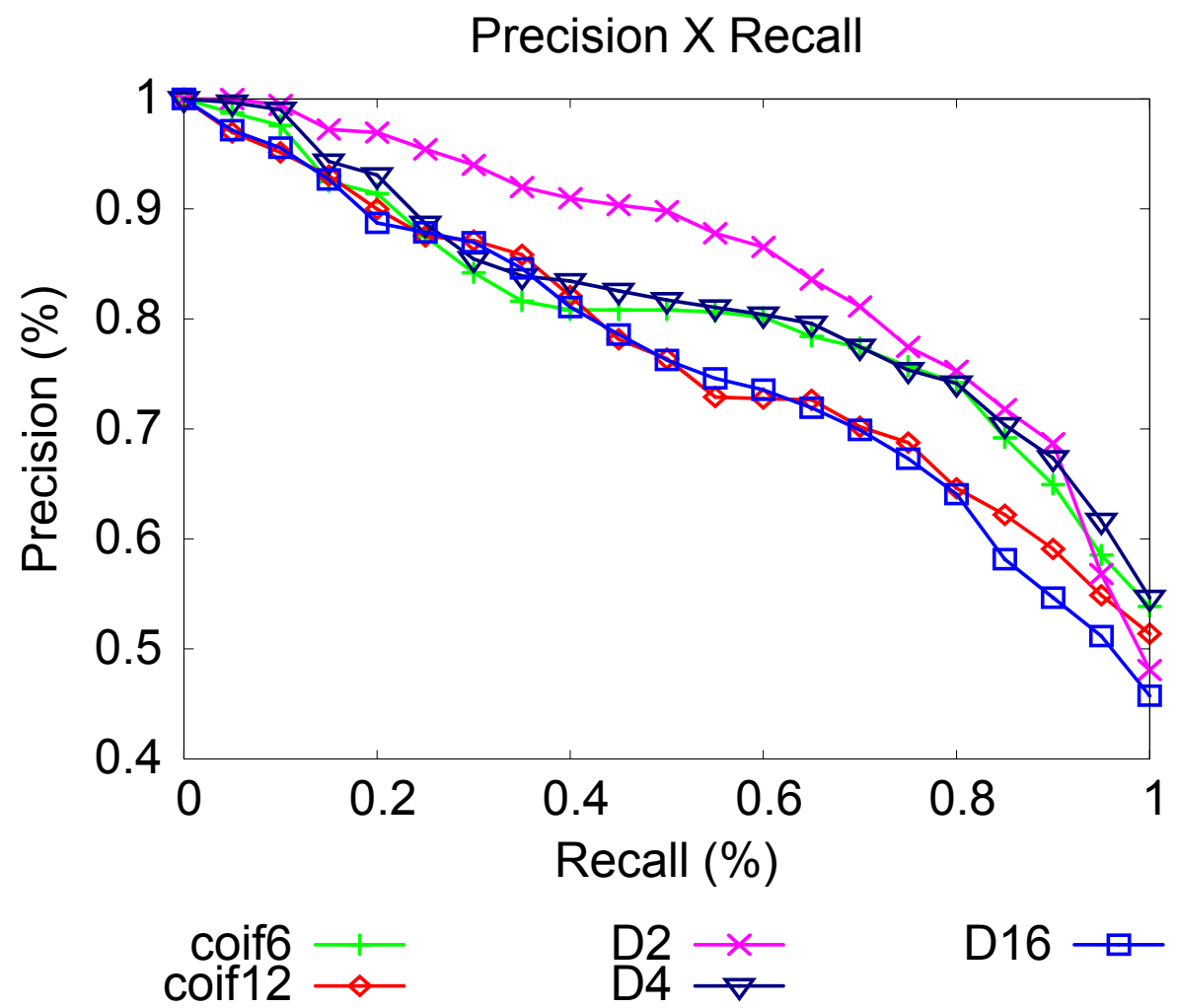

Figura 6.11: Gráfico de precision vs. recall das consultas realizadas na base de dados com 210 imagens de ressonância magnética e angiograma, representando a imagem através do subespaço de baixa freqüência gerado pela decomposição em 5 níveis.

5 níveis de decomposição chega a ser de até $82,55 \%$ em relação à curva gerada pelo Histograma para consultas que pedem até $90 \%$ das imagens da base. Esses métodos são bons para caracterizar as imagens da base experimental, já que a precisão das buscas é de mais de $80 \%$ para consultas que pedem até $65 \%$ das imagens da base.

Assim, podemos inferir que nos vetores de características com muitos atributos há atributos que não estão caracterizando bem a imagem. Assim, a redução da dimensionalidade dos dados por meio da aplicação de wavelet pelo método de multiresolução em 5 níveis de decomposição reduziu a redundância de dados e possibilitou uma melhor caracterização das imagens usando apenas o subespaço de baixa-freqüência.

\subsubsection{Experimento 3}

Agora, vamos realizar testes usando uma base de imagens maior, a base de 704 imagens de ressonância magnética e angiograma, descrita na Tabela 6.1. Como no experimento anterior o melhor resultado foi obtido aplicando uma transformada wavelet de Daubechies e segundo Wang et al. (2001), as wavelets de Daubechies obtêm excelentes resultados no processamento de imagens devido às suas propriedades, então testamos várias wavelets da família de Daubechies em 4, 5 e 6 níveis de decomposição por meio do método de 


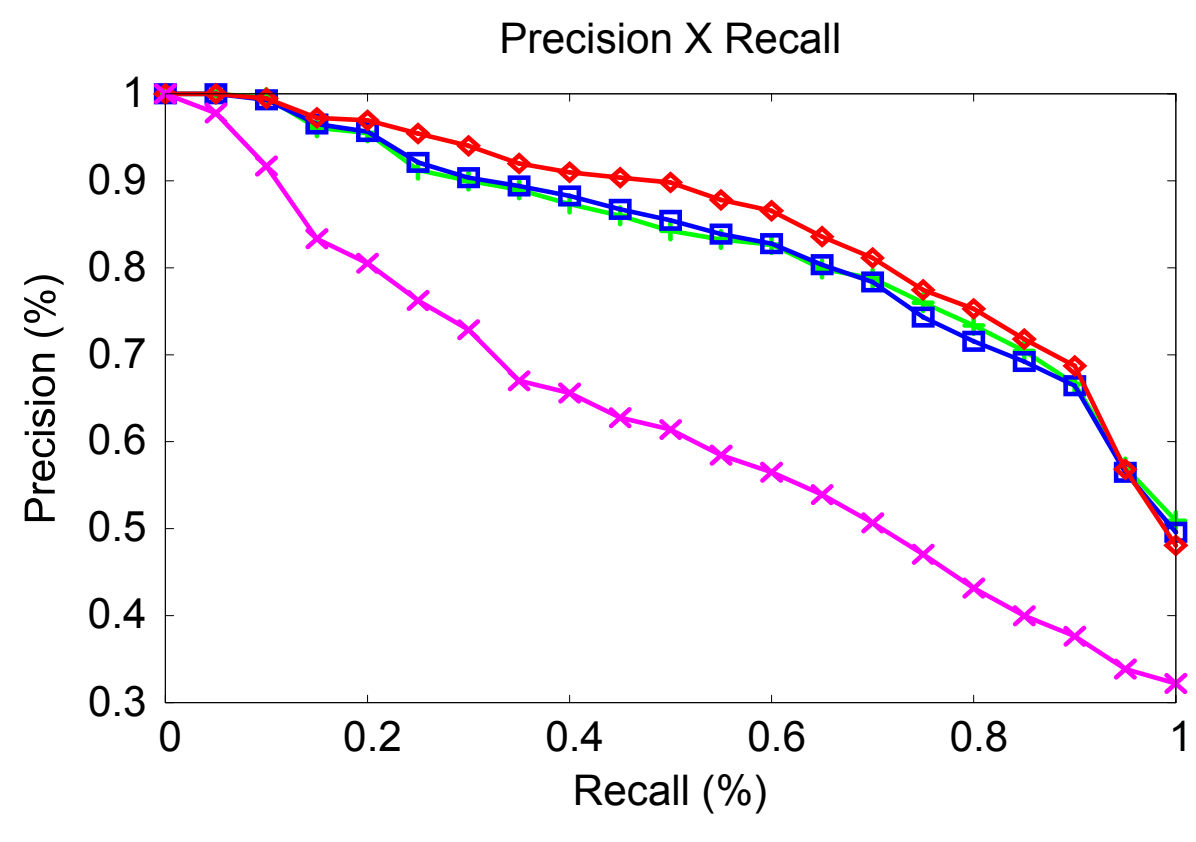

coif6-256 — D4-256 ๑ D2-64 $\leadsto$ Histograma $*$

Figura 6.12: Curvas médias de precision vs. recall usando: wavelet de Coifman 6 e $D_{4}$ em 4 níveis de decomposição, $D_{4}$ em 5 níveis e Histograma.

multiresolução. O gráfico da Figura 6.13 apresenta as curvas médias de precision vs. recall geradas pelos métodos propostos. A legenda das wavelets do gráfico foi feita usando a notação do Matlab, descrita na Seção 3.5.4. Primeiro é escrita a wavelet usada, depois o nível de resolução na análise de multiresolução e por fim o número de atributos do vetor de característica gerado.

Vamos analisar o gráfico da Figura 6.13. Note que as curvas de precision vs. recall geradas pela mesma tranformada wavelet em vários níveis de resolução decaem de acordo com a wavelet escolhida. Quanto maior é o índice, ou seja, quanto maior é o número de filtros, mais rapidamente as curvas decaem ao se escolher um nível de decomposição maior. Analisando a wavelet db1, a qual possui dois filtros, notamos que as curvas geradas em 4 e 5 níveis de decomposição são equivalentes, mesmo a diferença do número de atributos de seus vetores de características ser grande (em 4 níveis de decomposição temos um vetor de 256 atributos e em 5 níveis um vetor de 64 atributos). Para um nível de decomposição 6, ainda obtemos um excelente resultado (curva em vermelho), já que com apenas 16 atributos, a precisão é acima de $80 \%$ para consultas que pedem até $90 \%$ das imagens da base. E comparando os 256 atributos com os 16, temos uma redução na dimensionalidade dos dados de $93,75 \%$ !

Observe também que quanto maior o número de filtros, menor é a precisão das consultas realizadas, considerando um mesmo nível de decomposição.

No gráfico da Figura 6.14, plotamos as melhores curvas médias de precision vs. recall com 256 atributos, com 64 atributos e com 16 atributos vistas na Figura 6.13 e a curva 

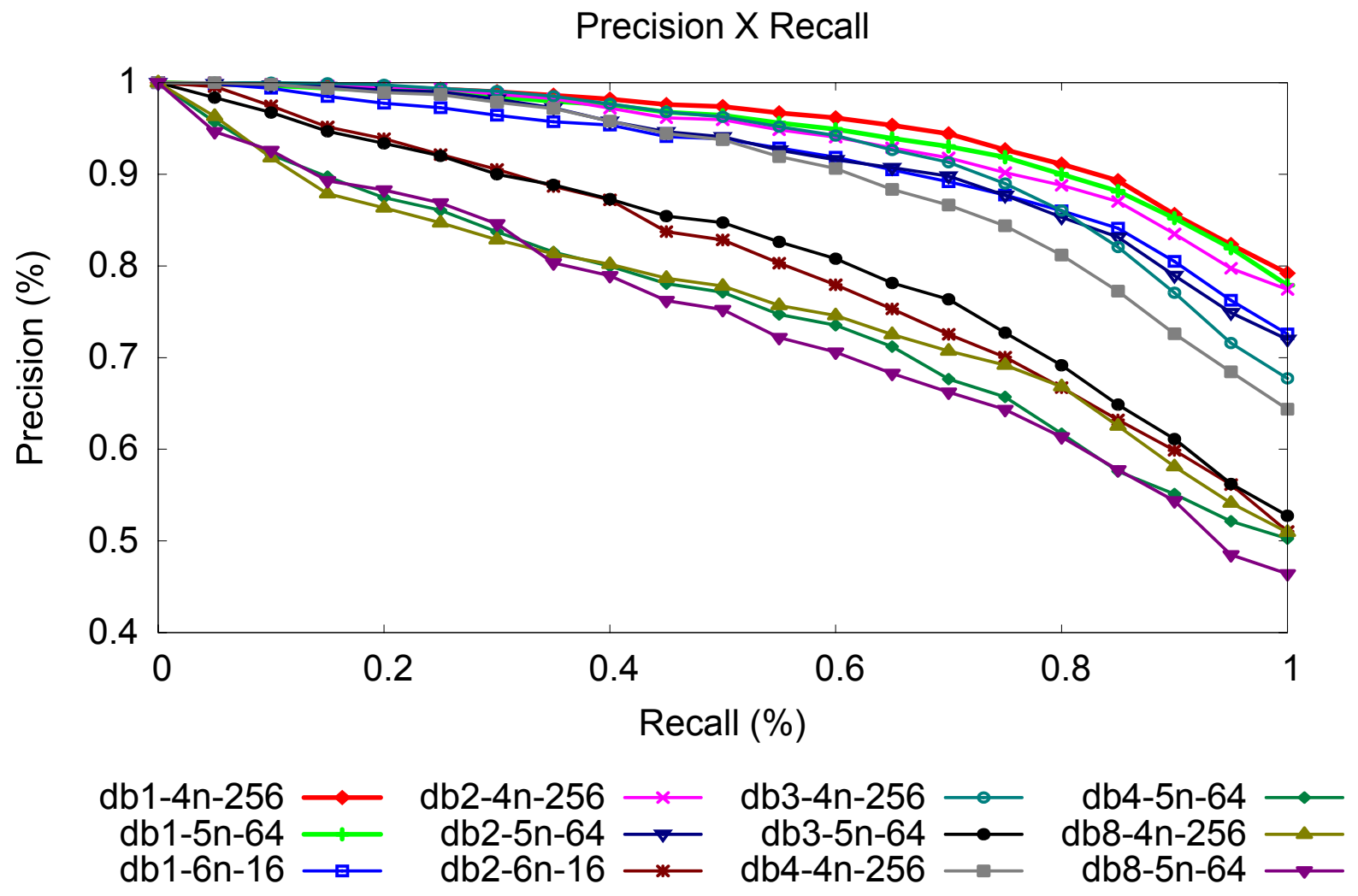

Figura 6.13: Curvas médias de precision vs. recall geradas pela aplicação de wavelets de Daubechies em vários níveis de decomposição.

gerada pelo Histograma. A Figura 6.15 ilustra uma consulta k-NN realizada, usando o método de Daubechies 1 em 6 níveis de decomposição, com 16 características (db1-6n-16). Note que todas as imagens retornadas são da mesma classe, ou seja, relevantes. Já a Figura 6.16 ilustra uma consulta $\mathrm{k}-\mathrm{NN}(\mathrm{K}=10)$, na qual podemos observar que apenas as imagens contornadas em vermelho são relevantes à consulta.

Visualmente, o ganho dos três métodos propostos em relação ao Histograma é notável. Numericamente, temos para o vetor com 256 atributos um ganho de até $531 \%$ na precisão para uma revocação (recall) de 95\%; para o vetor com 64 características o ganho na precisão chega a ser de até $528 \%$ para uma revocação (recall) de $95 \%$; e para o vetor de características com 16 atributos o ganho na precisão das consultas é de até $491 \%$ para uma revocação de $90 \%$.

O gráfico da Figura 6.17 apresenta curvas médias de precision vs. recall de cada classe de imagem referente ao método que aplica wavelet $d b 1$ em 4 níveis de decomposição sobre a imagem e tem como vetor de características o subespaço de baixa-freqüência. $\mathrm{O}$ objetivo é ilustrar o comportamento do vetor de características proposto para diferentes tipos de imagens. Observe que para a maioria das categorias o valor de precisão é acima de $80 \%$ para valores de revocação até $80 \%$ e, para valores de revocação até $50 \%$, todas as categorias de imagens possuem valor de precisão acima de $90 \%$. 


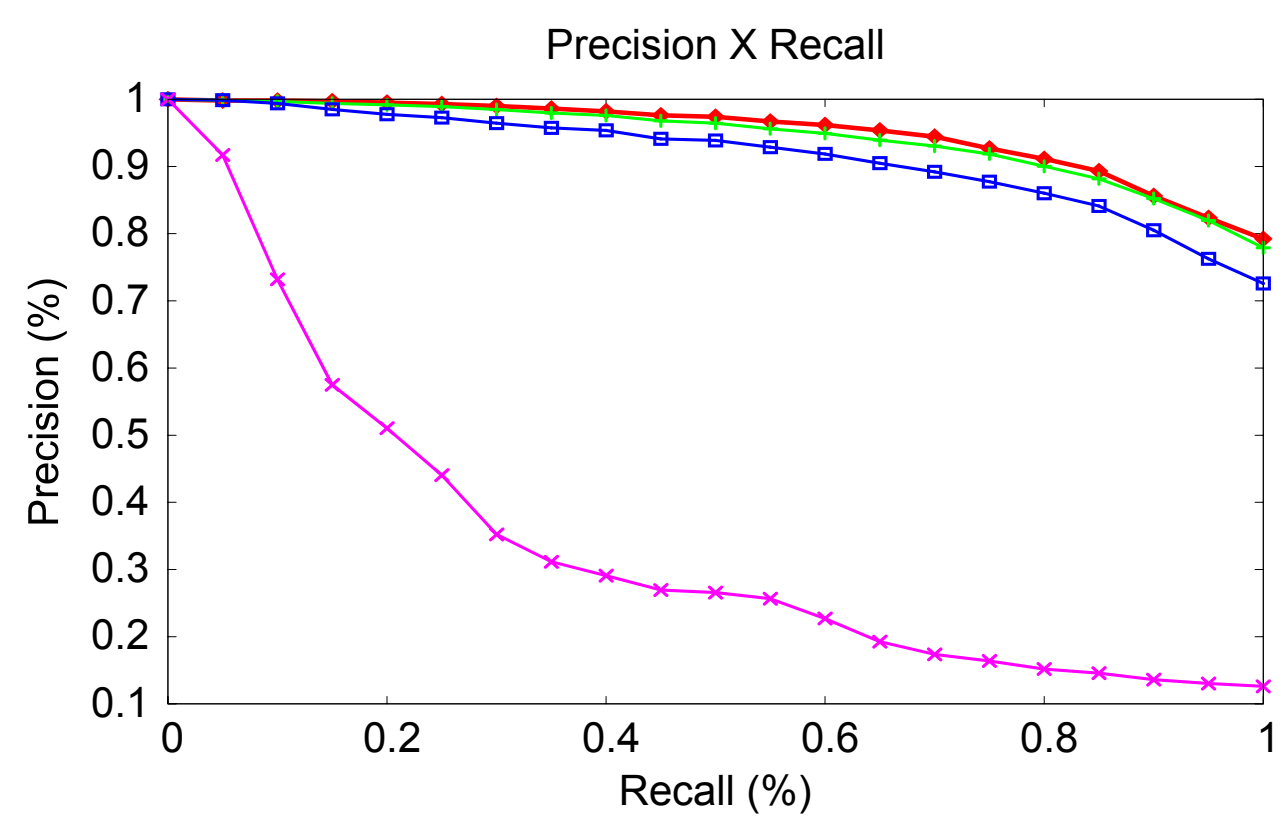

db1-4n-256 $\multimap \mathrm{db} 1-5 \mathrm{n}-64 \longrightarrow \mathrm{db} 1-6 \mathrm{n}-16 \rightarrow-$ Histograma $\multimap$

Figura 6.14: Curvas médias de precision vs. recall das consultas realizadas usando wavelet db1 em 4, 5 e 6 níveis de decomposição e Histograma.

\section{Chave de Busca}

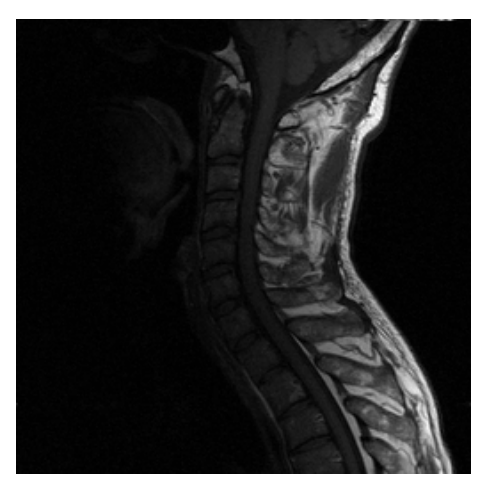

2290.jpg - espinha, corte sagital

\section{Miniatura dos 10 vizinhos mais próximos}
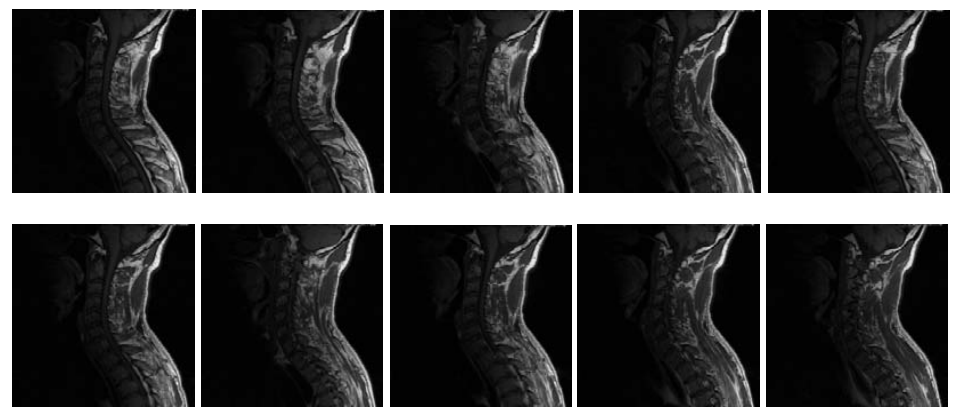

Figura 6.15: Exemplo de consulta k-NN (K=10). 


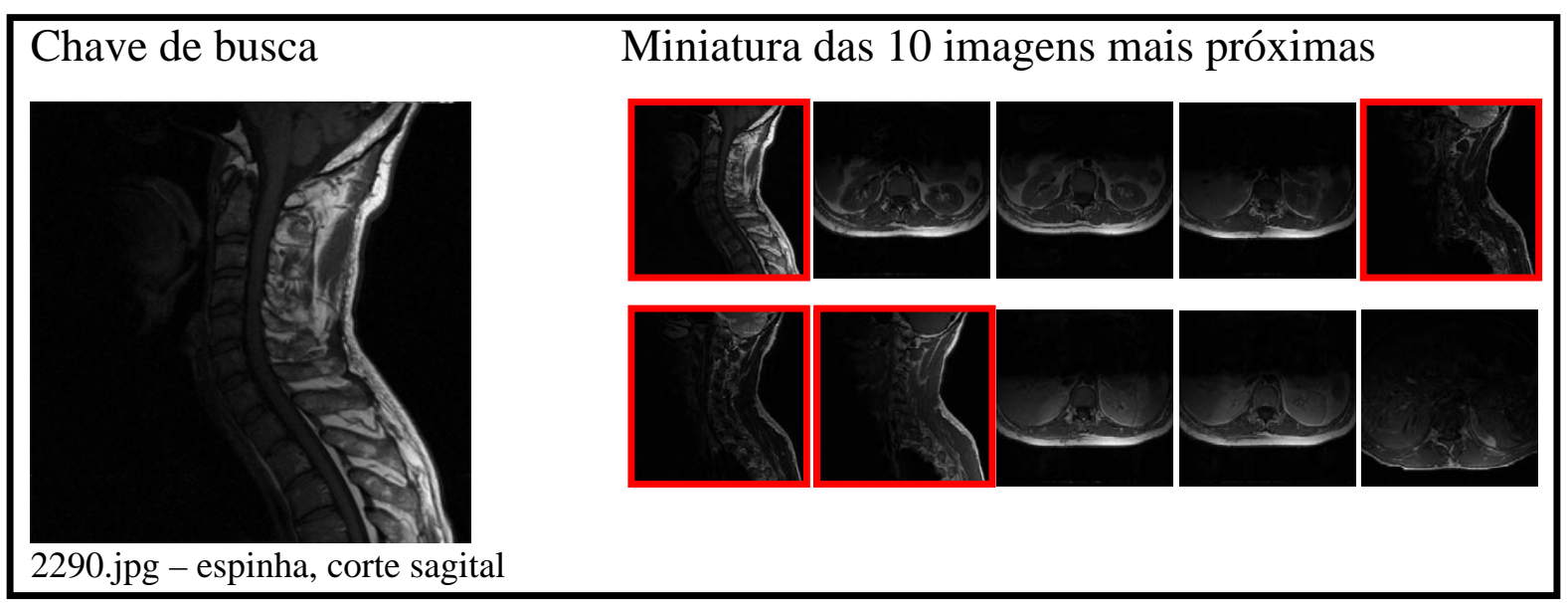

Figura 6.16: Consulta k-NN (K=10) usando histograma.
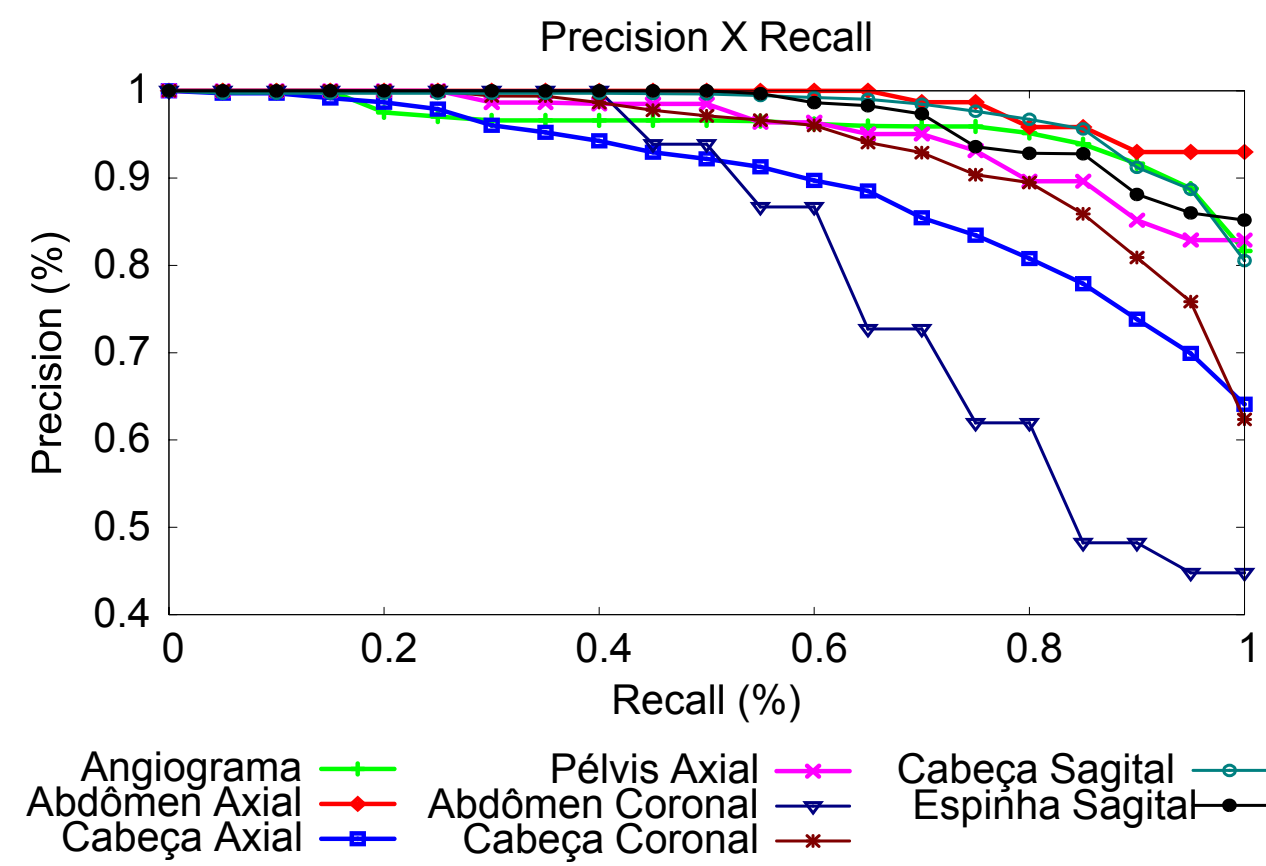

Pélvis Axial $* \quad$ Cabeça Sagital $\because-$ Abdômen Coronal $\rightarrow \quad$ Espinha Sagita $\bullet-$

Figura 6.17: Curvas médias de precision vs. recall de cada classe de imagem do método db1-4n. 


\subsection{Método 3 - Otimizando o método de Balan}

Como no método anterior (Seção 6.6) observou-se um bom desempenho na precisão das consultas realizadas sobre as imagens caracterizadas pelo subespaço de baixa freqüência, a próxima abordagem desenvolvida visa otimizar o método proposto por Balan (2007), aplicando uma transformada wavelet na fase de pré-processamento sobre as imagens.

\subsubsection{Proposta de Balan}

A proposta de Balan (2007) é representar as imagens extraindo medidas estatísticas de regiões obtidas pela segmentação da imagem, usando uma variação do método EM/MPM (Comer e Delp, 2000), o qual combina o algoritmo EM (Expectation and Maximization) para ajuste de um Modelo de Mistura Gaussiano (Gaussian Mixture Model) no histograma da imagem com um classificador baseado nos Campos Aleatórios de Markov que, essencialmente, incorpora o conceito de coerência espacial entre os pixels (Balan, 2007).

A variação está na aplicação da técnica de Annealing ao algoritmo de segmentação EM/MPM, de forma a aumentar gradativamente o valor do parâmetro de interação espacial do modelo de Markov $(\beta)$ durante a segmentação de uma imagem. Um maior detalhamento do algoritmo pode ser encontrado em Balan (2007).

A Figura 6.18 apresenta um exemplo do resultado da segmentação de imagem em quatro classes e background, usando o método de Balan. As regiões de textura obtidas também são mostradas separadamente para uma melhor visualização.

Depois de ter as imagens segmentadas pela textura em L classes, foram calculadas de cada região segmentada quatro medidas para sua representação: (1) a dimensão fractal (dimensão de correlação) $D_{2}$; (2) o centro de massa, ou centróide $x o$ e yo; (3) a massa, ou tamanho $m$; (4) e o nível de cinza médio $(\mu)$. Todas as medidas são valores reais e, sendo que o centróide da região é dado por duas coordenadas, cada região é representada por cinco valores reais. Como a região de plano de fundo (background) da imagem segmentada não é considerada na caracterização da imagem, o tamanho fixo do vetor de características proposto por Balan é definido por $5(L-1)$ valores reais, onde $L$ é o número de classes para segmentação. As características são agrupadas por região no vetor e dispostas conforme ilustrado na Figura 6.19.

Uma ordenação auxiliar é sempre realizada para garantir que os grupos de características de cada classe estejam ordenados pela característica de nível de cinza médio $\mu$. Ou seja, o primeiro grupo de cinco características no vetor está associado à classe de nível de cinza mais escuro, enquanto os demais grupos estão ordenados de maneira crescente de acordo com o nível médio de cinza correspondente. Esta ordenação é importante porque o nível de cinza médio em imagens de ressonância magnética, conforme já mencionado, 


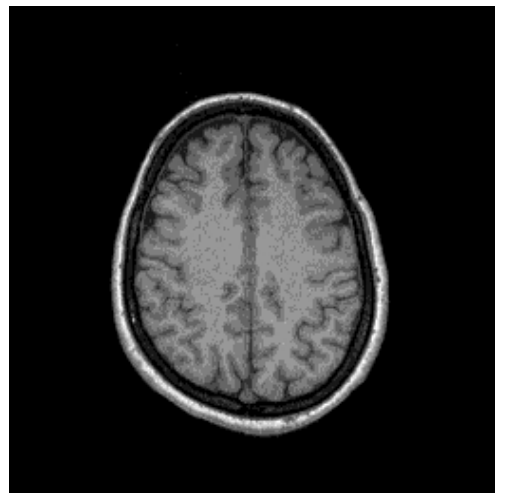

(a)

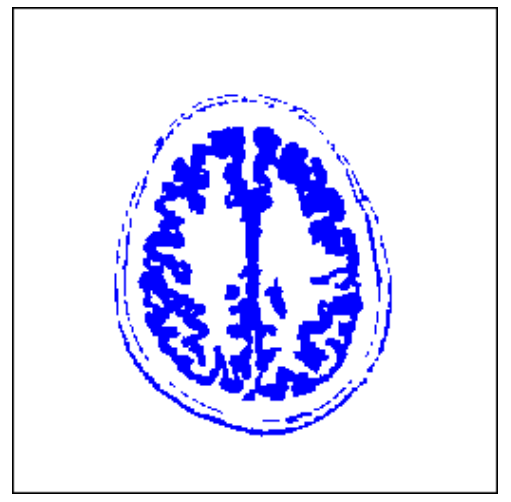

(d)

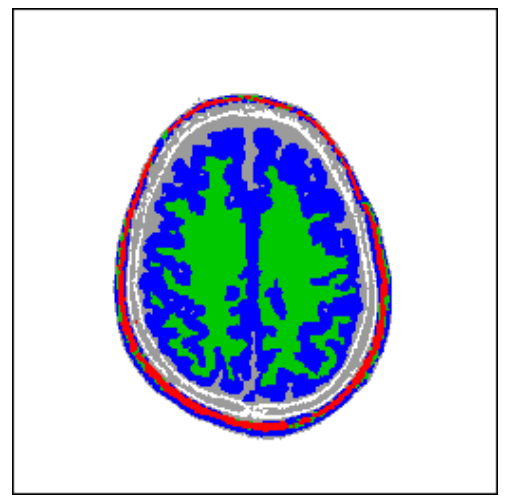

(b)

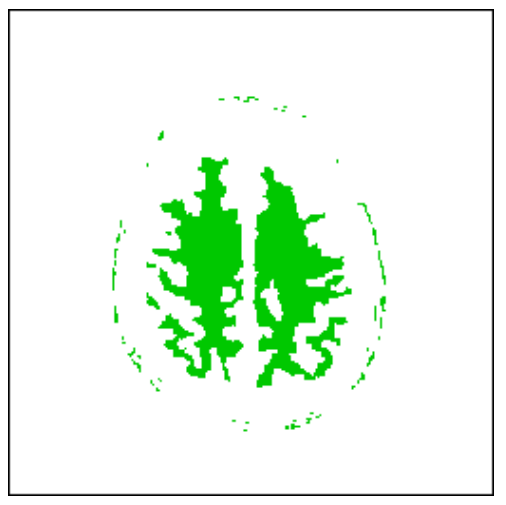

(e)

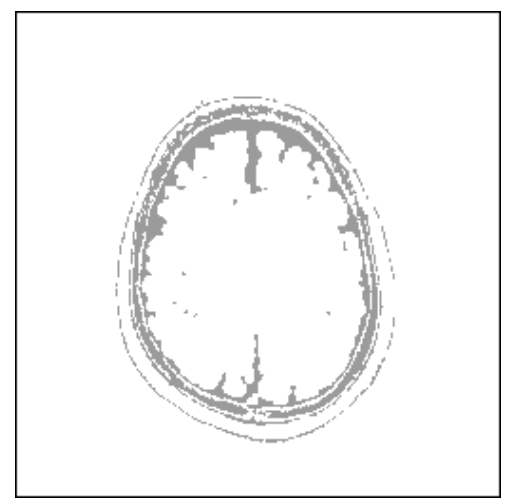

(c)

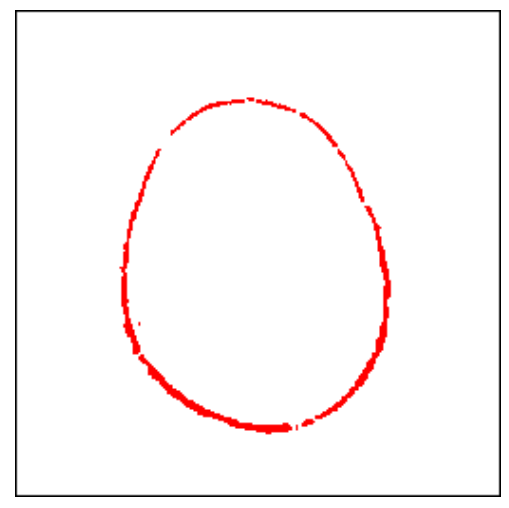

(f)

Figura 6.18: Exemplo de segmentação realizada pelo método de Balan (2007). (a) Imagem original; (b) imagem segmentada em 5 classes $(\mathrm{L}=5)$; (c) região de classe 1 (fluido cérebro-espinhal); (d) região de classe 2 (massa cinzenta); (e) região de classe 3 (massa branca); (f) região de classe 4 (dura, medula óssea, gordura).

está ligado à própria identificação dos tecidos na imagem. Assim, a ordenação dos grupos proporciona a correspondência das características com relação ao tecido que elas representam. Ainda que esta correspondência dos tecidos não ocorra entre imagens de categorias diferentes, cérebro e espinha, por exemplo, ela ainda é importante para manter o agrupamento no espaço vetorial das imagens similares de mesma categoria.

A função distância utilizada foi uma versão da distância Manhattan ponderada pela variância dos atributos da base de imagem. Denominada por $d_{W}$, a função distância para dois vetores de características $R$ e $S$, de tamanho $5(L-1)$ é definida por:

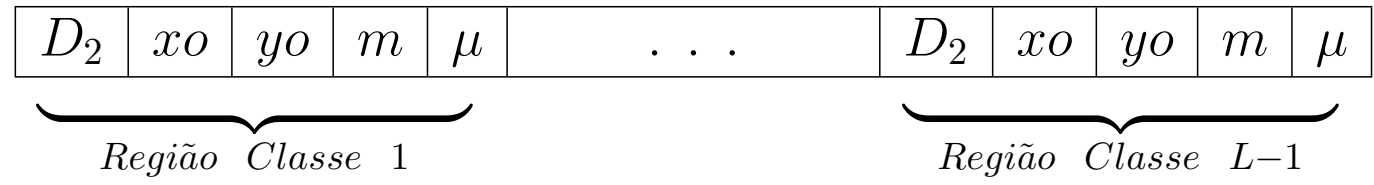

Figura 6.19: Vetor de características das imagens: $5(L-1)$ valores reais 


$$
d_{W}(R, S)=\sum_{i=1}^{5(L-1)} \frac{R_{i}-S_{i}}{\sigma_{i}^{2}}
$$

onde $\sigma_{i}^{2}$ é a variância da coluna de atributos $i$, para todo o conjunto de vetores de características da base de imagens.

\subsubsection{Otimizando o método de Balan}

O método proposto inicialmente é caro computacionalmente e custoso na parte que envolve segmentação das imagens. Para diminuir este custo, propomos então reduzir a dimensionalidade das imagens aplicando, antes da fase de pré-processamento, uma transformada wavelet por meio da análise de multiresolução, descrita anteriormente na Seção 3.6. Depois, o método de Balan é aplicado apenas sobre o thumbnail da imagem (subespaço de baixa freqüência) gerado pela transformada escolhida, para $L=5$ (número de classes para a segmentação). As wavelets usadas foram Coiflet (6 e 12), Symlet (3, 4 e 5), Haar e Daubechies $D_{4}$. Como pode ser visto na Seção 6.7.3, a redução de tempo chega a ser de $1 / 3$ do tempo inicial.

\subsubsection{Experimentos e resultados}

Foram feitos testes decompondo a imagem em 1 e 2 dois níveis de resolução. Aplicando apenas o método inicial, sem aplicar nenhuma transformada, obtemos, para uma base de 704 imagens de diferentes tipos de exames (ver Tabela 6.1) o gráfico da Figura 6.20.

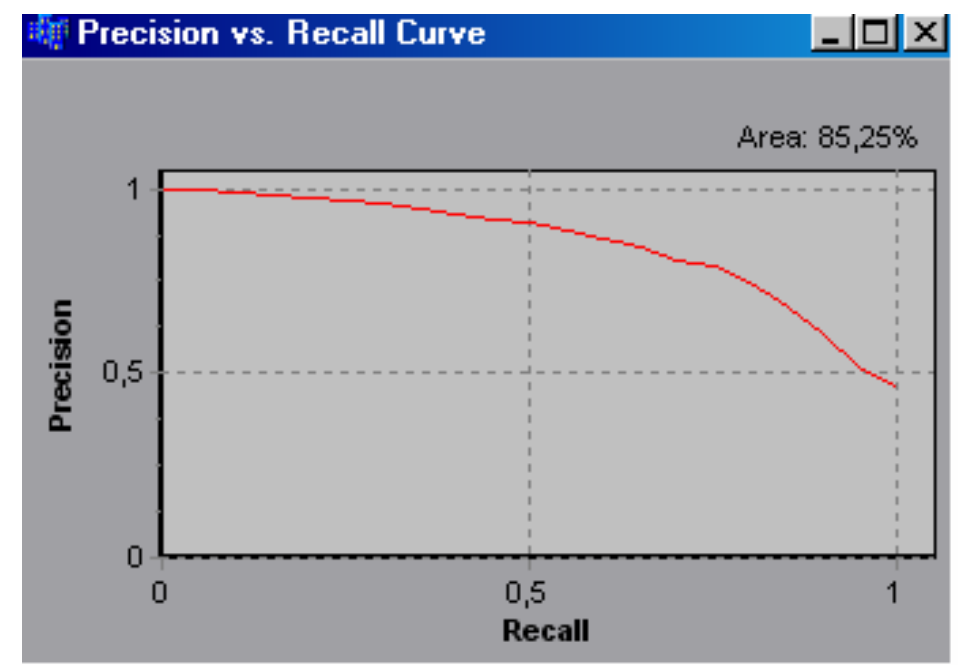

Figura 6.20: Gráfico de precision vs. recall gerado usando o método de Balan.

Note que a área abaixo do gráfico da Figura 6.20 é de 85,25\%. O tempo total de processamento de uma imagem é em média de 17,06 segundos. Aplicando as wavelets nas imagens e usando apenas o thumbnail gerado por elas para a aplicação do método, 
obteve-se como melhores resultados a utilização da wavelet Coiflet 12 , Symlet 5 e Daubechies 4 em 1 nível de decomposição, como pode ser visto na Tabela 6.3.

\begin{tabular}{|l|c|}
\hline $\begin{array}{l}\text { Wavelet/Método } \\
\text { Balan }\end{array}$ & Área (em \%) \\
\hline Balan & 85,25 \\
\hline Coiflet 6 - 1n & 75,7 \\
\hline Coiflet 12 - 1n & 80,99 \\
\hline Symlet 3 - 1n & 77,42 \\
\hline Symlet 4 - 1n & 79,62 \\
\hline Symlet 5 - 1n & 80,0 \\
\hline Haar - 1n & 76,63 \\
\hline Daubechies 4 - 1n & 80,76 \\
\hline Daubechies 4 - 2n & 68,26 \\
\hline
\end{tabular}

Tabela 6.3: Quadro resumo da análise dos gráficos de precision vs. recall do método que aplica transformada wavelet e o método proposto por Balan (2007).

Veja também o tempo médio de processamento de uma imagem para alguns métodos na Tabela 6.4. Considerando a aplicação das transformadas em um nível de resolução, observa-se que há uma redução de mais de 1/3 no tempo médio. E analisando a aplicação da wavelet de Daubechies-4 em 2 níveis de resolução, observa-se uma redução no tempo para quase $10 \%$ do tempo inicial.

\begin{tabular}{|l|c|}
\hline $\begin{array}{l}\text { Wavelet/Método } \\
\text { Balan }\end{array}$ & $\begin{array}{l}\text { Tempo } \\
\text { processamento (em } \\
\text { segundos) }\end{array}$ \\
\hline Balan & 17.0584 \\
\hline Coiflet $12-1 \mathrm{n}$ & 5.77 \\
\hline Symlet $5-1 \mathrm{n}$ & 5.11 \\
\hline Daubechies $4-1 \mathrm{n}$ & 4.858 \\
\hline Daubechies 4 - 2n & 1.74 \\
\hline
\end{tabular}

Tabela 6.4: Quadro de comparação do tempo médio de processamento.

\subsection{Método 4 - Extraindo características usando wavelets de Gabor}

Neste trabalho, a abordagem considerada na extração de características está baseada no trabalho de Ma e Manjunath (1996). O embasamento matemático desta técnica foi desenvolvida na Seção 3.8.1.

Além do vetor proposto por Ma e Manjunath (1996), como visto na Seção 3.8.2, os vetores propostos no presente trabalho foram gerados para diversos valores de escala $(S)$ e orientação $(K)$. Também caracterizou-se a região de textura pela medida de assimetria 
da distribuição de energia dos coeficientes da transformada (coeficiente skewness) e pela medida de achatamento (kurtosis), além da média $\mu_{m n}$ e do desvio padrão $\sigma_{m n}$.

$$
\begin{gathered}
\text { skewness }=\frac{\iint\left(\left|W_{m n}(x, y)\right|-\mu_{m n}\right)^{3} d x d y}{\sigma_{m n}^{3}} \\
\text { kurtosis }=\frac{\iint\left(\left|W_{m n}(x, y)\right|-\mu_{m n}\right)^{4} d x d y}{\sigma_{m n}^{4}}-3
\end{gathered}
$$

O número de atributos do vetor de características é dado por $S * K * F$, onde $S$ é o número de escalas, $K$ é o número de orientações e $F$ é o número de medidas a serem extraídas das texturas.

\subsubsection{Experimento 1 - Base de 704 imgens de ressonância magnética e angiograma}

De acordo com o trabalho de Ma e Manjunath (1996), para extrair características de textura por meio da wavelet de Gabor, são necessários os seguintes dados de entrada: número de escalas $(\mathrm{S})$, número de orientações $(\mathrm{K}), U_{l}$ e $U_{h}$ (o menor e o maior centro de freqüência de interessse). Aqui foram usados $U_{h}=0.4$ e $U_{l}=0.05$. Diversos valores de escala e orientação foram sugeridos e também várias medidas estatísticas foram extraídas de cada região de textura obtida. A Tabela 6.5 descreve os dados de cada vetor de características proposto.

Para cada teste executado, foi gerada uma curva média de precision vs. recall das consultas realizadas. Neste experimento, os vetores de características propostos foram testados extraindo características das imagens da base de ressonância magnética e angiograma de 704 imagens, descrita na Seção 6.3 (Tabela 6.1).

Para facilitar a análise dos gráficos, estes foram agrupados da seguinte maneira. No Gráfico 1, da Figura 6.21, foram plotados os gráficos dos testes 1, 2, 8, 9, 10, 12, 14 e 16, os quais possuem a característica do número de escalas ser menor que o número de orientações. O Gráfico 2, da Figura 6.22, representa as curvas médias de precision vs. recall dos testes $3,4,5$ e 18, nos quais o número de escalas é igual ao número de orientações. No Gráfico 3, da Figura 6.23, foram plotados os testes 6, 7, 11, 13, 15 e 17, nos quais o número de escalas é maior que o número de orientações. Os gráficos foram agrupados desta maneira para ser avaliada qual combinação de escala e orientação caracteriza melhor o grupo de imagens teste.

Analisando visualmente o Gráfico 1 (Figura 6.21), observa-se que as curvas médias de precision vs. recall dos testes 9 (64 atributos), 16 (60 atributos) e 1 (48 atributos) são equivalentes, mesmo estes possuindo quantidade diferente de atributos em seus vetores de características. Destes três, o teste 1 é o que possui menor número de atributos e representa o vetor de característica proposto por Ma e Manjunath (1996). Observa-se 


\begin{tabular}{|c|c|c|c|c|c|}
\hline Teste & Escala (S) & $\begin{array}{l}\text { Orientação } \\
\text { (K) }\end{array}$ & Características & \#Atributos & $\begin{array}{l}\text { Tempo médio } \\
\text { para extrair } \\
\text { características } \\
\text { de uma ima- } \\
\text { gem (segs.) }\end{array}$ \\
\hline 1 & 4 & 6 & $\mu, \sigma$ & 48 & 1.53 \\
\hline 2 & 2 & 4 & $\mu, \sigma$ & 16 & 0.54 \\
\hline 3 & 4 & 4 & $\mu, \sigma$ & 32 & 1.04 \\
\hline 4 & 3 & 3 & $\mu, \sigma$ & 18 & 0.6 \\
\hline 5 & 5 & 5 & $\mu, \sigma$ & 50 & 1.6 \\
\hline 6 & 4 & 3 & $\mu, \sigma$ & 24 & 0.79 \\
\hline 7 & 6 & 3 & $\mu, \sigma$ & 36 & 1.165 \\
\hline 8 & 3 & 6 & $\mu, \sigma$ & 36 & 1.16 \\
\hline 9 & 4 & 8 & $\mu, \sigma$ & 64 & 2.04 \\
\hline 10 & 3 & 4 & $\mu, \sigma$ & 24 & 0.79 \\
\hline 11 & 6 & 4 & $\mu, \sigma$ & 48 & 1.53 \\
\hline 12 & 3 & 5 & $\mu, \sigma$ & 30 & 0.99 \\
\hline 13 & 5 & 3 & $\mu, \sigma$ & 30 & 0.98 \\
\hline 14 & 4 & 5 & $\mu, \sigma$ & 40 & 1.28 \\
\hline 15 & 5 & 4 & $\mu, \sigma$ & 40 & 1.29 \\
\hline 16 & 5 & 6 & $\mu, \sigma$ & 60 & 1.97 \\
\hline 17 & 6 & 5 & $\mu, \sigma$ & 60 & 1.99 \\
\hline 18 & 6 & 6 & $\mu, \sigma$ & 72 & 2.41 \\
\hline 19 & 4 & 6 & $\mu, \sigma$, skew & 72 & 1.78 \\
\hline 20 & 3 & 8 & $\mu, \sigma$, skew & 72 & 1.81 \\
\hline 21 & 5 & 6 & $\mu, \sigma$, skew & 90 & 2.19 \\
\hline 22 & 4 & 4 & $\mu, \sigma$, skew & 48 & 1.24 \\
\hline 23 & 4 & 8 & $\mu, \sigma$, skew & 96 & 2.4 \\
\hline 24 & 4 & 6 & $\mu, \sigma$, skew, kur & 96 & 1.99 \\
\hline 25 & 3 & 4 & $\mu, \sigma$, skew, kur & 48 & 0.96 \\
\hline
\end{tabular}

Tabela 6.5: Testes realizados.

também que a curva do teste 14 está muito próxima da curva dos três testes citados acima, e este possui apenas 40 atributos, havendo uma redução na dimensionalidade do vetor de 37,5\%. Analisando agora as curvas dos testes 8, 12 e 10, vê-se que estão próximas, mas estão em ordem decrescente de precisão. Por fim, o teste 2 é o que apresenta um desempenho abaixo dos outros testes. Pode-se observar que a eficiência da precisão das buscas das imagens aos vizinhos mais próximos para estes testes está relacionada ao número de atributos que seus vetores de características possuem. Observa-se que o teste que possui melhor precisão é cujo o vetor de característica é composto por mais atributos, e o que possui menor precisão é cujo vetor possui menor número de atributos. A Tabela 6.6 apresenta em ordem decrescente de precisão os testes apresentados no gráfico da Figura 6.21. 


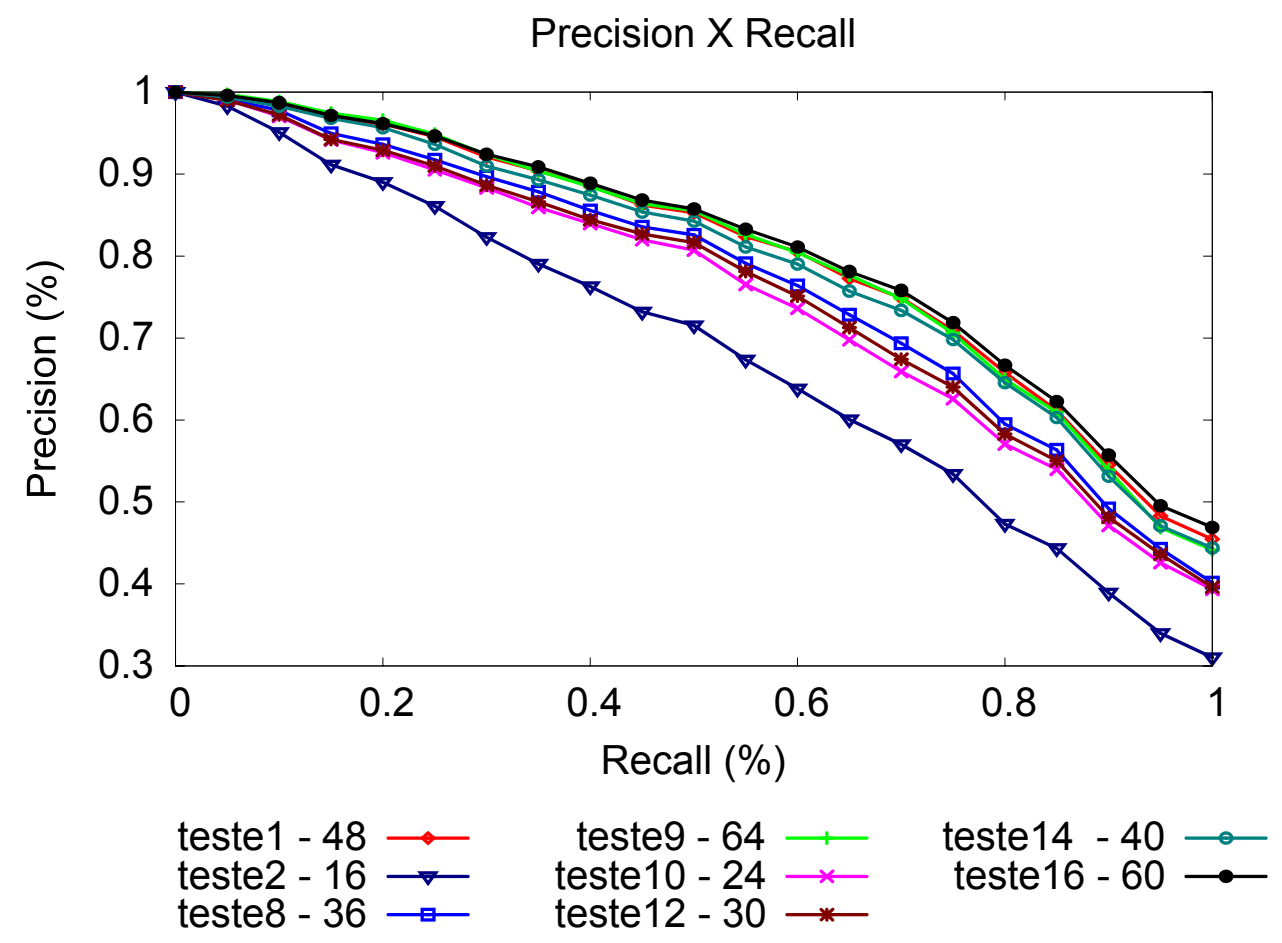

Figura 6.21: Gráfico 1: Curvas médias de precision vs. recall dos testes 1, 2, 8, 9, 10, 12, 14 e 16, descritos na Tabela 6.5.

O Gráfico 2 (Figura 6.22) apresenta as curvas médias de precision vs. recall dos testes 3, 4, 5 e 18, os quais possuem a característica do número de escalas ser igual ao número de orientações. O vetor de características do teste 18, com 72 atributos é o que melhor caracteriza as imagens e o teste 4, com 18 atributos, é o que pior as caracteriza. Pode-se observar que as curvas do teste 18 e do teste 5 são equivalentes, apesar do vetor de características do teste 5 possuir apenas 50 atributos. Assim, para um desempenho equivalente ao do teste 18 , pode-se caracterizar as imagens com um vetor de característica com a dimensionalidade 30,55\% menor! Como no Gráfico 1, da Figura 6.21, o desempenho das consultas também está relacionado com o número de atributos do

\begin{tabular}{|c|c|}
\hline Teste & \# Atributos \\
\hline 9 & 64 \\
\hline 16 & 60 \\
\hline 1 & 48 \\
\hline 14 & 40 \\
\hline 8 & 36 \\
\hline 12 & 30 \\
\hline 10 & 24 \\
\hline 2 & 16 \\
\hline
\end{tabular}

Tabela 6.6: Testes em ordem decrescente de precisão. 


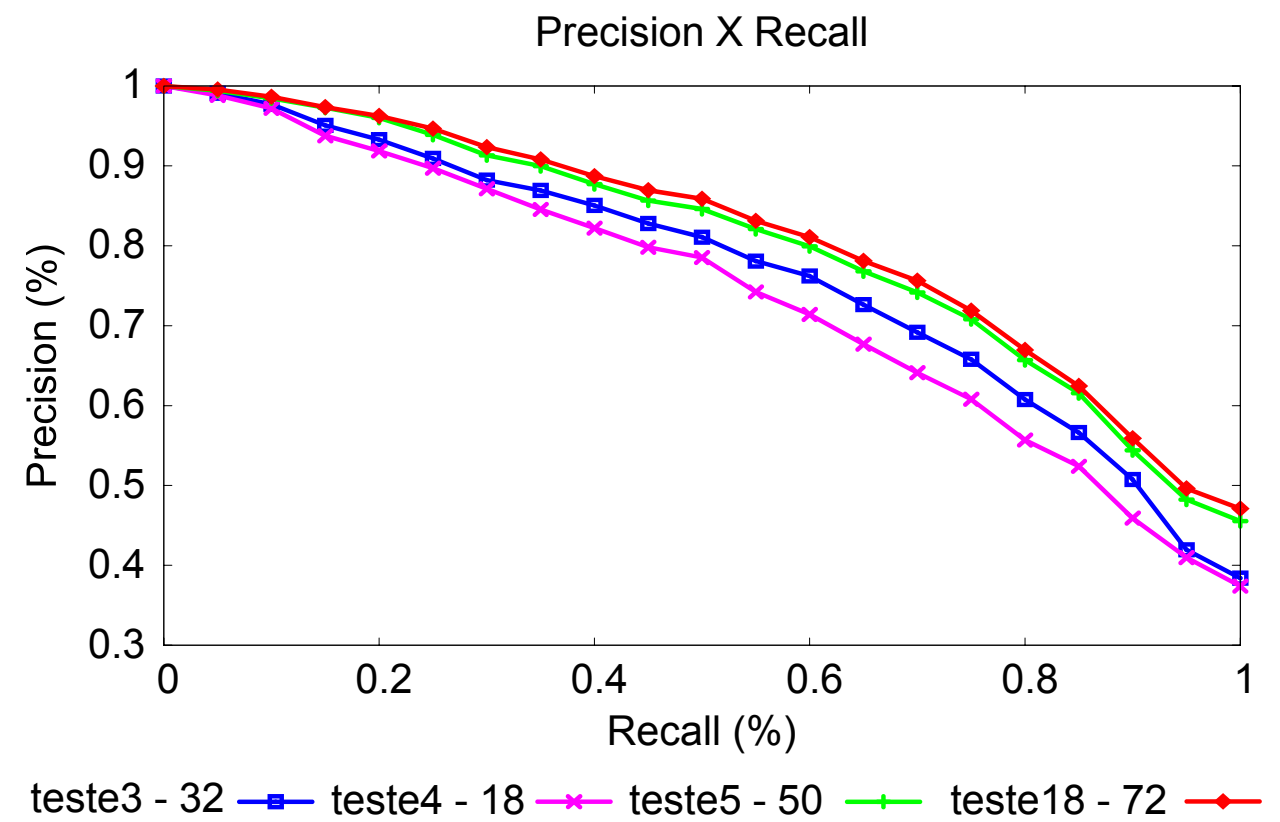

Figura 6.22: Gráfico 2: Curvas médias de precision vs. recall dos testes $3,4,5$ e 18 descritos na tabela 6.5 .

vetor de características. Quanto mais atributos compõem o vetor, maior é a precisão das consultas.

Já no gráfico da Figura 6.23 é observado que o vetor do teste 17 é o que melhor caracteriza as imagens deste gráfico. Depois, os gráficos dos testes 11 (com 48 atributos) e 15 (com 40 atributos) podem ser ditos equivalentes, sendo que o vetor do teste 15 representa uma redução na dimensionalidade em relação ao vetor do teste 11 de 16,67\%. As curvas de precision vs. recall dos testes 7 e 13 também podem ser consideradas equivalentes, com uma redução de dimensionalidade do segundo em relação ao primeiro também de 16,67\%. E por fim, a curva do teste 6 está bem próxima das curvas dos testes 7 e 13, sendo que possui apenas 24 atributos, ou seja, sua precisão é muito próxima da precisão obtida pelo teste 7 , e com uma redução de dimensionalidade em relação ao teste 7 de 33,33\%. A precisão das consultas deste gráfico também está relacionada com o número de atributos dos vetores. Quanto maior o número de atributos do vetor, maior é a precisão da busca das imagens por conteúdo. A ordem decrescente de precisão dos testes é mostrada na Tabela 6.7.

O gráfico da Figura 6.24 plota dois a dois as curvas médias de precision vs. recall dos Gráficos 1 e 3, considerando os valores de escala e orientação. Seja o valor da escala $s$ e da orientação $o$. Então, a curva apresentada em vermelho, referente ao Gráfico 1 possuirá o par ordenado $(s, o)$, no qual a abscissa é o valor da escala e a ordenada é o valor da orientação. A curva em azul, referente ao Gráfico 3, terá o par ordenado $(o, s)$. Note que as curvas são praticamente equivalentes e possuem o mesmo número de atributos. Entretanto, as curvas em vermelho apresentam um pequeno ganho em relação à curva azul. 


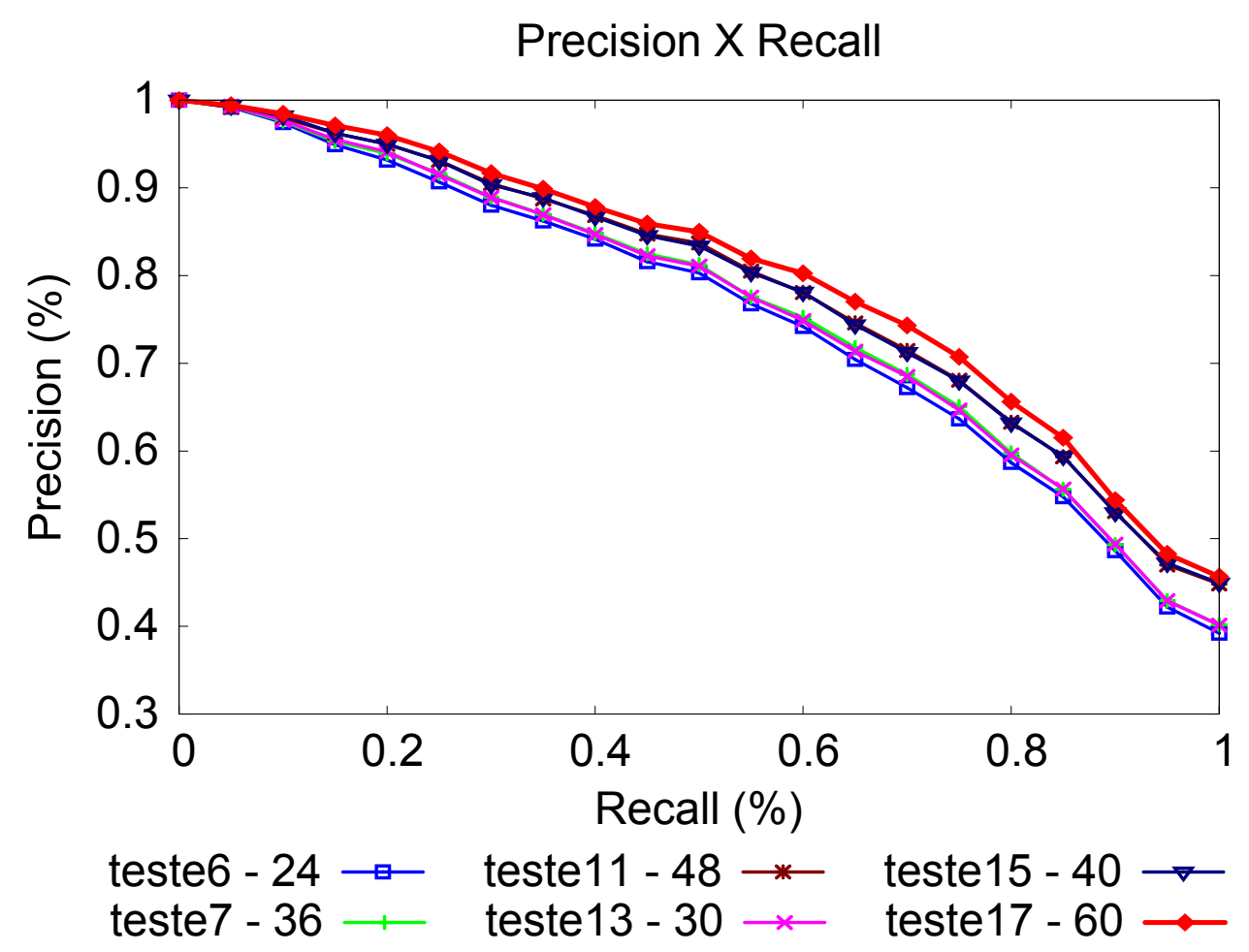

Figura 6.23: Gráfico 3: Curvas médias de precision vs. recall dos testes $6,7,11,13,15$ e 17 descritos na Tabela 6.5.

\begin{tabular}{|c|c|}
\hline Testes & \# Atributos \\
\hline 17 & 60 \\
\hline 11 & 48 \\
\hline 15 & 40 \\
\hline 7 & 36 \\
\hline 13 & 30 \\
\hline 6 & 24 \\
\hline
\end{tabular}

Tabela 6.7: Testes em ordem decrescente de precisão. 
Assim, pode-se concluir que para estes testes realizados, obtemos um melhor desempenho nas consultas cujas imagens são caracterizadas por filtros de Gabor que combinam um número maior de orientações que escalas $(s<o$ - número de escalas menor que o número de orientações). Quantitativamente, no gráfico da Figura 6.24 que apresenta as curvas do teste 1 e do teste 11, o ganho de precisão da curva vermelha em relação à azul é de até $4,8 \%$.
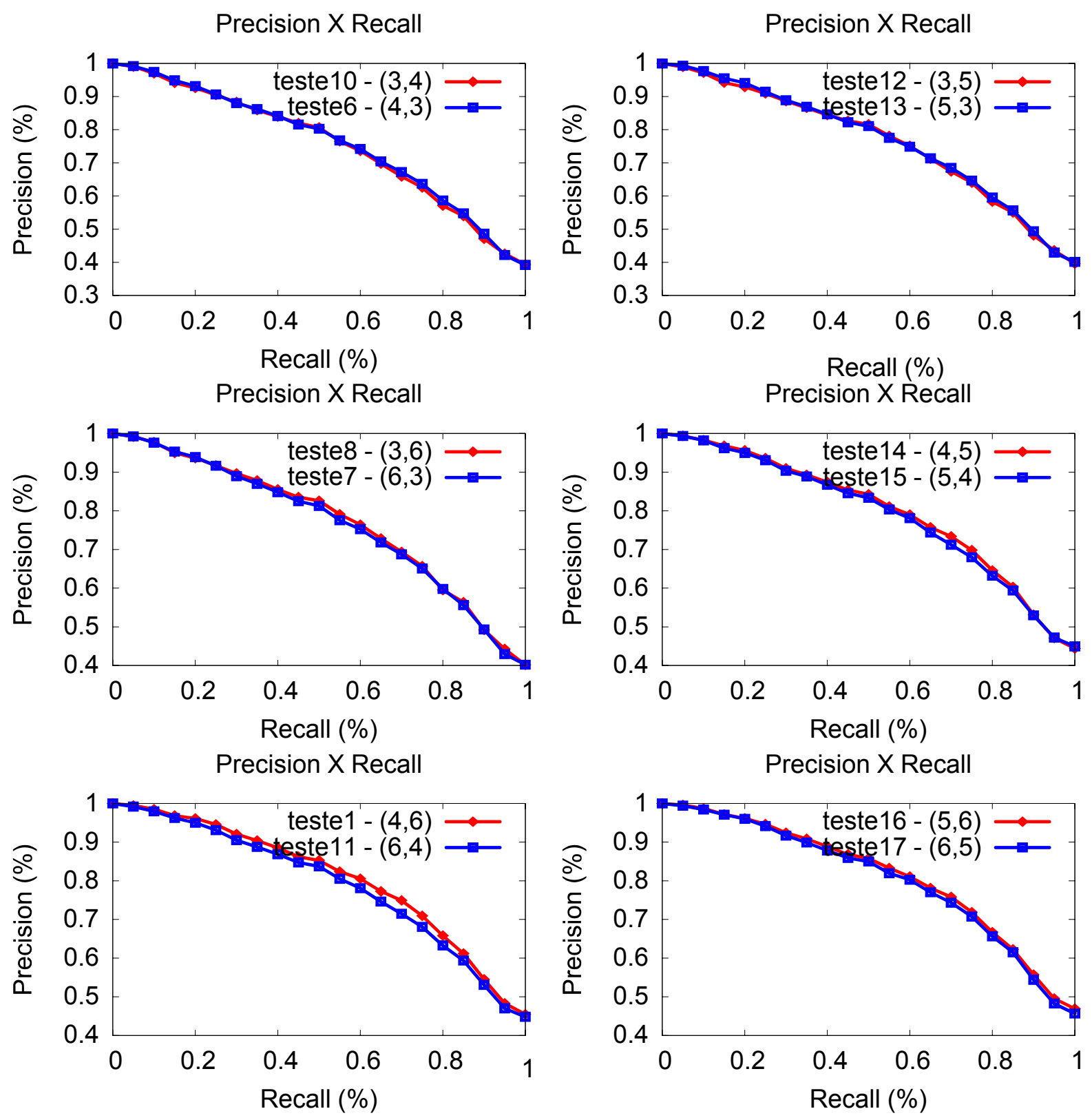

Figura 6.24: Várias curvas de precision vs. recall.

Como vimos que para a maioria dos vetores propostos obtemos uma melhor precisão nas consultas cujos vetores são gerados com $s<o$, então dos vetores que também possuem as medidas skewness (Equação 6.2) e kurtosis (Equação 6.3) são usadas apenas entradas do tipo $s<o$, como pode ser visto na Tabela 6.5, para os testes 19 a 25 . O Gráfico 4 da 
Figura 6.25 apresenta as curvas médias de precision vs. recall dos testes 19 a 23, cujos vetores de características são compostos pela média, pelo desvio padrão e pela medida skewness. Já o Gráfico 5 da Figura 6.26 apresenta as curvas médias de precision vs. recall dos testes 24 e 25, cujos vetores de características são compostos pela média, pelo desvio padrão e pelas medidas skewness e kurtosis de cada região de textura obtida.

Na Figura 6.25, pode-se dizer que as curvas médias dos testes 23, 21 e 19 são equivalentes para consultas que pedem até $70 \%$ das imagens mais semelhantes. O número de atributos de cada teste é, respectivamente, 96, 90 e 72. Ou seja, é possível ter uma precisão equivalente entre os testes 23 e 19 sendo que o vetor de características do teste 19 é $25 \%$ menor que o vetor do teste 23 (com 96 atributos). Observa-se também que, apesar dos testes 19 e 20 possuirem o mesmo número de atributos em seus vetores de característica, suas curvas médias de precision vs. recall não são equivalentes. Assim, podemos concluir, a partir desta observação e de observações anteriores que a combinação adequada da escala e orientação para extrair texturas e a escolha das medidas estatísticas é de grande importância para a representação das imagens da base de ressonância magnética e angiograma. Com a combinação certa é possível ter uma caracterização das imagens de forma a obtermos grande precisão nas curvas de precision vs. recall com uma baixa dimensionalidade dos vetores de características.
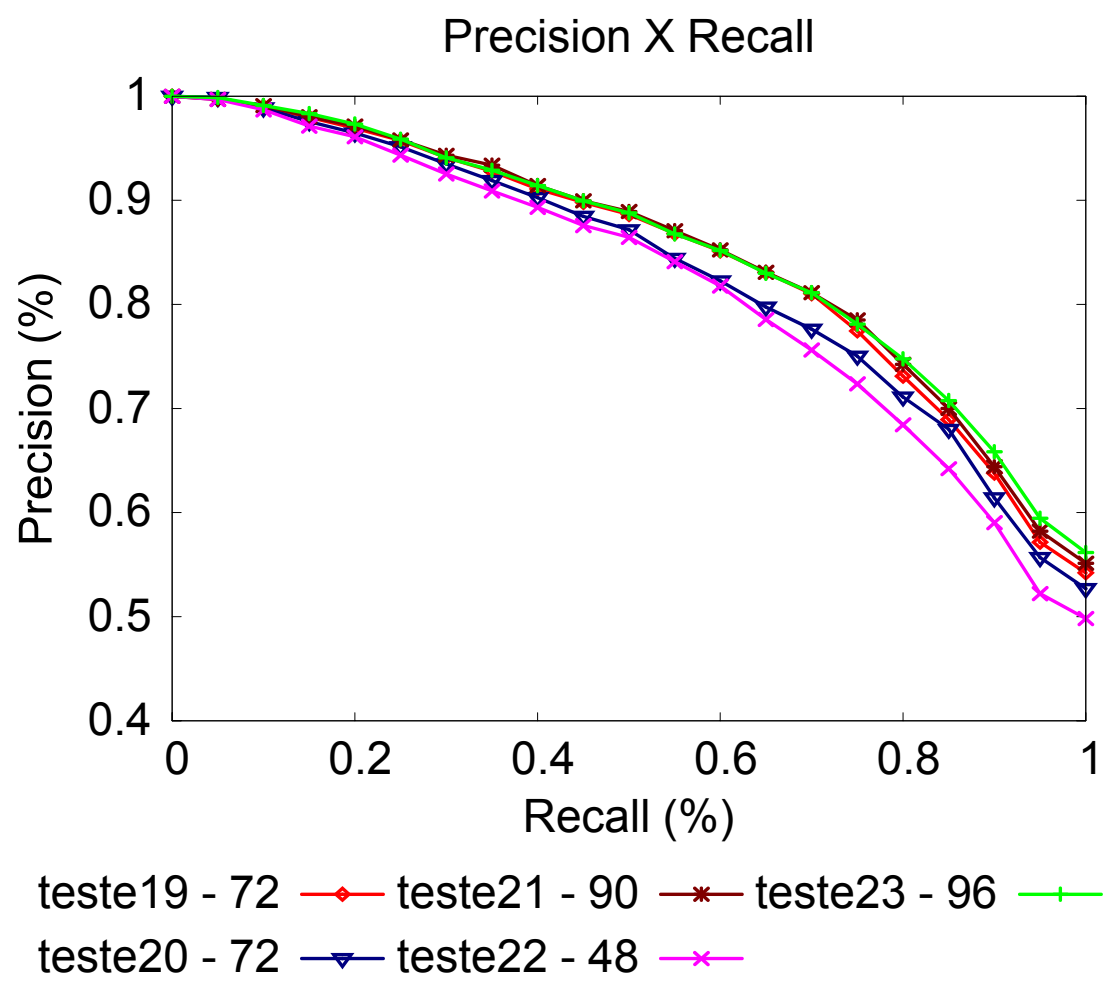

Figura 6.25: Gráfico 4: Curvas médias de precision vs. recall dos testes 19, 20, 21, 22 e 23 descritos na Tabela 6.5 .

No Gráfico 5, da Figura 6.26, além dos testes 24 e 25, também estão os testes 21 e 23, que possuem como características: média, desvio padrão e skewness; e o teste 1, com 
apenas média e desvio padrão. Os testes 1 e 25 possuem o mesmo número de atributos, mas o teste 1 possui uma precisão maior nas consultas. Note também que os testes 21 e 23, que possuem um número igual ou maior de atributos também possuem uma maior precisão nas consultas do que o teste 24 apresenta. Daí concluimos que ao inserir a medida de kurtosis das regiões de textura extraída das imagens o desempenho das consultas decai. Ou seja, vetores de características que usam momentos de ordem maior, para esta base de imagens, não justificam a complexidade adicional.

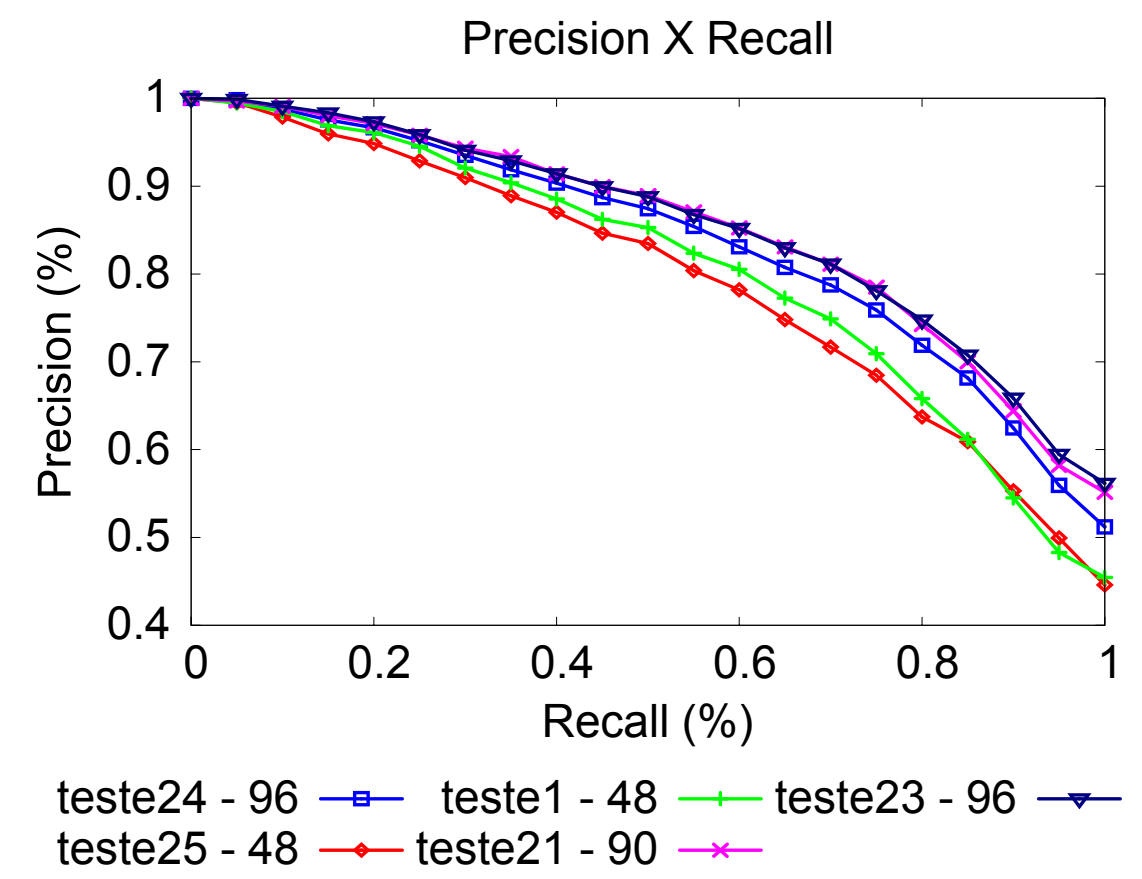

Figura 6.26: Gráfico 5: Curvas médias de precision vs. recall dos testes 24 e 25 descritos na Tabela 6.5 .

Considerando o número de atributos do vetor de características e precisão das consultas realizadas, escolhemos as melhores curvas médias de precision vs. recall dos gráficos vistos e plotamos no gráfico da Figura 6.27. Além desses, foi plotado também o resultado considerando o vetor de características proposto por Castañón (2002), o qual usa como parâmetros $U_{h}=0.3, U_{l}=0.04, S=2$ e $K=6$. Para uma melhor visualização, vamos considerar dos gráficos equivalentes, os que possuem menos atributos. Analisando o gráfico, vemos que são equivalentes: testes 16 (com 60 atributos) e 18 (com 72 atributos) e testes 1 (48 atributos), 5 (com 50 atributos) e 17 (60 atributos). Então, vamos considerar os testes 16 e 1 . Além disso, analisando os testes 14 e 15, vemos que ambos possuem 40 atributos, mas a curva média de precision vs. recall do teste 14 é melhor que a do teste 15; portanto, consideremos apenas o teste 14. Também vamos considerar o teste 19 (com 72 atributos), que foi o que apresentou melhor curva média de precision vs. recall, o vetor proposto por Castañón (com 24 atributos) e o teste 10, o qual possui o mesmo número de atributos que o vetor de características de Castañón. O novo gráfico é mostrado na Figura 6.28. 


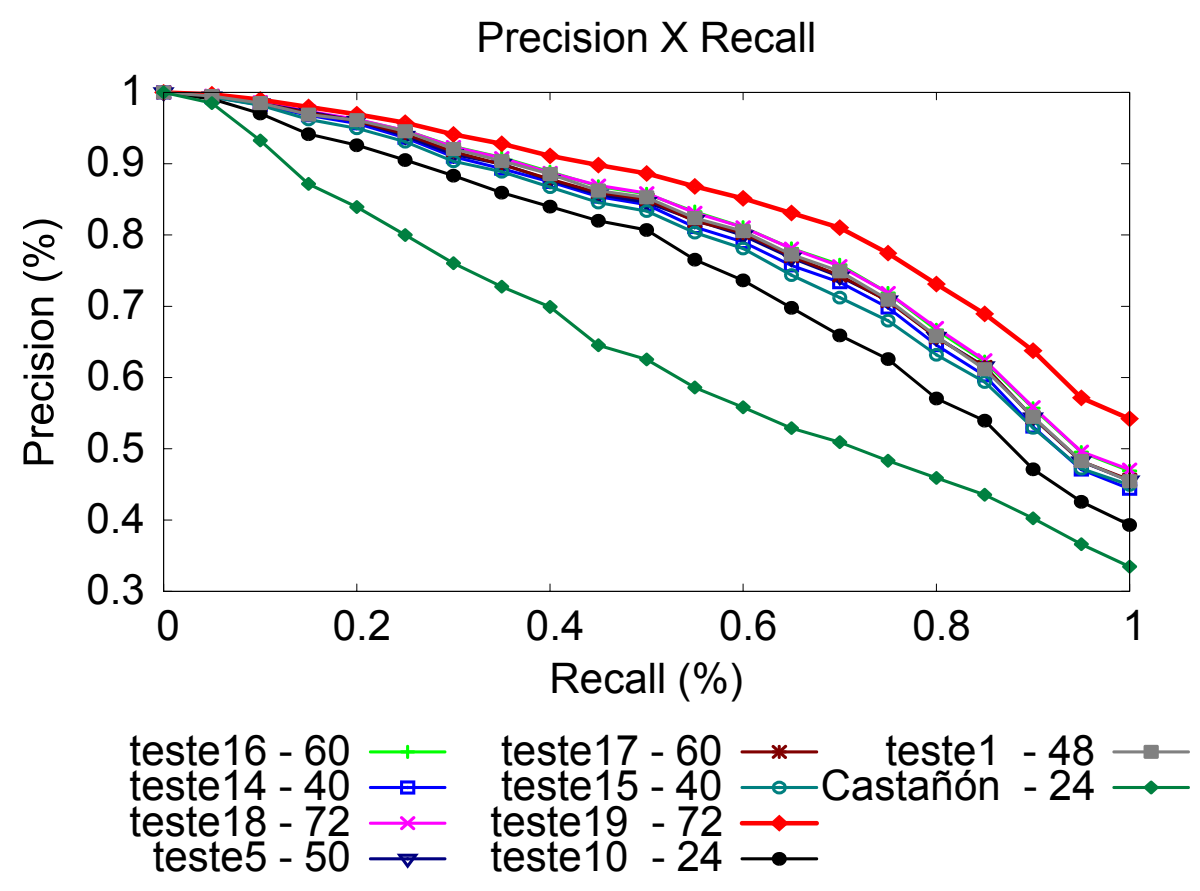

Figura 6.27: Curvas médias de precision vs. recall dos testes 16, 14, 18, 5, 17, 15, 19, 10, 1 e vetor de Castañón descritos na Tabela 6.5.

Analisando o gráfico da Figura 6.28, dos vetores de características propostos neste experimento, o que apresentou melhor curva média de precision vs. recall foi o teste 19, com 72 características, gerados pelos parâmetros $S=4, K=6$ e com as medidas estatísticas média, desvio padrão e skewness. Podemos notar também que as curvas de precision vs. recall dos métodos propostos são melhores que a curva gerada pelo método de Castañón. O teste 19 chega a ter um ganho de até $62 \%$ sobre o método de Castañón. Observe também que o valor de precisão é acima de $80 \%$ para valores de revocação de até $75 \%$ da base. A Figura 6.29 ilustra uma consulta k-NN aos 10 vizinhos mais próximos com o teste 19. Note que todas imagens retornadas são relevantes.

Para uma análise qualitativa, a Figura 6.30 mostra as curvas médias de precision vs. recall do teste 19 para cada categoria de imagem. Podemos observar que as classes melhores representadas neste teste são Pélvis Axial, Angiograma, Abdômen Axial, Cabeça Sagital e Espinha Sagital, as quais apresentam uma precisão acima de $80 \%$ para consultas que pedem até $65 \%$ da base de imagens. As três primeiras categorias citadas (Pévis Axial, Angiograma e Abdômen Axial) apresentam uma precisão de acima de 90\% para consultas que pedem até $80 \%$ das imagens.

O algoritmo StARMiner foi aplicado sobre a base de 704 imagens selecionando um total de 56 características, ou seja, reduziu de 72 para $56(22,22 \%)$ o tamanho do vetor de características. No gráfico da Figura 6.31 temos as curvas de precision vs. recall obtidas usando as 72 características iniciais do teste 19 e usando as 56 características selecionadas pelo algoritmo StARMiner. Analisando o gráfico da Figura 6.31, é possível observar que a redução de $22,22 \%$ da dimensionalidade obtida pelo algoritmo StARMiner 


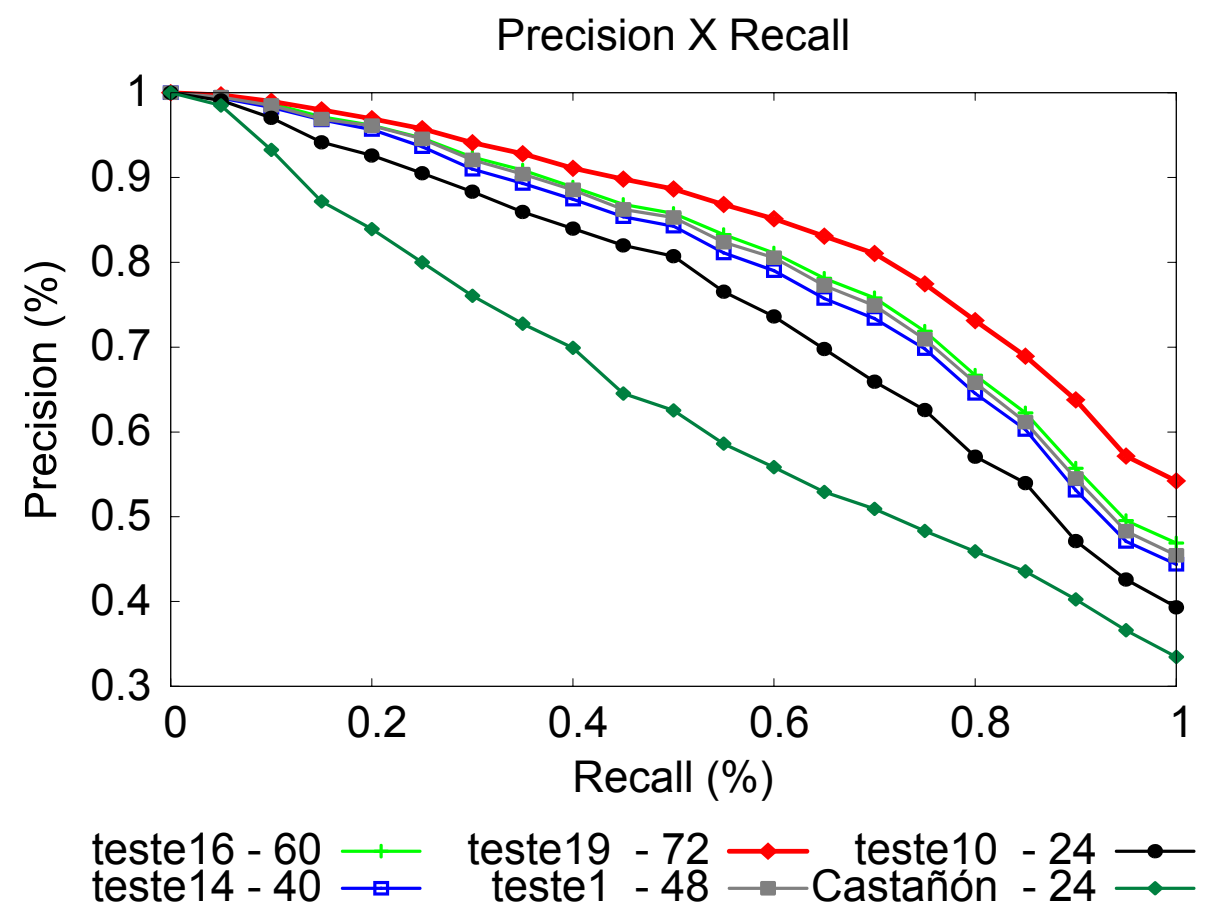

Figura 6.28: Curvas médias de precision vs. recall dos testes 16, 14, 19, 10, 1 e vetor de Castañón descritos na Tabela 6.5.

\begin{tabular}{|c|c|c|c|c|c|}
\hline Teste & $\begin{array}{c}\text { Escala } \\
\text { (S) }\end{array}$ & $\begin{array}{c}\text { Orientação } \\
\text { (K) }\end{array}$ & Características & \# Atributos & $\begin{array}{c}\text { Tempo médio para } \\
\text { extrair características } \\
\text { de uma imagem } \\
\text { (segs.) }\end{array}$ \\
\hline 26 & 4 & 6 & $\mu, \sigma$ & 48 & 1.69 \\
\hline 27 & 4 & 6 & $\mu, \sigma$, skewness & 72 & 1.80 \\
\hline
\end{tabular}

Tabela 6.8: Testes realizados.

aproximadamente mantém os mesmos valores de precisão das buscas por conteúdo. Isso indica que o algoritmo StARMiner é adequado para reduzir a dimensionalidade de imagens médicas, reduzindo a complexidade das buscas e mantendo a precisão dos resultados.

\subsubsection{Experimento 2 - Base de 103 imagens de mamografia}

O segundo experimento com wavelets de Gabor foi representar as imagens da base de imagens mamográficas (Tabela 6.2, Figura 6.3) por meio do vetor de características proposto na Seção 3.8.2. Como descrito na Seção 6.3, a semelhança entre as imagens adotada neste trabalho é de acordo com a classificação BI-RADS.

Foram testados dois vetores de características para esta base de imagens: o vetor proposto por Ma e Manjunath (1996) e o vetor que obtivemos como melhor resultado na Seção 6.8.1. A Tabela 6.8 descreve os dados de cada vetor de características proposto.

Analisando o gráfico da Figura 6.32, observa-se que a representação das imagens com esses vetores não é tão boa quanto a caracterização das imagens de ressonância magnética 


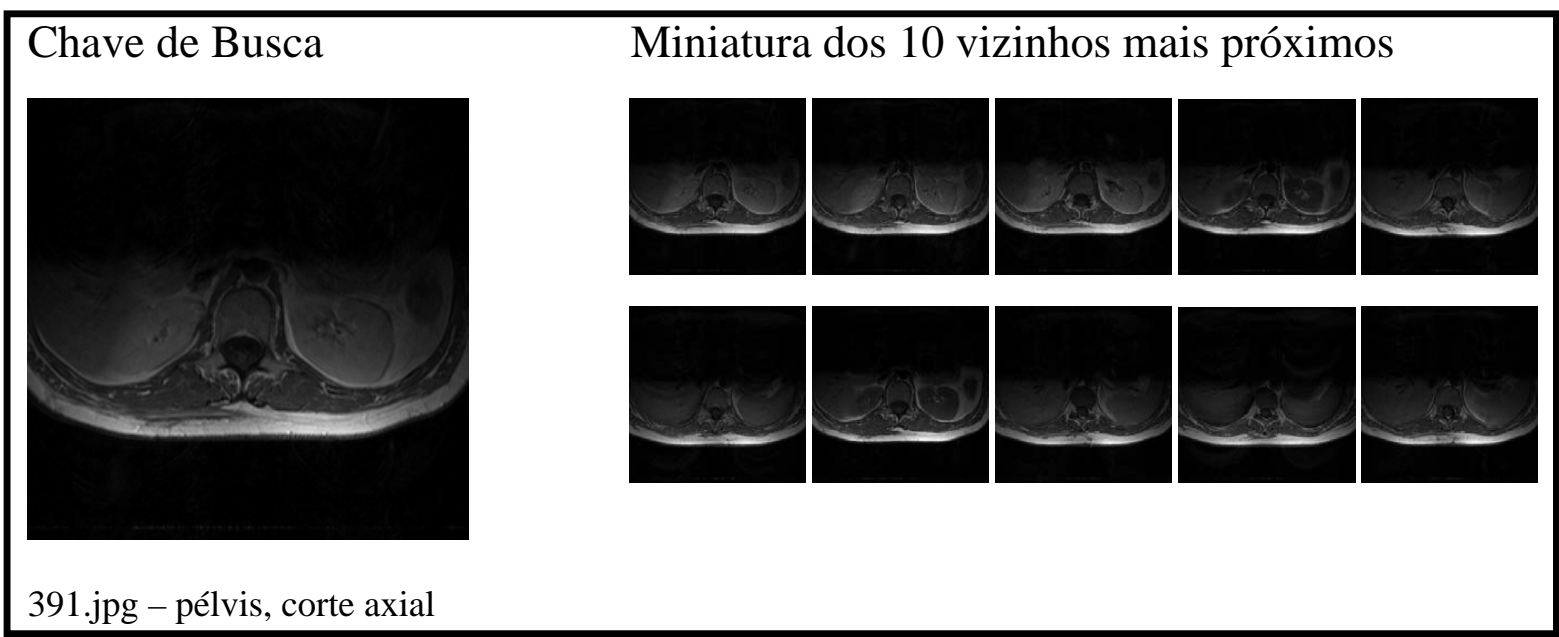

Figura 6.29: Exemplo de consulta k-NN (K=10).
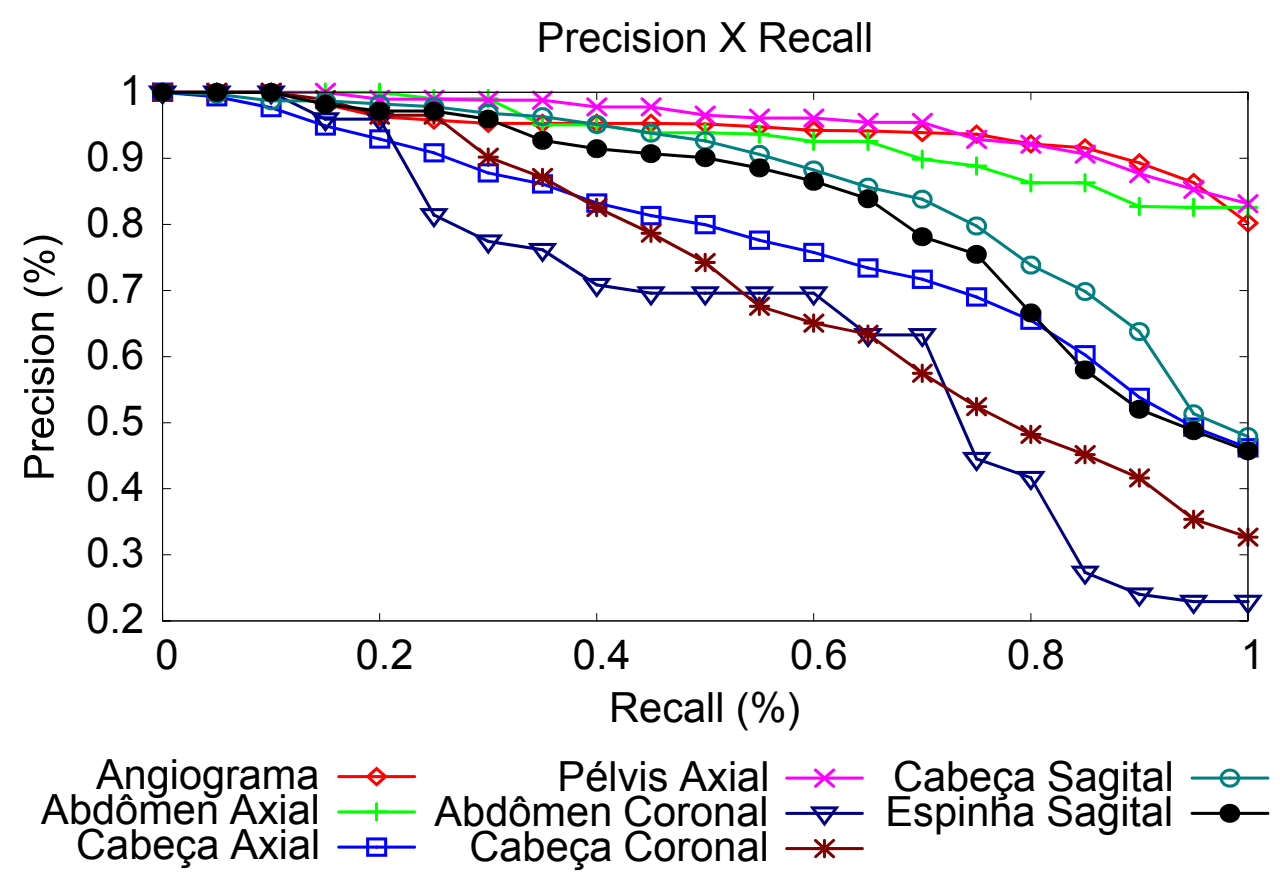

Figura 6.30: Curvas médias de precision vs. recall de cada categoria de imagem. 


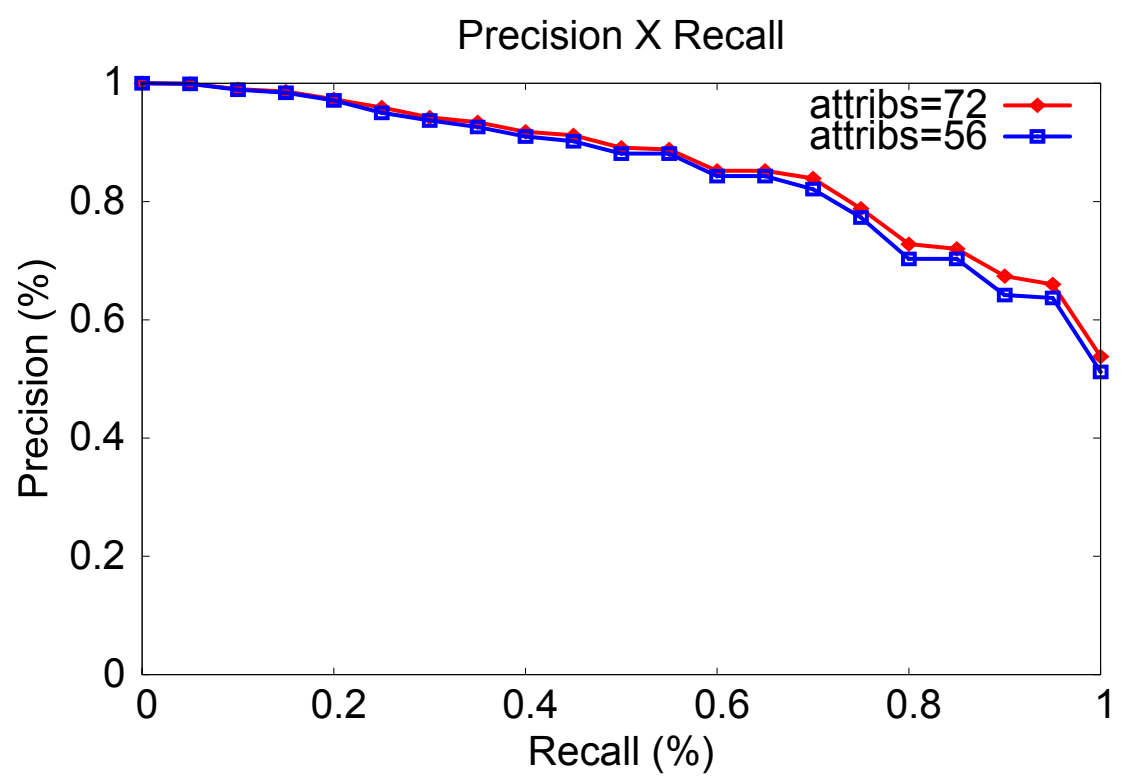

Figura 6.31: Curvas médias de precision vs. recall obtidas usando o vetor original do teste 19 com 72 atributos e o vetor de 56 características selecionadas pelo algoritmo StARMiner.

e angiograma de coração. Note que para as consultas que pedem até $20 \%$ da base de imagens, o decaimento do gráfico é brusco, indicando que as imagens que deveriam ser mais semelhantes não pertenciam à mesma categoria de imagens de acordo com a classificação BI-RADS. Depois a curva permanece constante. Porém, quando comparamos com a curva de Histograma, o teste 26 tem um ganho de até 23,33\% e o teste 27 de até $22,15 \%$.

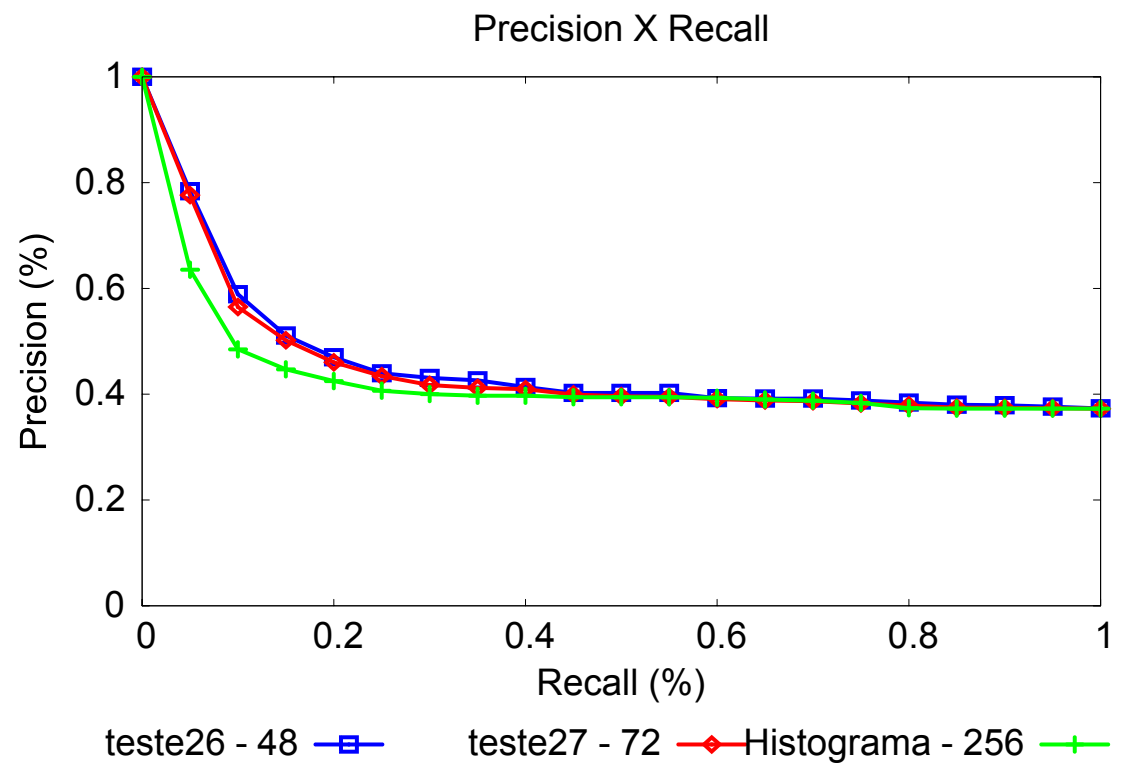

Figura 6.32: Gráfico 6: Curvas médias de precision vs. recall dos testes 26 e 27. 


\subsection{Considerações finais}

Neste capítulo foram apresentadas novas abordagens de extração de características de imagens médicas usando wavelets, para realização de consultas por similaridade em sistemas CBIR. Das wavelets usadas, obtivemos excelentes resultados com a wavelet de Daubechies e com a wavelet de Gabor. Para o Método 1, conseguimos representar bem as imagens médicas com um vetor de características de apenas 10 atributos. Já no Método 2, obtivemos um vetor de características com apenas 16 atributos que gerou como resultado precisão nas buscas realizadas nos experimentos de mais de $90 \%$ para consultas que pediram até $70 \%$ das imagens da base.

Além disso, usamos as wavelets para compressão de imagens e assim otimizar o método proposto por Balan (2007). Também usamos as wavelets de Gabor para caracterizar imagens de mamografia, obtendo um ganho de até $23 \%$ em relação às consultas usando Histograma. É também importante ressaltar a aplicação do algoritmo StARMiner sobre os vetores com 72 características gerados pela transformada wavelet de Gabor, reduzindo a dimensionalidade em $22,22 \%$ do vetor. 


\section{Capítulo 7 \\ Conclusões}

Dos elementos que compõem um sistema CBIR, a extração de características de imagens é uma das tarefas que apresenta os maiores desafios, que estão principalmente relacionados à grande barreira que divide o funcionamento do cérebro humano do computador que ele mesmo criou. Este divisor, que pode ser considerado a fonte do problema conhecido como gap semântico, é o resultado da tentativa de fazer a máquina servir não só como um simples processador de números, mas também como um simulador da percepção humana. É o anseio de minimizar de alguma forma essa barreira que motiva a integração de diversas áreas de conhecimento científico, e faz com que um número cada vez maior de pesquisadores se dediquem a estudar e desenvolver algoritmos e técnicas para a recuperação de informação por conteúdo (Balan, 2007).

Neste trabalho, o tema de recuperação baseada em conteúdo é abordado para o domínio de imagens médicas. O tema principal é a extração de características para representação sucinta do conteúdo visual das imagens, visando estabelecer medidas que possibilitem inferir computacionalmente níveis de similaridade. Neste trabalho foram estudadas técnicas de extração de características em imagens por meio da transformada wavelet. Foram abordados três enfoques, sendo que o primeiro foi sobre técnicas de caracterização de imagens aproveitando os espaços de wavelet gerados após aplicar os filtros de wavelet, para assim, mediante medidas estatísticas desses espaços, montar o vetor de características. O segundo enfoque foi caracterizar as imagens com o subespaço de baixa-freqüência gerado após aplicar os filtros de wavelet.

No primeiro método utilizamos a transformada wavelet Daubechies 4 e a energia dos subespaços gerados para caracterizar as imagens. Para o segundo método, várias 
wavelets foram aplicadas sobre as imagens a fim de caracterizar as mesmas por meio do subespaço de baixa freqüência. Procuramos encontrar a wavelet que melhor caracterizava as imagens com o menor número de características em seu vetor, através de maiores níveis de decomposição da imagem. O terceiro método focou na propriedade de compressão de imagens que as wavelets possuem, otimizando assim o método proposto por Balan (2007). Por fim, no quarto método foram aplicados filtros de Gabor, os quais permitem modelar o comportamento das células do córtex visual humano. As funções Gabor podem ser moduladas mediante mudanças na orientação e escala dos filtros, os quais geram subespaços transformados que contém micro-características que podem ser usadas para mapear a informação de textura da imagem.

Como parte final do trabalho, foram realizados testes práticos para verificação da eficiência do método. Estes testes foram realizados por meio de consultas aos vizinhos mais próximos ( $k$-Nearest Neighbor Queries, $k$-NNQ) sobre um conjunto de imagens médicas. Os resultados foram medidos e quantificados por meio de gráficos de precision e recall, que fornecem uma indicação gráfica da eficiência do método. Os resultados obtidos foram satisfatórios, pois a maioria das imagens retornadas como sendo mais similares, pertenciam à mesma classe da imagem de entrada.

\subsection{Principais Contribuições}

As principais contribuições deste trabalho estão descritas a seguir.

- Ampliou-se o domínio de extratores de características de imagens médicas a serem incluídas no sistema cbPACS, permitindo ter um novo domínio de espaço de características baseados na transformada wavelets.

- Extensão do vetor de características proposto por Castañón (2002), o qual extrai a energia dos subespaços gerados pela wavelet mãe, em três níveis de decomposição. Nossa proposta foi considerar também o subespaço de baixa freqüência, com a qual obtivemos um ganho na precisão das consultas;

- Explorou-se o subespaço de baixa-freqüência gerado pelas transformadas wavelets, obtendo um vetor de características compacto de apenas 16 atributos, com precisão acima de $90 \%$ para consultas com revocação até $70 \%$.

- Usando a propriedade de compressão que as wavelets possuem, foi possível otimizar o método proposto por Balan (2007) na parte de segmentação das imagens, possibilitando a aplicação deste excelente método de uma forma mais rápida, chegando a usar apenas $1 / 3$ do tempo gasto inicial.

- Explorou-se a extração de características de textura usando os filtros de Gabor e estendeu-se o vetor de características proposto por Ma e Manjunath (1996). Um 
novo vetor foi proposto, o qual é composto de medidas estatísticas de média, desvio padrão e medida skewness extraídas dos subespaços gerados pela aplicação dos filtros de Gabor em quatro escalas e seis orientações.

- O novo método usando filtros de Gabor também foi usado para caracterizar as imagens mamográficas, obtendo um melhor resultado que o Histograma de brilho.

- Uma revisão bibliográfica rica em detalhes sobre o estudo das wavelets, passando a ter valor como material de referência para estudos futuros dentro do Grupo de Base de Dados e Imagens do ICMC-USP.

Além dessas contribuições, também foram desenvolvidos outros trabalhos em cooperação com outros membros do GBDI para a validação do algoritmo StARMiner. Para a comunidade científica, deste trabalho foram gerados os artigos Watanabe e Traina (2006b), Ribeiro et al. (2006) e Watanabe e Traina (2006a).

\subsection{Trabalhos futuros}

A seguir estão apresentados algumas sugestões de tópicos que podem ser abordados em estudos futuros.

- Na maioria dos testes realizados usamos a distância Euclidiana como função de distância. É interessante investigar o desenvolvimento de uma função distância que dê maior ênfase a características que melhor identifiquem imagens pertencentes a uma determinada classe, o que é uma continuação natural deste trabalho;

- Um estudo mais aprofundado da aplicação das wavelets sobre as imagens de mamografia para um melhor desempenho de um sistema CAD;

- Suporte ao desenvolvimento e aprimoramento de algoritmos de mineração de imagens, os quais dependem fortemente da qualidade das características de imagens obtidas por extratores que consigam representar fielmente as propriedades mais relevantes das imagens. 


\section{Referências Bibliográficas}

Agrawal, R.; Imielinski, T.; Swami, A. N. Mining association rules between sets of items in large databases. In: Buneman, P.; JAJodia, S., eds. ACM SIGMOD International Conference on Management of Data, Washington, D.C.: ACM Press, 1993, p. 207-216.

Albuz, E.; Kocalar, E.; Khokhar, A. A. Scalable color image indexing and retrieval using vector wavelets. IEEE Transactions on Knowledge and Data Engineering (TKDE), v. 13, n. 5, p. 851-861, 2001.

Alto, H.; Rangayyan, R. M.; Desautels, J. E. L. Content-based retrieval and analysis of mammographic masses. Journal of Electronic Imaging, v. 14, n. 2, p. 023016 (1-17), 2005.

Aslandogan, Y. A.; Yu, C. T. Techniques and systems for image and video retrieval. IEEE Transactions on Knowledge and Data Engineering (TKDE), v. 11, n. 1, p. 56-63, 1999.

Aumann, Y.; Lindell, Y. A statistical theory for quantitative association rules. In: Press, A., ed. The fifth ACM SIGKDD international conference on Knowledge discovery and data mining, San Diego, California, United States, 1999, p. 261-270.

Baeza-Yates, R. A.; Ribeiro-Neto, B. A. Modern information retrieval. Wokingham, UK: Addison-Wesley, 1999.

Balan, A. G. R. Técnicas de extração de características baseadas em textura e forma para suporte ao processamento de consultas por similaridade em imagens médicas. Tese de mestrado, Universidade de São Paulo, 2004.

Balan, A. G. R. Métodos adaptativos de segmentação aplicados à recuperação de imagens por conteúdo. Tese de doutorado, Universidade de São Paulo, 2007. 
Biederman, I. Recognition-by-components: a theory of human image understanding. Psychological Review, v. 94, n. 2, p. 115-147, 1987.

Bortolotti, L. M. Recuperação de imagens médicas por conteúdo considerando regiões definidas pela energia. Tese de mestrado, Universidade de São Paulo, 2004.

CAmpo, C. Y. Utilização de histogramas adaptativos para recuperação de imagens por conteúdo em um sistema pacs. Tese de mestrado, Universidade de São Paulo, 2002.

CaO, X.; Huang, H. Current Status and Future Advances of Digital Radiography and PACS. IEEE Engineering in Medicine and Biology Magazine, v. 9, n. 5, p. 80-88, 2000.

Carson, C.; Belongie, S.; Greenspan, H.; Malik, J. Region-based image querying. In: Proceedings of IEEE Workshop onContent-Based Access of Image and Video Libraries, San Juan, Puerto Rico, 1997, p. 42-49.

Castañón, C. A. B. Extração de características em imagens médicas utilizando wavelets. Tese de mestrado, Universidade de São Paulo, 2002.

Castañón, C. A. B.; Traina, A. J. M. Caracterização de imagens através de análise multiresolução por wavelets para sistemas CBIR. In: Guerrero, C. I., ed. XXIX Conferência LatinoAmericana de Informática - CLEI2003, La Paz - Bolivia, 2003, p. 12 pags.(em CDROM).

Chen, A. L.; TAmer, A. M.; OrIA, V. Using multi-scale histograms to answer pattern existence and shape match queries. In: 17th international conference on Scientific and statistical database management, Santa Barbara, CA, 2005, p. 217-226.

CHui, C. An introduction to wavelets. Boston, MA: Academic Press, 1992.

Chung, S.; WAng, Q. Content-based retrieval and data mining of a skin cancer image database. In: International Conference on Information Technology: Coding and Computing, 2001, p. $611-615$.

Chávez, E.; Navarro, G.; Baeza-Yates, R. A.; Marroquín, J. L. Searching in metric spaces. ACM Computing Surveys, v. 33, n. 3, p. 273-321, 2001.

Ciaccia, P.; Nanni, A.; Patella, M. A query-sensitive cost model for similarity queries with M-tree. In: RodDICK, J. F., ed. Australasian Database Conference, Auckland, New Zealand: Springer Verlag, 1999, p. 65-76 (Australian Computer Science Communications, v.21-2). 
Comer, M. L.; DelP, E. J. The EM/MPM algorithm for segmentation of textured images: Analysis and further experimental results. IEEE Transactions on Image Processing, v. 9, n. 10, p. 1731-1744, 2000.

Costa, L. F. D.; Cesar JR, R. M. Shape analysis and classification - theory and practice. Boca Raton, CA: CRC Press, 2001.

DAtCu, M.; SEIDEL, K. Image information mining: exploration of image content in large archives. In: Aerospace Conference, 2000, p. 253 - 264.

Daubechies, I. Ten lectures on wavelets, v. 61. Philadelphia, PA, USA: Society for Industrial and Applied Mathematics, 1992.

Daugman, D. Complete Discrete 2-D Gabor Transforms by Neural Networks for Image Analysis and Compression. IEEE Transactions on Acoustics, Speech, and Signal Processing, v. 36, n. 7, p. 1169-1179, 1988.

Daugman, D. How iris recognition works. In: Proceedings of 2002 International Conference on Image Processing, 2002, p. 33-36.

Daugman, J. G. Uncertainty relation for resolution in space, spatial frequency, and orientation optimized by two-dimensional visual cortical filters. Journal of the Optical Society of America A - Optics, Image Science, and Vision, v. 2, n. 7, p. 1160-1169, 1985.

DoI, K. Current status and future potential of computer-aided diagnosis in medical imaging. Br. J. Radiol, v. 78, n. 1, p. 13-19, 2005.

EAKINS, J. P. Automatic image content retrieval - are we getting anywhere? In: Proceedings of Third International Conference on Electronic Library and Visual Information Research (ELVIRAS), De Montfort University, 1996, p. 123-135.

FARIA, R. R. A. Aplicação de wavelets na análise de gestos musicais em timbres de instrumentos acústicos tradicionais. Tese de mestrado, Universidade de São Paulo, 1997.

Felipe, J. C.; Traina, A. J. M.; Traina JR., C. A new similarity measure for histograms applied to content-based retrieval of medical images. In: 21st Annual ACM Symposium on Applied Computing (SAC 2006), Dijon, France, 2006.

Ferhatosmanoglu, H.; Tuncel, E.; Agrawal, D.; Abbadi, A. E. High dimensional nearest neighbor searching. Information Systems, v. 31, n. 6, p. 512-540, 2006. 
Feris, R. S.; Krueger, V.; JR., R. M. C. Efficient real-time face tracking in wavelet subspace. In: Proceedings of ICCV'2001 International Conference on Computer Vision, Workshop on Recognition, Analysis and Tracking of Faces and Gestures in Real-Time Systems, Vancouver, BC., 2001, p. 113-118.

Fournier, A.; Cohen, M.; DeRose, T. D.; Lounsbery, M.; Reissell, L.-M.; SwELDEns, W. Wavelets and their applications to computer graphics. In: $A C M$ Siggraph'95, Los Angeles, CA, 1995.

Furuie, S. S.; Bertozoo, N.; Figueiredo, J.; Yamaguti, M. Archiving and Retrieving Long-Term Cineangiographic Images in a PACS. Computers in Cardiology, p. 435-438, 1999.

GABOr, D. Theory of communication. IEE (London), v. 93, Part III, n. 26, p. 429-457, 1946.

Gomes, J.; Velho, L.; Goldenstein, S. Wavelets : Teoria, software e aplicações. 21 Colóquio Brasileiro de Matemática. Rio Janeiro: Instituto de Matemática Pura e Aplicada, 1997.

Gonzalez, R. C.; Wintz, P. Digital image processing. 2nd ed. Addison-Wesley, 1987.

Gonzalez, R. C.; Woods, R. E. Digital image processing. Addison-Wesley, 1993.

Granlund, G. H. Seach of a general picture processing operator. Computer Graphics and Image Processing, v. 8, p. 155-173, 1978.

Graps, A. L. An introduction to wavelets. IEEE Computational Sciences and Engineering, v. 2, n. 2, p. 50-61, 1995.

Grigorova, A.; De Natale, F. G. B.; Dagli, C.; Huang, T. S. Content-based image retrieval by feature adaptation and relevance feedback. IEEE Transactions on Multimedia, v. 9, n. 6, p. 1183-1192, 2007.

Guttman, A. R-tree: A dynamic index structure for spatial searching. In: $A C M$ SIGMOD International Conference on Management of Data, Boston, MA: ACM PRess, 1984, p. 47-57.

Hamamoto, Y.; Uchimura, S.; Watanabe, M.; Yasuda, T.; Mitani, Y.; Tomita, S. A Gabor filter-based method for recognizing handwritten numerals. Pattern Recognition, v. 31, p. 395-400, 1998. 
Haralick, R. M.; Shanmugam, K.; Distein, I. Textural features for image classification. IEEE Transactions on Systems, Man and Cybernetics, v. 3, n. 6, p. 610-621, 1973.

Hsu, W.; Lee, M. L.; GoH, K. G. Image mining in IRIS: integrated retinal information system. ACM - Special Interest Group on Management of Data (SIGMOD), v. 29, n. 2, p. 593, 2000.

Hsu, W.; Lee, M. L.; Zhang, J. Image mining: Trends and developments. Journal of Intelligent Information Systems, v. 19, n. 1, p. 7 - 23, iSSN:0925-9902, 2002.

Jain, A. K.; Farrokhnia, F. Unsupervised Texture Segmentation using Gabor Filters. Pattern Recognition, v. 24, p. 1167-1186, 1991.

Jain, A. K.; Ross, K. A.; PrabAKAR, N. Fingerprint matching using minutiae and texture features. Technical Report MSU-CSE-01-17, Department of Computer Science, Michigan State University, 2001.

Jain, A. K.; Tuceryan, M. Texture analysis. In: Chen, C. H.; Pau, L.; Wang, P., eds. HandBook of Pattern Recognition and Computer Vision, World Scientific, p. 235-276, 1993.

Jain, A. K.; Vailaya, A. Shape-based retrieval: A case study with trademark image databases. Pattern Recognition Letters, v. 21, n. 9, p. 1369-1390, 1998.

Jiang, Y.; Nishikawa, R. M.; Schmidt, R. A.; Toledano, A. Y.; Doi, K. Potential of Computer-aided Diagnosis to Reduce Variability in Radiologists' Interpretations of Mammograms Depicting Microcalcifications. Radiology, v. 220, n. 3, p. 787-794, 2001.

JiAnG, Z.; Guo, X. A note on the extension of a family of biorthogonal Coifman wavelet systems. The Australian $\&$ New Zealand Industrial and Applied Mathematics Journal, ANZIAM, v. 46, p. 111-120, 2004.

Kaiser, G. A friendly guide to wavelets. Boston, MA, p. 44-45, 1994.

Katayama, N.; Satoh, S. The SR-tree: an index structure for high-dimensional nearest neighbor queries. In: Proceedings of ACM Special Interest Group on Management of Data (SIGMOD), 1997, p. 369-380.

Kim, C.; Chung, C.-W. A multi-step approach for partial similarity search in large image data using histogram intersection. In: Information and software technology, v. 45, 4 ed, Elsevier, p. 203-215(13), 2003. 
Kim, S. C.; KAng, T. J. Texture classification and segmentation using wavelet packet frame and Gaussian mixture model. Pattern Recognition, v. 40, n. 4, p. 1207-1221, 2007.

Kobayashi, T.; Doi, K. Effect of CAD on radiologists' detection of lung nodules on chest radiographs. Innervision, v. 14, p. 44-46, 1999.

Krueger, V.; Sommer, G. Affine real-time face tracking using a wavelet network. In: Proceedings of ICCV'99 Workshop Recognition, Analysis and Tracking of Faces and Gestures in Real-Time Systems, Corfu, Greece, 1999.

Kumar, V.; Heikkonen, J.; Rissanen, J.; Kaski, K. Minimum description length denoising with histogram models. IEEE Transactions on Acoustics, Speech, and Signal Processing, v. 54, n. 8, p. 2922-2928, 2006.

Kunttu, I.; Lepistö, L.; RauhamaA, J.; Visa, A. Multiscale Fourier descriptors for defect image retrieval. Pattern Recognition Letters, v. 27, n. 2, p. 123-132, 2006.

LeE, C.; WAng, S. D. Fingerprint feature extraction using Gabor filters. Eletronics Letters, v. 35, p. 288-290, 1999.

LEE, T. S. Image Representation Using 2D Gabor Wavelets. IEEE Transactions on Pattern Analysis and Machine Intelligence (PAMI), v. 18, n. 10, 1996.

Lima, L. R. S. D.; Laender, A. H. F.; Ribeiro-Neto, B. A. A hierarchical approach to the automatic categorization of medical documents. In: International Conference on Information and Knowledge Management (CIKM), Bethesda, Maryland, 1998, p. 132-139.

Lin, K.-I. D.; Jagadish, H. V.; Faloutsos, C. The TV-Tree: An index structure for high-dimensional data. VLDB Journal, v. 3, n. 4, p. 517-542, 1994.

Liu, C. J.; Wechsler, H. Gabor feature based classification using the enhanced Fisher linear discriminant model for face recognition. IEEE Transactions on Image Processing, v. 11, p. 467-476, 2002.

Ma, W. Y.; Manjunath, B. S. Texture features and learning similarity. In: IEEE International Conference on Computer Vision and Pattern Recognition, San Francisco, CA, 1996, p. 425-430.

Macmahon, H.; Engelmann, R.; Behlen, F. M.; Hoffmann, K. R.; Ishida, T.; Roe, C.; Metz, C. E.; Doi, K. Computer-aided diagnosis of pulmonary nodules: Results of a large-scale observer test. Radiology, v. 213, p. 723-726, 1999. 
Mallat, S. G. A theory for multiresolution signal decomposition: The wavelet representation. IEEE Transactions on Pattern Analysis and Machine Intelligence (PAMI), v. 11, n. 7, p. 674-693, 1989.

Mallat, S. G. A wavelet tour of signal processing. Second ed. San Diego - CA: Academic Press, 1999.

Manjunath, B. S.; MA, W.-Y. Texture features for browsing and retrieval of image data. IEEE Transactions on Pattern Analysis and Machine Intelligence (PAMI), v. 18, n. 8, p. 837-842, 1996.

Marques, P. M. D. A. Diagnóstico auxiliado por computador na radiologia. Radiologia Brasileira, v. 34, n. 5, p. 285-293, 2001.

Messer, K.; Kittler, J.; SAdeghi, M. Face authentication test on the banca database. In: Proceedings of 17th International Conference on Pattern Recognition (ICPR'04), Cambridge, UK, 2004, p. 523-532.

Meyer, Y. Wavelets: Algorithms and applications. First edition, Society for Industrial and Applied Mathematics, 1993.

Misiti, M.; Oppenheim, G.; Poggi, J.-M.; Misiti, Y. Wavelet toolbox documentation. 2001.

Müller, H.; Michoux, N.; Bandon, D.; Geissbuhler, A. A review of content-based image retrieval systems in medical applications-clinical benefits and future directions. International Journal of Medical Informatics, v. 73, n. 1, p. 1-23, 2004.

OJAnEN, H. Wavekit: a wavelet toolbox for matlab. 1998.

OkAJima, K. Two-dimensional gabor-type receptive field as derived by mutual information maximmzation. Neural Networks, v. 11, n. 3, p. 441-447, 1998.

Pare, G.; Aubry, D.; Lepanto, L.; Sicotte, C. Evaluating pacs success: A multidimensional model. In: 38th Annual Hawaii International Conference on System Sciences (HICSS'05), Island of Hawaii, 2005, p. 147-155.

Pass, G.; Zabih, R.; Miller, J. Comparing images using color coherence vector. In: ACM Multimedia, Boston, MA: ACM Press, 1996, p. 65-73.

Petrakis, E. G.; Faloutsos, C. Similarity searching in medical image databases. IEEE Transactions on Knowledge and Data Engineering (TKDE), v. 9, n. 3, p. 435-447, 1997. 
Phillips, P. J.; Moon, H.; Rizvi, S. A.; Rauss, P. J. The FERET evaluation methodology for face-recognition algorithms. IEEE Transactions on Pattern Analysis and Machine Intelligence (PAMI), v. 22, n. 10, p. 1090-1104, 2000.

Press, W.; AL, E. Numerical recipes in fortran. New York: Cambridge University Press, p. 498-499, 584-602, 1992.

Quek, S.; Thng, C.; Khoo, J.; KoH, W. Radiologists' detection of mammographic abnormalities with and without a computer-aided detection system. Australasian Radiology, v. 47, n. 3, p. 257-269, 2003.

Ribeiro, M. X.; Watanabe, C. Y. V.; Felipe, J. C.; Balan, A. G. R.; Traina, A. J. M.; Traina JR., C. Apoiando a Busca por Conteúdo em Imgens Médicas através da Mineração de Regras de Associação Estatísticas. In: II Workshop em Algoritmos e Aplicações de Mineração de Dados do XX Simpósio Brasileiro de Banco de Dados, Florianópolis, SC, 2006, p. 17-24.

Roden, J.; Burl, M. C.; Fowlkes, C. Mining for image content. In: Systemics, Cybernetics, and Informatics / Information Systems: Analysis and Synthesis, Orlando, FL, EUA, 1999.

Romdhani, S. Face recognition using principal component analysis. Master's thesis, University of Glasgow, 1996.

Rosa, N. A. Inserção do conhecimento do especialista no processo de realimentação de relevância em recuperação de imagem por conteúdo. Doutorado, Universidade de São Paulo, 2007.

Rubner, Y.; Tomasi, C. Perceptual metrics for image database navigation. The Kluwer International Series in Engineering and Computer Science. Kluwer Academic Publishers, 2001.

Sajuanhar, A.; Lu, C.-T.; Zhang, A.; Zhou, A. A composite descriptor for shape retrieval. In: 6th IEEE/ACIS International Conference on Computer and Information Science (ICIS 2007), 2007, p. 795-800.

SAlton, G.; McGill, M. Introduction to modern information retrieval. McGraw-Hill Book Company, 1983.

Santos Filho, R. F.; Traina, A. J. M.; Traina JR., C. Algoritmos para indexação em bases de dados através de estruturas multidimensionais. Technical report 85, USP, 1999.

Shen, L. Recognizing Faces - An Approach Based on Gabor Wavelets. Ph.d. thesis, University of Nottingham, 2005. 
Shen, L.; BAI, L. Face recognition based on Gabor features using kernel methods. In: Proc. of the 6th IEEE Conference on Face and Gesture Recognition, Korea, 2004.

Shen, L.; BAI, L. Information Theory for Gabor Feature Selection for Face Recognition. EURASIP'Journal oon Applied Signal Processing, v. 2006, p. 1-11, doi:10.1155/ASP/2006/30274, 2006.

Shen, L.; Bai, L.; Fairhurst, M. Gabor wavelets and General Discriminant Analysis for face identification and verification. Image Vision Computing, v. 25, n. 5, p. 553-563, 2007.

Shiraishi, J.; Abe, H.; Englemann, R.; Aoyama, M.; MacMahon, H.; Doi, K. Effect of the computer output on radiologists decision-making for classification of solitary pulmonary nodules in chest radiographs. In: LEMKE, H. U.; VANNIER, M. W.; Inamura, K.; Farman, A. G.; Doi, K.; Reiber, J. H. C., eds. 18th Intl Congress and Exhibition Computer Assisted Radiology and Surgery (CARS 2002), Berlin, Germany: Springer Verlag, 2002, p. 712-716.

Smeulders, A. W. M.; Worring, M.; SAntini, S.; Gupta, A.; Jain, R. Content-based image retrieval at the end of the early years. IEEE Transactions on Pattern Analysis and Machine Intelligence (PAMI), v. 22, n. 12, p. 1349-1380, 2000.

Sмiтн, J. Integrated spatial and feature image systems: Retrieval. Ph.d. thesis, Columbia University, 1997.

SRIKAnt, R.; Agrawal, R. Mining quantitative association rules in large relational tables. In: ACM SIGMOD International Conference on Management of Data, Montreal, Canada: ACM Press, 1996, p. 1-12.

Stollnitz, E. J.; DeRose, T. D.; Salesin, D. H. Wavelets for computer graphics theory and applications. San Francisco, CA: Morgan Kaufmann Publishers, Inc, 1996.

Strang, G.; Nguyen, T. D. Wavelets and filter banks. Wellesley-Cambridge Press, 1996.

Stricker, M.; Orengo, M. Similarity of color images. In: Niblack, W. R.; Jain, R. C., eds. SPIE: Storage and Retrieval for Image and Video Databases III, San Jose, CA, 1995, p. 381-392.

Swain, M. J.; BAllard, D. H. Color indexing. International Journal of Computer Vision, v. 2, p. 11-32, 1991.

Sweldens, W. The lifting scheme: A new philosophy in biorthogonal wavelet constructions. In: LAIne, A. F.; Unser, M., eds. Wavelet Applications in Signal and Image Processing III, SPIE, 1995, p. 68-79. 
Tesar, L.; Smutek, D.; Shimizu, A.; Kobatake, H. Medical image segmentation using cooccurrence matrix based texture features calculated on weighted region. In: SAHni, S., ed. Advances in Computer Science and Technology, Phuket, Thailand, 2007.

Theodoridis, S.; Koutroumbas, K. Pattern recognition. New York, 1999.

Tomita, F.; SABuro, T. Computer analysis of visual textures. Kluwer Academic Publishers, 1990.

Traina, A. J. M.; Prado, A. H. D. A.; Bueno, J. M. A System for 3D Reconstruction of Largely Spaced Tomographic Images. Journal of Medical Systems Plenum Press, v. 21, n. 6, p. 353-367, invited Paper, 1997.

Traina Jr., C.; Traina, A. J. M.; Faloutsos, C.; Seeger, B. Fast indexing and visualization of metric datasets using slim-trees. IEEE Transactions on Knowledge and Data Engineering (TKDE), v. 14, n. 2, p. 244-260, 2002.

Turner, M. R. Texture Discrimination by Gabor Functions. Biological Cybernetics, v. 55, n. 2-3, p. 71-82, 1986.

Vailaya, A.; Figueiredo, M. A. T.; Jain, A. K.; Zhang, H.-J. Image classification for content-based indexing. IEEE Transactions on Image Processing, v. 10, n. 1, p. 117-30, 2001.

Vetterli, M.; Herley, C. Wavelets and filter banks: Theory and design. IEEE Transactions on Signal Processing, v. 40, p. 2207-2232, 1992.

Vogel, J.; Schiele, B. Performance evaluation and optimization for content-based image retrieval. Pattern Recognition, v. 39, n. 5, p. 897-909, 2006.

Wang, J. Z.; Li, J.; Wiederhold, G. SIMPLIcity: Semantic-Sensitive Integrated Matching for Picture Libraries. In: IEEE Transaction on Pattern Analysis and Machine Intelligence, 2001, p. 947-963.

WANG, X. J.; MA, W. Y.; LI, X. Exploring statistical correlations for image retrieval. Multimedia System, v. 11, n. 4, p. 340-351, 2006.

WARD, L. Introduction to wavelets and their applications - lectures math 185. 2000.

Watanabe, C. Y. V.; Traina, A. J. M. Analisando Wavelets como Geradoras de Características de Imagens para Recuperação por Conteúdo. In: II Workshop de Visão Computacional, São Carlos - SP, 2006a, p. 1-6.

Watanabe, C. Y. V.; Traina, A. J. M. Recuperação de Imagens Médicas por Conteúdo utilizando Wavelets e PCA. In: X Congresso Brasileiro de Informática em Saúde, Florianópolis, SC, 2006b, p. 1-6. 
Wei, D.; Evans, B. L.; Bovik, A. C. Generalized coiflets: A new family of orthonormal wavelets. In: IEEE Asilomar Conference on Signals, Systems, and Computers, Pacific Grove, CA USA, 1997, p. 101-104.

Weldon, T. P.; Higgins, W. E.; Dunn, D. F. Efficidng Gabor filter design for texture segmentation. Pattern Recognition, v. 29, n. 12, p. 2005-2015, 1996.

Wickerhauser, M. V. Adapted wavelet analysis from theory to software. A K Peters, Wellesley, 1994.

Yadav, R. B.; Nishchal, N. K.; Gupta, A. K.; Rastogi, V. K. Retrieval and classification of shape-based objects using Fourier, generic Fourier, and wavelet-Fourier descriptors technique: A coomparative study. Optics and Lasers in Engineering, v. 45, n. 6, p. 695-708, 2007.

Yin, J.; Chen, G.; Lin, Z. New multiresolution modeling techniques in CAD. Computer-Aided Design, v. 38, n. 2, p. 134-142, 2006.

YuAn, C.; Peng, Z.; YAn, X. Surface characterization using wavelet theory and confocal laser scanning microscopy. Journal of Tribology, v. 127, n. 2, p. 394-404, 2005.

ZAhn, C.; Roskies, R. Z. Fourier descriptors for plane closed curves. IEEE Transactions on Computers, v. 21, p. 269-281, 1972.

ZaiAne, O. R.; HAN, J.; LI, Z.-N.; Hou, J. Mining multimedia data. In: The 1998 conference of the Centre for Advanced Studies on Collaborative Research, Toronto, Ontario, Canada: IBM Press, 1998, p. $24-41$.

Zhang, B.; Shan, S.; Chen, X.; GaO, W. Histogram of Gabor Phase Patterns (HGPP): A Novel Object Representation Approach for Face Recognition. IEEE Transactions on Image Processing, v. 16, n. 1, p. 57-68, 2007.

Zhang, D. S.; Lu, G. Content-Based Shape Retrieval Using Different Shape Descriptors: A Comparative Study. In: IEEE Conference on Multimedia and Expo (ICME'01), Tokyo, Japan: IEEE Computer Society, 2001, p. 317-320.

ZhANG, D. S.; Lu, G. An integrated approach to shape based image retrieval. In: Fifth Asian Conference on Computer Vision, Melbourne, Australia, 2002, p. 652-657.

Zhao, N.; Sun, H.; Xu, X. A new approach of nonlinear wavelet transforms for image compression and progressive image transmission. In: 2006 IEEE International Conference on Mechatronics and Automation, Luoyang, Henan, 2006, p. 2362-2366. 
Zheng, Z.; YAng, F.; TAN, W.; JiA, J.; YANG, J. Fast communication: Gabor feature-based face recognition using supervised locality preserving projection. Signal Process., v. 87, n. 10, p. 2473-2483, 2007. 


\section{Apêndice}

A

Filtros de wavelets

Os filtros descritos nas seções A.1 e A.2 encontram-se em Wickerhauser (1994).

\section{A.1 Filtros de Coifman ou "Coiflets"}

Os filtros de Coifman são caracterizados por ambos, tanto a função escala como a wavelet mãe, possuirem momentos nulos.

\section{Coifman 6}

Coifman 12

$$
\begin{array}{ll}
\text { Passa-baixa } & \text { Passa-alta } \\
\frac{\sqrt{15}-3}{32} \cdot \sqrt{2} & \frac{9-\sqrt{15}}{32} \cdot \sqrt{2} \\
\frac{1-\sqrt{15}}{32} \cdot \sqrt{2} & -\frac{\sqrt{15}+13}{32} \cdot \sqrt{2} \\
\frac{3-\sqrt{15}}{16} \cdot \sqrt{2} & \frac{\sqrt{15}+3}{16} \cdot \sqrt{2} \\
\frac{\sqrt{15}+3}{16} \cdot \sqrt{2} & \frac{\sqrt{15}-3}{16} \cdot \sqrt{2} \\
\frac{\sqrt{15}+13}{32} \cdot \sqrt{2} & \frac{1-\sqrt{15}}{32} \cdot \sqrt{2} \\
\frac{9-\sqrt{15}}{32} \cdot \sqrt{2} & \frac{3-\sqrt{15}}{32} \cdot \sqrt{2}
\end{array}
$$

$$
\begin{array}{ll}
\text { Passa - baixa } & \text { Passa - alta } \\
1.6387336463179785 E-02 & -7.2054944536811512 \text { E-04 } \\
-4.1464936781966485 E-02 & 1.8232088709100992 E-03 \\
-6.737255472229874 E-02 & 5.6114348193659885 E-03 \\
3.8611006682309290 E-01 & -2.3680171946876750 E-02
\end{array}
$$




$$
\begin{array}{ll}
\text { Passa-baixa } & \text { Passa-alta } \\
8.1272363544960613 E-01 & -5.9434418646471240 E-02 \\
4.1700518442377760 E-01 & 7.6488599078264594 E-02 \\
-7.6488599078264594 E-02 & 4.1700518442377760 E-01 \\
-5.9434418646471240 E-02 & -8.1272363544960613 E-01 \\
2.3680171946876750 E-02 & 3.8611006682309290 E-01 \\
5.6114348193659885 E-03 & 6.737255472229874 E-02 \\
-1.8232088709100992 E-03 & -4.1464936781966485 E-02 \\
-7.2054944536811512 E-04 & -1.6387336463179785 E-02
\end{array}
$$

\section{A.2 Filtros de Daubechies}

Dado um tamanho, os filtros de Daubechies maximizam a suavidade da função escala associada maximizando a taxa de decaimento de sua transformada wavelet.

\section{Daubechies 2 ou Haar}

$\begin{array}{ll}\text { Passa-baixa } & \text { Passa-alta } \\ \sqrt{2} & \sqrt{2} \\ \sqrt{2} & -\sqrt{2}\end{array}$

\section{Daubechies 4}

$\begin{array}{ll}\text { Passa-baixa } & \text { Passa-alta } \\ \frac{1+\text { sqrt } 3}{4 \cdot \sqrt{2}} & \frac{1-\text { sqrt } 3}{4 \cdot \sqrt{2}} \\ \frac{3+\text { sqrt } 3}{4 \cdot \sqrt{2}} & \frac{\text { sqrt } 3-3}{4 \cdot \sqrt{2}} \\ \frac{3-\text { sqrt } 3}{4 \cdot \sqrt{2}} & \frac{3+\text { sqrt } 3}{4 \cdot \sqrt{2}} \\ \frac{1-\text { sqrt } 3}{4 \cdot \sqrt{2}} & -\frac{1+\text { sqrt } 3}{4 \cdot \sqrt{2}}\end{array}$

\section{Daubechies 6}

Vamos definir $A=\frac{1}{4} \sqrt{2}[1+\sqrt{10}+\sqrt{5+2 \sqrt{10}}]$ e $B=\frac{3}{4 A}$.
Passa - baixa
Passa - alta
$0.125 \cdot A$
$0.125 \cdot B$
$0.125 \cdot(\sqrt{2}+2 \cdot A-B)$
$0.125 \cdot(A-\sqrt{2}-2 \cdot B)$
$0.125 \cdot(3 \sqrt{2}-2 \cdot B)$
$0.125 \cdot(3 \sqrt{2}-2 \cdot A)$
$0.125 \cdot(3 \sqrt{2}-2 \cdot A)$
$0.125 \cdot(2 B-3 \sqrt{2})$
$0.125 \cdot(\sqrt{2}+2 \cdot B-A)$
$0.125 \cdot(\sqrt{2}+2 \cdot A-B)$
$0.125 \cdot B$
$-0.125 \cdot A$ 


\section{Daubechies 8}

$$
\begin{array}{ll}
\text { Passa-baixa } & \text { Passa-alta } \\
2.30377813309 E-01 & -1.05974017850 E-02 \\
7.14846570553 E-01 & -3.28830116670 E-02 \\
6.30880767930 E-01 & 3.08413818370 E-02 \\
-2.79837694170 E-02 & 1.87034811719 E-01 \\
-1.87034811719 E-0 & -2.79837694170 E-02 \\
3.08413818370 E-02 & -6.30880767930 E-01 \\
3.28830116670 E-02 & 7.14846570553 E-01 \\
-1.05974017850 E-02 & -2.30377813309 E-01
\end{array}
$$

\section{Daubechies 16}

$$
\begin{array}{ll}
\text { Passa-baixa } & \text { Passa - alta } \\
5.44158422430 E-02 & -1.17476784000 E-04 \\
3.12871590914 E-01 & -6.75449406000 E-04 \\
6.75630736297 E-01 & -3.91740373000 E-04 \\
5.85354683654 E-01 & 4.87035299300 E-03 \\
-1.58291052560 E-02 & 8.74609404700 E-03 \\
-2.84015542962 E-01 & -1.39810279170 E-02 \\
4.72484574000 E-04 & -4.40882539310 E-02 \\
1.28747426620 E-01 & 1.73693010020 E-02 \\
-1.73693010020 E-02 & 1.28747426620 E-01 \\
-4.40882539310 E-02 & -4.72484574000 E-04 \\
1.39810279170 E-02 & -2.84015542962 E-01 \\
8.74609404700 E-03 & 1.58291052560 E-02 \\
-4.87035299300 E-03 & 5.85354683654 E-01 \\
-3.91740373000 E-04 & -6.75630736297 E-01 \\
6.75449406000 E-04 & 3.12871590914 E-01 \\
-1.17476784000 E-04 & -5.44158422430 E-02
\end{array}
$$

\section{A.3 Filtro Symlets}

Os filtros aqui apresentados são os mesmos apresentados pelo Matlab.

\section{Symlet 2}

$$
\begin{array}{llll}
\text { Passa-baixa } & & & \\
-0.1294 & 0.2241 & 0.8365 & 0.4830
\end{array}
$$




$$
\begin{array}{llll}
\text { Passa - alta } & & & \\
-0.4830 & 0.8365 & -0.2241 & -0.1294
\end{array}
$$

\section{Symlet 3}

$\begin{array}{ll}\text { Passa-baixa } & \text { Passa-alta } \\ 0.0352 & -0.3327 \\ -0.0854 & 0.8069 \\ -0.1350 & -0.4599 \\ 0.4599 & -0.1350 \\ 0.8069 & 0.0854 \\ 0.3327 & 0.0352\end{array}$

Symlet 4

$\begin{array}{ll}\text { Passa-baixa } & \text { Passa-alta } \\ -0.0758 & -0.0322 \\ -0.0296 & -0.0126 \\ 0.4976 & 0.0992 \\ 0.8037 & 0.2979 \\ 0.2979 & -0.8037 \\ -0.0992 & 0.4976 \\ -0.0126 & 0.0296 \\ 0.0322 & -0.0758\end{array}$

Symlet 5

$\begin{array}{lcccc}\text { Passa-baixa } & & & & \\ 0.0273 & 0.0295 & -0.0391 & 0.1994 & 0.7234 \\ 0.7234 & -0.1994 & -0.0391 & -0.0295 & 0.0273 \\ & & & & \\ \text { Passa-alta } & & & & \\ -0.0195 & -0.0211 & 0.1753 & 0.0166 & -0.6340 \\ 0.7234 & -0.1994 & -0.0391 & -0.0295 & 0.0273\end{array}$

Symlet 15 


$\begin{array}{ll}\text { Passa-baixa } & \text { Passa-alta } \\ 0.0000 & 0.0000 \\ 0.0000 & 0.0000 \\ -0.0002 & 0.0004 \\ 0.0001 & -0.0001 \\ 0.0011 & -0.0035 \\ -0.0003 & 0.0015 \\ -0.0036 & 0.0172 \\ 0.0034 & -0.0087 \\ 0.0101 & -0.0680 \\ -0.0194 & 0.0684 \\ -0.0389 & 0.1341 \\ 0.0219 & -0.1966 \\ 0.0407 & -0.2440 \\ -0.0411 & 0.7218 \\ 0.1115 & -0.5786 \\ 0.5786 & 0.1115 \\ 0.7218 & 0.0411 \\ 0.2440 & 0.0407 \\ -0.1966 & -0.0219 \\ -0.1341 & -0.0389 \\ 0.0684 & 0.0194 \\ 0.0680 & 0.0101 \\ -0.0087 & -0.0034 \\ -0.0172 & -0.0036 \\ 0.0015 & 0.0003 \\ 0.0035 & 0.0011 \\ -0.0001 & -0.0001 \\ -0.0004 & -0.0002 \\ 0.0000 & 0.0000 \\ 0.0000 & 0.0000 \\ & \end{array}$

